ALYNE FREITAS DA SILVA BORDALO RODRIGUES

DESSULFURIZAÇÃO DE BUTANO LÍQUIDO POR ADSORÇÃO MEDIANTE UTILIZAÇÃO DE PENEIRA MOLECULAR 13X

São Paulo

2016 
ALYNE FREITAS DA SILVA BORDALO RODRIGUES

\title{
DESSULFURIZAÇÃO DE BUTANO LÍQUIDO POR ADSORÇÃO MEDIANTE UTILIZAÇÃO DE PENEIRA MOLECULAR 13X
}

\author{
Dissertação apresentada à Escola Politécnica \\ da Universidade de São Paulo para obtenção \\ do título de Mestre em Ciências.
}

São Paulo

2016 
ALYNE FREITAS DA SILVA BORDALO RODRIGUES

\section{DESSULFURIZAÇÃO DE BUTANO LÍQUIDO POR ADSORÇÃO MEDIANTE UTILIZAÇÃO DE PENEIRA MOLECULAR 13X}

Dissertação apresentada à Escola Politécnica da Universidade de São Paulo para obtenção do título de Mestre em Ciências.

Área de Concentração: Engenharia Química

Orientador: Prof. Dr. José Luis de Paiva

São Paulo

2016 
Este exemplar foi revisado e corrigido em relação à versão original, sob responsabilidade única do autor e com a anuência de seu orientador.

São Paulo, de de

Assinatura do autor:

Assinatura do orientador:

Catalogação-na-publicação

Rodrigues, Alyne Freitas da Silva Bordalo

DESSULFURIZAÇÃO DE BUTANO LÍQUIDO POR ADSORÇÃO MEDIANTE UTILIZAÇÃ̃O DE PENEIRA MOLECULAR 13X / A. F. S. B. Rodrigues -- versão corr. -- São Paulo, 2016. $135 \mathrm{p}$.

Dissertação (Mestrado) - Escola Politécnica da Universidade de São Paulo. Departamento de Engenharia Química.

1.Adsorção 2.Peneira molecular 3.Modelagem e simulação I.Universidade de São Paulo. Escola Politécnica. Departamento de Engenharia Química II.t. 


\section{DEDICATÓRIA}

Ao meu grande amor, Rodrigo. 


\section{AGRADECIMENTOS}

Aos meus amados e admirados pais, Maria Elisabeth e Sidney Celso, pela preciosa herança doada: a educação e o amor sem limites. E, por tudo!

Às minhas irmãs adoradas, Ariane Silva e Alessandra Silva, que compartilharam comigo suas experiências até a adolescência e são exemplos de força e independência, pela parceria.

À minha querida avó Léa, por representar tão bem o conceito carinhoso de avó e por me ensinar o valor da resiliência.

Às minhas queridas amigas, Magdalena Espinola e Micheline Bechtold, cujos valores me inspiraram, pela cumplicidade e pela compreensão nas minhas ausências.

À minha querida amiga Ariane Nishimori, pelo carinho e alegria de sempre.

Ao excepcional professor José Luis de Paiva, pela orientação com maestria, por toda a paciência e pelos preciosos conselhos e sugestões.

Ao excelente gestor Rodrigo Pazzini, a quem admiro pelos seus valores, pela contribuição essencial, incentivo e confiança.

À querida equipe do Laboratório de Controle de Qualidade da Liquigás Distribuidora, Gislainy Dantas, Lucas Vellozo, Thiago Takechi, Bruno Henrique, Diego Cabral, Dalila, Milton Kudo pela alegria do convívio e pela prestativa contribuição.

Aos queridos colegas da Liquigás, Flávio Diniz e Maurício Pereira, cuja dedicação e competência surpreendem, pelos seus valores e palavras de estímulo.

Ao meu gestor, Rogério Teramoto pelo incentivo.

Aos queridos colegas Gabriela Malta, Patrícia de Castro, Fernanda Rodrigues, Adriano Biral e Flávia Cuzziol pelo profissionalismo, competência e parceria em todos os momentos.

Aos colegas supervisores Robson, Ed Carlos, Eduardo Brandão e suas respectivas equipes da Liquigás Distribuidora pela parceria e grande ajuda na realização dos experimentos. 
Aos estagiários Marcelo Sasso, André Crescenzo e Flávia Lumy pela competência, disciplina e valiosa contribuição para o desenvolvimento deste trabalho.

Ao meu marido, Rodrigo Bordalo, minha maior conquista e interminável fonte de inspiração, pelo apoio incondicional aos meus maiores sonhos e pela compreensão de todos os momentos.

À minha segunda família amada, meus sogros Solano Rodrigues e Dyrce Bordalo, meus cunhados Karina Bordalo, Marcelo Bordalo e Gabriela Stump pelo imenso carinho e incentivo constante.

Aos meus tios queridos, Diana Calixto e Demeval Calixto pela alegria contagiante e pelo carinho de sempre. 


\section{EPÍGRAFE}

O correr da vida embrulha tudo, a vida é assim: esquenta e esfria, aperta e daí afrouxa, sossega e depois desinquieta. $O$ que ela quer da gente é coragem. O que Deus quer é ver a gente aprendendo a ser capaz de ficar alegre a mais, no meio da alegria, e inda mais alegre ainda no meio da tristeza! (João Guimarães Rosa - Grande Sertão: Veredas) 


\section{RESUMO}

Atualmente, o tipo de propelente para produtos em aerossol mais usado no mundo é uma mistura de hidrocarbonetos leves (butano e propano - sendo o primeiro em maior proporção). Parte de seu processo de produção é a dessulfurização do butano líquido, através de adsorção em leito fixo usando peneiras moleculares 13X. A literatura científica não apresenta muitas publicações sobre o tema e considerando que a técnica de adsorção é fortemente dependente de dados experimentais para seu maior entendimento, é objetivo deste trabalho estudar este processo através do equilíbrio de adsorção, das curvas de ruptura e do desenvolvimento de um modelo matemático que represente o funcionamento de uma coluna de adsorção de leito fixo a temperatura constante. Obtiveram-se dados sobre o equilíbrio de adsorção por meio de ensaios em banho finito comparando-se a interação de diferentes compostos de enxofre com a peneira molecular $13 \mathrm{X}$ e o efeito da temperatura. Utilizou-se a técnica de cromatografia gasosa como método analítico para obtenção dos teores de compostos sulfurados e de hidrocarbonetos. O modelo de Langmuir apresentou bom ajuste aos dados experimentais. Avaliando-se a interação dos componentes sulfurados com a zeólita 13X, identificou-se diferenças significativas, sendo a maior em ordem decrescente: etil-mercaptana, n-propil-mercaptana e terc-butil-mercaptana, respectivamente. A dinâmica do processo de adsorção foi estudada através da obtenção das curvas de ruptura em leitos em escala laboratorial e piloto. Avaliaramse as influências da variação da concentração de entrada da n-propil-mercaptana e da velocidade do fluido em leito fixo recheado com zeólitas $13 \mathrm{X}$, mantendo os demais parâmetros constantes. Conforme esperado o aumento da concentração inicial reduz o tempo de ruptura, aumenta a quantidade total adsorvida pelo leito e não altera o comportamento da zona de transferência de massa (ZTM). Analisando-se a elevação da velocidade, nota-se também uma diminuição no tempo de ruptura e um aumento da ZTM. O modelo matemático apresentado considera os balanços de massa microscópicos aplicados ao leito, os fenômenos de transporte de massa com modelo de dispersão axial e transporte por convecção da fase líquida para a superfície da partícula e as isotermas de adsorção. As equações diferenciais parciais resultantes foram adimensionalizadas e resolvidas empregando-se o método de diferenças finitas, implementado por código Matlab $\AA^{\circledR}$. A partir da simulação matemática das condições 
experimentais obtiveram-se os parâmetros de dispersão axial e de transferência de massa que possibilitaram uma boa reprodução do tempo de ruptura quanto do perfil da zona de transferência de massa para os experimentos em escala laboratorial e piloto.

Palavras-chave: Adsorção. Dessulfurização de butano. Peneiras moleculares 13X. Zeólitas. Curva de ruptura. Isoterma de adsorção. Leito fixo. Modelagem e simulação. Zona de transferência de massa (ZTM). 


\begin{abstract}
Currently, the kind of propellant for aerosol products most widely used in the world is a blend of light hydrocarbons (butane and propane - the first in greater proportion). Part of the production of propellant is the desulfurization of liquid-phase butane by molecular sieves $13 \mathrm{X}$ in a fixed bed. The scientific literature concerning the adsorption of the mercaptans using zeolite are scarce and considering that the adsorption technique is strongly dependent on experimental data for its better knowlegde, the aim of this work was to study this process by adsorption equilibrium, the breakthrough curves and the development of a mathematic model, simulation and comparison with the operation of a fixed-bed pilot and laboratory-scale column. Adsorption equilibrium parameters were obtained using finite bath experiment and comparing the interaction of different sulfur compounds with molecular sieve $13 \mathrm{X}$ and the temperature effect. It was used the gas chromatography as an analytical method in order to obtain the levels of hydrocarbons and sulfur compounds. The Langmuir model well fit the experimental data. Significant differences were identified in the interaction of the sulfur components with zeolite 13X. The major interactions of the sulfur components are in decreasing order: ethyl-mercaptan, n-propyl-mercaptan and terc-butyl-mercaptan. The dynamic of the adsorption process was studied by obtaining the breakthrough curves in laboratory and pilot scale. It was investigated the influence of the initial concentration of $n$-propyl mercaptan and the fluid velocity in a fixed bed packed with zeolite $13 \mathrm{X}$ keeping the other parameters constant. As it was expected, as the inlet sulfur concentration increases the break point time decrease, and enhances the total amount adsorbed by the bed. Analyzing the increase in velocity on the breakthroug profile, it was noted that also decreases the break point time and causes a greater decline of the curve resulting in greater ZTM and anticipating the bed saturation time. The model equations account the mass balance applied in the flowing liquid phase in the column, transport phenomena as the effect of axial dispersion and convection from liquid phase to the adsorbent surface and adsorption isotherm. Finite difference method was used to solve the dimensionless general partial differential equations and it was implemented by Matlab® software. From mathematical simulation of experimental conditions it were obtained the axial dispersion parameters and mass transfer coefficient which allowed a fair agreement in predicting break point time and the mass transfer zone profile.
\end{abstract}


Keywords: Adsorption. Desulfurization of butane. Molecular sieves 13X. Zeolite. Breakthrough curve. Adsorption isotherm. Fixed bed. Modeling and simulation. Mass transfer zone (MTZ). 


\section{LISTA DE ILUSTRAÇÕES}

Figura 1.1. Curvas de ruptura das 4 colunas industriais de leito recheado com peneiras moleculares $13 \mathrm{X}$ novas e regeneradas. Sistema multicomponente. .2

Figura 3.1 - llustração do fenômeno de adsorção. Fonte: (LUZ, 2006) ………..........7

Figura 3.2. Processo de produção de peneiras moleculares da UOP.....................13 Figura 3.3. Estrutura de uma zeólita $X$ ou Y. $(b, c)$ Representação simplificada de um cubo octaedro, em que aparecem os átomos de oxigênio, silício e alumínio (a) Estes cubos octaedros unidos formam a zeólita faujasita (d) . Fonte: (CERUTTI, 2007) ....14 Figura 3.4. Tipos de isoterma, classificação IUPAC (União Internacional de Química Pura e Aplicada). (PERRY, 1999).

Figura 3.5. Isotermas típicas. Fonte: Acesso em 01/06/2014: http://labvirtual.eq.uc.pt/siteJoomla/index.php?ltemid=450\&id=188\&option=com cont ent\&task=view

Figura 3.6. Esquema do comportamento de adsorção em um sistema multicomponente ou competitivo na superfície do adsorvente.................................23

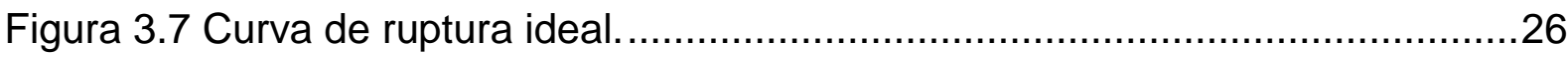

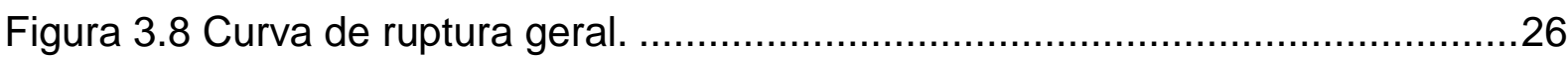

Figura 3.9. Isoterma de adsorção de $\mathrm{H}_{2} \mathrm{~S}$ para a amostra $13 \mathrm{X}$ a $\mathrm{T}=25^{\circ} \mathrm{C}$. (Souza, 2002). .33

Figura 3.10. (a) Equação do balanço de massa retirada do artigo referência. (pag. 571).(b) Tabela com parâmetros do leito considerados na simulação do artigo (pag.573). (SHAMS et al, 2007).

Figura 4.1. Esquema processo industrial de adsorção utilizando peneira molecular 13X.

Figura 4.2. (a) Foto do dessecador com sílica gel. (b) Foto da estufa modelo Q317M do fabricante Quimis. .42

Figura 4.3. Cilindro de aço inox com sulfinert e capacidade para 1 litro. .43

Figura 4.4. (a) Foto ampliada do tanque agitador com os 6 cilindros imersos em água

(b) Foto do agitador desenvolvido, acoplado a um banho termostatizado.

Figura 4.5 (a) Esquema do projeto do agitador desenvolvido. (b) Foto do cilindro de $300 \mathrm{~mL}$ de alumínio e acrílico desenvolvido para testes de adsorção. 46 
Figura 4.6. Esquema do protótipo laboratorial para obtenção das curvas de ruptura.

Figura 4.7. Esquema do teste realizado em planta piloto com dois caminhões conectados. Somente a primeira coluna de adsorção é utilizada no experimento. ...51 Figura 4.8. Foto do protótipo utilizado para testes em escala piloto, sendo que somente a $1^{\text {a }}$ coluna é utilizada.

Figura 4.9. (a) Sensor de temperatura modelo Scanterm ST600.2, fabricante Incoterm. (b) Medidor de fluxo série, fabricante GPI utilizado para medição da vazão do processo. .52

Figura 4.10 Cromatógrafo Gasoso Agilent - Modelo 7890A. Detector SCD e FID. ...55

Figura 4.11. Analisador de Enxofre Total Antek .56

Figura 4.12. Analisador de Umidade Karl Fischer Metrohn. .56

Figura 5.1. Volume de controle macroscópico. Coluna recheada com peneira molecular 13X. 59

Figura 5.2. Ilustração das condições de contorno de Danckwerts. 62

Figura 5.3. Volume de controle da partícula de adsorvente. 63

Figura 6.1. Gráfico da isoterma de equilíbrio de $\mathrm{H}_{2} \mathrm{~S}$ em usando peneira molecular 13X. (AXENS, 1990) .78

Figura 6.2. Isoterma de equilíbrio a $25 \stackrel{\circ}{\circ}$ obtida experimentalmente para tercbutilmercaptana em butano em zeólita $13 \mathrm{X}$ como adsorvente. .79

Figura 6.3. Isoterma de equilíbrio a $25{ }^{\circ} \mathrm{C}$ obtida experimentalmente para etilmercaptana em butano em zeólita $13 \mathrm{X}$ como adsorvente.

Figura 6.4. Isoterma de equilíbrio a $25 \stackrel{\circ}{ } \mathrm{C}$ obtida experimentalmente para $\mathrm{n}$-propilmercaptana em butano em zeólita $13 \mathrm{X}$ como adsorvente.

Figura 6.5. Comparação entre as isotermas de equilíbrio a $25{ }^{\circ} \mathrm{C}$ dos solutos (tercbutil-mercaptana, n-propil-mercaptana e etil-mercaptana)

Figura 6.6. Isoterma de equilíbrio modificada a $25{ }^{\circ} \mathrm{C}$ obtida experimentalmente para n-propil-mercaptana em butano em zeólita $13 \mathrm{X}$ como adsorvente, incluindo pontos obtidos das curvas de ruptura.

Figura 6.7. Isoterma de equilíbrio a $10 \stackrel{\circ}{\circ} \mathrm{C}$ obtida experimentalmente para n-propilmercaptana em butano em zeólita 13X como adsorvente.

Figura 6.8. Comparação das isotermas de equilíbrio de n-propil-mercaptana em butano líquido na zeólita $13 \mathrm{X}$ nas temperaturas de $10 \stackrel{\circ}{\circ}$ e $25^{\circ} \mathrm{C}$ 
Figura 6.9. Comparação das isotermas de equilíbrio de n-propil-mercaptana em butano líquido usando zeólita $13 \mathrm{X}$ nas temperaturas de $10 \stackrel{\circ}{\circ} \mathrm{C}$ e $25 \stackrel{\circ}{\circ} \mathrm{C}$, incluindo as curvas de ajuste ao modelo de Langmuir.

Figura 6.10. Curvas de ruptura obtidas experimentalmente (coluna laboratório) para as concentrações de alimentação: 81 ppm, 174 ppm e 315 ppm de n-propilmercaptana, mantendo constante a velocidade média de $0,0040 \mathrm{~m} / \mathrm{s}$ que equivale a $4,5 \mathrm{~kg} / \mathrm{h}$ de vazão mássica. .85

Figura 6.11. Curvas de ruptura obtidas experimentalmente para as vazões de 4,61 $\mathrm{kg} / \mathrm{h}, 7,01 \mathrm{~kg} / \mathrm{h}$ e $9,15 \mathrm{~kg} / \mathrm{h}$, mantendo a concentração inicial de n-propil-mercaptana em torno de $174 \mathrm{mg} / \mathrm{kg}$.

Figura 6.12. Curvas de ruptura em escala piloto para diferentes compostos sulfurados em butano através de um leito recheado com peneira molecular 13X. .92 Figura 6.13. Resultado simulação computacional diferenças finitas. Teste Lab 1: Npropil-mercaptana $\mathrm{C}_{0}=81 \mathrm{ppm}, \mathrm{v}=0,0039 \mathrm{~m} / \mathrm{s}$. 95

Figura 6.14. Resultado simulação computacional diferenças finitas. Teste Lab 2: Npropil-mercaptana $\mathrm{C}_{0}=174 \mathrm{ppm}, \mathrm{v}=0,0039 \mathrm{~m} / \mathrm{s}$.

Figura 6.15. Resultado simulação computacional diferenças finitas. Teste Lab 3: Npropil-mercaptana $\mathrm{C}_{0}=315 \mathrm{ppm}, \mathrm{v}=0,0040 \mathrm{~m} / \mathrm{s}$. 96

Figura 6.16. Resultado simulação computacional diferenças finitas. Teste Lab 4: Npropil-mercaptana $\mathrm{C}_{0}=170 \mathrm{ppm}, \mathrm{v}=0,0060 \mathrm{~m} / \mathrm{s}$.

Figura 6.17. Resultado simulação computacional diferenças finitas. Teste Lab 5: Npropil-mercaptana $\mathrm{C}_{0}=174 \mathrm{ppm}, \mathrm{v}=0,0077 \mathrm{~m} / \mathrm{s}$.

Figura 6.18. Resultado simulação computacional diferenças finitas. Teste Piloto 6: Tercbutil-mercaptana $\mathrm{C}_{0}=12,1 \mathrm{ppm}, \mathrm{v}=0,0132 \mathrm{~m} / \mathrm{s}$. 99

Figura 6.19. Resultado simulação computacional diferenças finitas. Teste Piloto 7: Isopropil-mercaptana $\mathrm{C}_{0}=13,6 \mathrm{ppm}, \mathrm{v}=0,0134 \mathrm{~m} / \mathrm{s}$. 99

Figura 6.20. Resultado simulação computacional diferenças finitas. Teste Piloto 8: Npropil-mercaptana $\mathrm{C}_{0}=91,8 \mathrm{ppm}, \mathrm{v}=0,0169 \mathrm{~m} / \mathrm{s}$. 100

Figura 6.21 - Resultado simulação computacional de escala industrial para etilmercaptana com variação da concentração de alimentação 102 


\section{LISTA DE TABELAS}

Tabela 3-1 - Comparativo adsorção física e química. (CAVALCANTE, 1998) .8

Tabela 3-2. Classificação do tamanho dos poros e microporos de peneiras moleculares. (IUPAC).

Tabela 3-3. Classificação por tamanho dos microporos de peneiras moleculares. (IUPAC).

Tabela 3-4. Propriedades típicas alumina ativada comercial, fabricante AXENS........9

Tabela 3-5. Características típicas sílica gel.

Tabela 3-6. Classificação quanto ao teor de sílica na rede de zeólitas. (PAYRA; DUTRA, 2003). 12

Tabela 3-7. Propriedades da Zeólita 13X. (CHEREMISINOFF, 1986) ....................15

Tabela 3-8. Propriedades físicas do adsorvente 13X. 16

Tabela 3-9. Quantidades máximas ( $\mathrm{mg} \mathrm{H} \mathrm{H}_{2} \mathrm{~S} / \mathrm{g}$ adsorvente) adsorvidas em gás natural por adsorvente. (SOUZA, 2002). .33

Tabela 4-1. Características do processo industrial de dessulfurização de butano. ...38 Tabela 4-2. Composição média da matéria-prima Butano processada na planta industrial da Liquigás Distribuidora. 39

Tabela 4-3. Propriedades físico-químicas do butano. (DENNY, LUXON; 1962) .......40

Tabela 4-4. Características dos compostos sulfurados.

Tabela 4-5. Experimento para obtenção isoterma de equilíbrio a $25{ }^{\circ} \mathrm{C}$ tercbutilmercaptana em butano com peneira molecular 13X.

Tabela 4-6. Experimento para obtenção isoterma de equilíbrio a $25 \stackrel{\circ}{\circ} \mathrm{C}$ etilmercaptana em butano com peneira molecular 13X

Tabela 4-7. Experimento para obtenção isoterma de equilíbrio a $25 \stackrel{\circ}{\circ} \mathrm{n}$-propilmercaptana em butano com peneira molecular $13 X$.

Tabela 4-8. Experimento para obtenção isoterma de equilíbrio a $10 \stackrel{\circ}{ } \mathrm{C}$ n-propilmercaptana em butano com peneira molecular $13 \mathrm{X}$

Tabela 4-9. Características do protótipo utilizado para testes em escala laboratorial.

Tabela 4-10. Condições experimentais da adsorção em coluna em escala laboratorial.

Tabela 4-11. Características do protótipo utilizado para testes em escala piloto. .....51 
Tabela 4-12 Experimentos realizados em escala piloto para obter as curvas de ruptura com butano e peneira molecular 13X.

Tabela 4-13. Parâmetros do método de análise de enxofre por Quimiluminescência.

Tabela 4-14. Parâmetros da análise de enxofre total por Fluorescência.

Tabela 4-15. Parâmetros para análise de hidrocarbonetos por cromatografia a gás.

Tabela 5-1. Parâmetros de transporte teóricos para os experimentos em escala laboratorial e piloto.

Tabela 6-1. Parâmetros para as isotermas de equilíbrio a $25^{\circ} \mathrm{C}$ do tipo I, Langmuir a partir de dados experimentais.

Tabela 6-2. Propriedades termodinâmicas e parâmetros de equilíbrio para as isotermas de n-propil-mercaptana obtidos pelo ajuste ao modelo de Langmuir a partir de dados experimentais.

Tabela 6-3. Resultados zona de transferência de massa (ZTM) nas curvas de ruptura com aumento da concentração inicial de n-propil-mercaptana e vazão constante de 4 $\mathrm{kg} / \mathrm{h}$.

Tabela 6-4. Resultados dos experimentos para obtenção de curvas de ruptura com aumento da velocidade, considerando constante a concentração inicial de n-propilmercaptana em média a $\mathrm{C}_{0}=174 \mathrm{mg} / \mathrm{kg}$.

Tabela 6-5. Resultados calculados da ZTM nos experimentos em escala piloto para saturação da $1^{\text {a }}$ coluna do protótipo.

Tabela 6-6. Parâmetros utilizados para simulação dos experimentos em escala laboratorial com variação da concentração de entrada.

Tabela 6-7. Parâmetros utilizados para simulação dos experimentos em escala laboratorial com variação da velocidade do fluido.

Tabela 6-8. Parâmetros utilizados para simulação dos experimentos em escala piloto.

Tabela 6-9. Parâmetros utilizados para simulação em escala industrial. 101 


\section{LISTA DE ABREVIATURAS E SIGLAS}

ABAS Associação brasileira de aerossóis e saneantes

ASTM American Society for Testing and Materials

ANP Agência Nacional do Petróleo

BET Brunauer Emmet Teller

CFC Clorofluorcarbono

DF Diferenças finitas

EDO Equação diferencial ordinária

FID Flame ionization detector

GÁS LP Gás liquefeito de petróleo

IUPAC União Internacional de Química Pura e Aplicada

LDF Linear driving force

SCD Sulfur chemiluminescence detector 


\section{LISTA DE SÍMBOLOS}

A $\quad$ área da seção transversal do leito $\quad\left[\mathrm{m}^{2}\right]$

A matriz de coeficientes para a derivada de primeira ordem un.

$a_{p}$ área interfacial das partículas $\left[\mathrm{m}^{2}\right]$

b constante de equilíbrio de adsorção, $k_{a d} / k_{d} \quad$ adim.

B matriz de coeficientes para a derivada de segunda ordem un.

$C_{i} \quad$ concentração do soluto i na fase líquida externa ao poro $\quad\left[\mathrm{kg} / \mathrm{m}^{3}\right]$

$C_{i}^{0} \quad$ concentração de alimentação do soluto i na coluna, $\quad\left[\mathrm{kg} / \mathrm{m}^{3}\right]$

$\bar{C}_{i} \quad$ concentração adimensional do soluto i na fase líquida externa adim.

$C_{0} \quad$ concentração de alimentação do soluto na curva de ruptura $\quad[\mathrm{mg} / \mathrm{kg}]$

CLI comprimento do leito inutilizado [m]

$\begin{array}{lll}d_{B} & \text { diâmetro da coluna } & \text { [m] }\end{array}$

$\begin{array}{lll}\mathrm{d}_{\mathrm{p}} & \text { diâmetro da partícula } & {[\mathrm{m}]}\end{array}$

$\mathrm{D}_{\mathrm{Li}} \quad$ coeficiente de dispersão axial do componente i $\left[\mathrm{m}^{2} / \mathrm{s}\right]$

$D_{p} \quad$ difusividade molecular do soluto na mistura $\left[\mathrm{m}^{2} / \mathrm{s}\right]$

De difusividade efetiva do soluto na partícula $\left[\mathrm{m}^{2} / \mathrm{s}\right]$

E matriz de massa da fase fluida externa e interna ao poro

$\mathrm{H}$ constante de Henry [ $\left.\mathrm{m}^{3} / \mathrm{kg}\right]$

I vetor de Nc valores

J jacobiano

$k_{a d}$ constante de taxa de adsorção $\quad\left[\mathrm{m}^{3} / \mathrm{kg}\right]$

$k_{d} \quad$ constante de taxa de dessorção $\quad\left[\mathrm{m}^{3} / \mathrm{kg}\right]$

k constante de BET [ $\left[\mathrm{m}^{3} / \mathrm{kg}\right]$

$\mathrm{K}$ constante de equilíbrio de Langmuir e de Langmuir-Freundlich [ $\left[\mathrm{m}^{3} / \mathrm{kg}\right]$

K' constante de equilíbrio de Freundlich $\left[\mathrm{m}^{3} / \mathrm{kg}\right]$

$k_{b} \quad$ constante de Boltzman $\quad\left[\mathrm{m}^{2} . \mathrm{kg} / \mathrm{s}^{2} . \mathrm{K}\right]$

$\mathrm{k}_{\mathrm{fi}} \begin{aligned} & \text { coeficiente } \\ & \text { componente } \mathrm{i}\end{aligned}$ 
$\mathrm{k}_{\mathrm{i}} \quad$ coeficiente de transferência de massa interno [m/s]

ke coeficiente de transferência de massa externo [m/s]

K constante de adsorção obtida pelo modelo de Langmuir [ $\quad\left[\mathrm{m}^{3} / \mathrm{kg}\right]$

L altura da coluna [m]

Lu altura da coluna útil [m]

$m_{\text {pen }}$ massa da zeólita [kg]

$m_{\text {liq }} \quad$ massa de líquido no interior do pellet [kg]

$\mathrm{MB}_{\mathrm{B}}$ massa molecular do solvente [ $[\mathrm{kg} / \mathrm{kmol}]$

M matriz de massa da fase fluida externa

$M_{t} \quad$ massa total processada [kg]

$M_{u} \quad$ massa processada até a capacidade útil do leito [kg]

n constante empírica de Freundlich adim.

$\mathrm{N}$ fluxo mássico total da espécie química $\quad\left[\mathrm{kg} / \mathrm{m}^{2} . \mathrm{s}\right]$

$\mathrm{Nr}$ número de pontos de elementos finitos un.

$\mathrm{Nz}$ número de pontos internos de colocação un.

Nc número de componentes. un.

Pe número de Peclet da dispersão axial para o soluto adim.

$R \quad$ constante universal dos gases $\quad[\mathrm{J} / \mathrm{mol} . \mathrm{K}]$

$\bar{q}_{i} \quad$ quantidade adimensional adsorvida adim.

$q_{i} \quad$ quantidade de soluto adsorvido na fase líquida no sólido $\quad\left[\mathrm{kg} / \mathrm{m}^{3}\right]$

$q_{i}^{*} \quad$ quantidade de soluto adsorvido no sólido [ $[\mathrm{kg} / \mathrm{kg}]$

$q_{m} \quad$ quantidade máxima adsorvida do soluto no sólido [ $[\mathrm{kg} / \mathrm{kg}]$

$q_{u} \quad$ quantidade de soluto adsorvido até o ponto de ruptura [ $\quad[\mathrm{mg} / \mathrm{kg}]$

Q vazão do fluido no leito [ $[\mathrm{kg} / \mathrm{h}]$

$r_{m}$ raio de Stokes-Einstein do soluto [m]

Re número de Reynolds adim.

$\mathrm{R}_{\mathrm{p}}$ raio equivalente da partícula [m]

Sc número de Schmidt adim.

Sh número de Sherwood adim. 


\begin{tabular}{|c|c|c|}
\hline $\mathrm{T}$ & temperatura & {$\left[{ }^{\circ} \mathrm{C}\right]$} \\
\hline$t$ & tempo & {$[\mathrm{s}]$} \\
\hline$t_{e}$ & tempo de exaustão do leito & {$[\mathrm{s}]$} \\
\hline$t_{b}$ & tempo de ruptura do leito & {$[s]$} \\
\hline tu & tempo equivalente à capacidade útil do leito & [h] \\
\hline$t_{t}$ & $\begin{array}{l}\text { tempo equivalente à quantidade de soluto trocado até o tempo de } \\
\text { exaustão }\end{array}$ & {$[\mathrm{h}]$} \\
\hline u & número de pontos experimentais para cálculo do resíduo & [unid] \\
\hline v & velocidade intersticial & {$[\mathrm{m} / \mathrm{s}]$} \\
\hline$v_{0}$ & velocidade superficial & {$[\mathrm{m} / \mathrm{s}]$} \\
\hline V & volume da coluna & {$\left[\mathrm{m}^{3}\right]$} \\
\hline$V_{b_{A}}$ & volume molar do soluto & {$\left[\mathrm{m}^{3} / \mathrm{mol}\right]$} \\
\hline$V_{b_{m}}$ & volume molar do solvente & {$\left[\mathrm{m}^{3} / \mathrm{mol}\right]$} \\
\hline$Y_{m}$ & concentração do soluto na saturação de todas as camadas & {$\left[\mathrm{kg} / \mathrm{m}^{3}\right]$} \\
\hline$Y_{i}$ & $\begin{array}{l}\text { concentração do soluto i na fase fluida no interior do poro da } \\
\text { partícula }\end{array}$ & {$\left[\mathrm{kg} / \mathrm{m}^{3}\right]$} \\
\hline $\bar{Y}_{l}$ & concentração adimensional do adsorvato i na fase fluida interna & {$\left[\mathrm{kg} / \mathrm{m}^{3}\right]$} \\
\hline$z$ & coordenada axial & $\mathrm{m}$ \\
\hline $\bar{z}$ & coordenada axial adimensional & adim. \\
\hline ZTM & diferença entre altura total e a altura útil da coluna & $\mathrm{m}$ \\
\hline
\end{tabular}

\section{Letras Gregas}

$\begin{array}{lll}\Delta G & \text { variação da energia de Gibbs } & {[\mathrm{J} / \mathrm{mol}]} \\ \Delta H & \text { entalpia de adsorção } & {[\mathrm{J} / \mathrm{mol}]} \\ \Delta S & \text { entropia do sistema } & {[\mathrm{J} / \mathrm{mol}]} \\ \varepsilon_{b} & \text { porosidade do leito } & \text { adim. } \\ \varepsilon_{p} & \text { porosidade da partícula } & \text { adim. } \\ \rho & \text { massa específica do solvente } & {\left[\mathrm{kg} / \mathrm{m}^{3}\right]} \\ \rho_{p} & \text { massa específica do adsorvente } & {\left[\mathrm{kg} / \mathrm{m}^{3}\right]} \\ \varepsilon^{*} & \text { porosidade do leito global, definida como } \varepsilon^{*}=\varepsilon_{b}+\left(1-\varepsilon_{b}\right) \varepsilon_{\mathrm{p}} & \mathrm{adim} . \\ \lambda & \text { razão entre os raios do soluto }\left(r_{m}\right) \text { e do poro }\left(r_{p}\right) & \mathrm{adim} .\end{array}$


$\lambda_{i} \quad$ constante adimensional para o componente i, $3 k_{i} L /\left(v_{0} R_{p}\right) \quad$ adim.

$\mu \quad$ viscosidade da fase fluida

$\varphi_{i} \quad$ constante adimensional para o componente i, $\rho_{p} q_{m i}^{*}\left(1-\varepsilon_{p}\right) / C_{i}^{0} \quad$ adim.

$\tau \quad$ tempo adimensional adim.

$\tau_{p} \quad$ tortuosidade adim.

$\theta$ fração do comprimento útil da coluna até o ponto de exaustão adim.

$\gamma_{1}$ constante para cálculo coeficiente de dispersão axial adim.

$\gamma_{2}$ constante para cálculo coeficiente de dispersão axial adim. 


\section{SUMÁRIO}

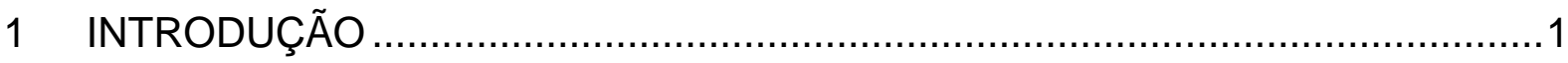

2 OBJETIVOS E ORGANIZAÇÃO DO TRABALHO........................................

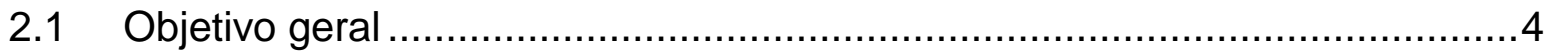

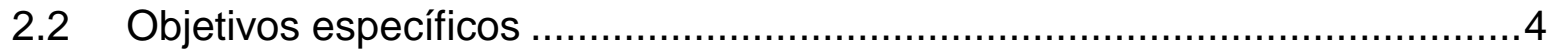

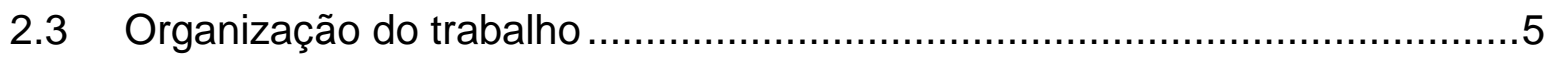

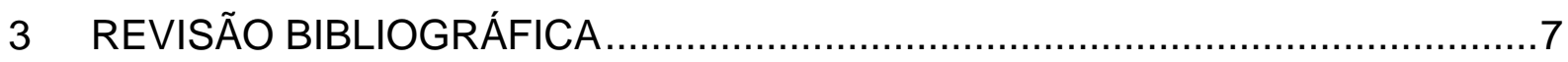

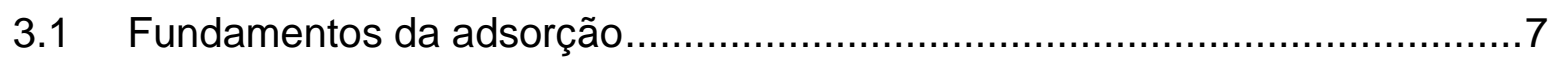

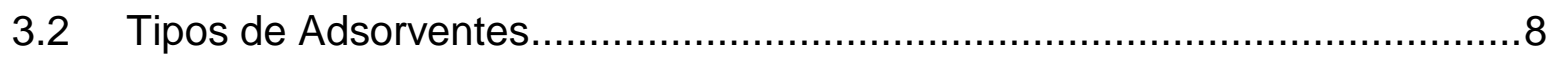

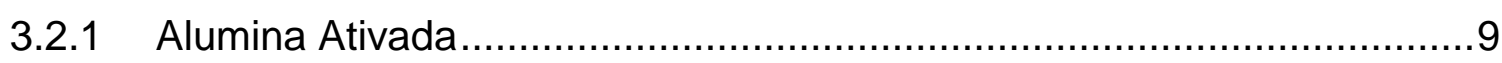

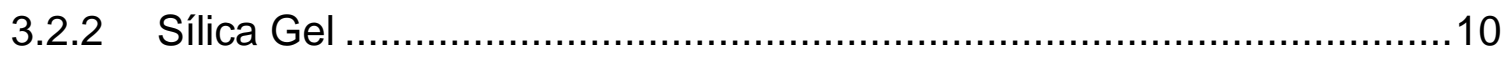

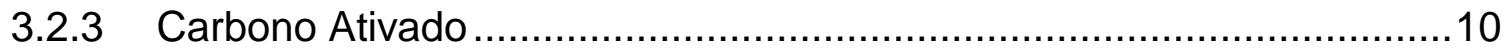

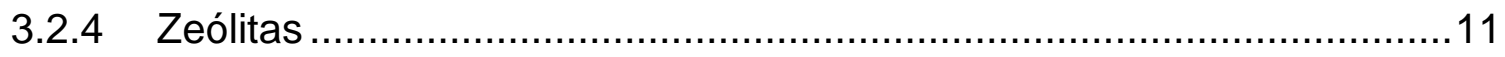

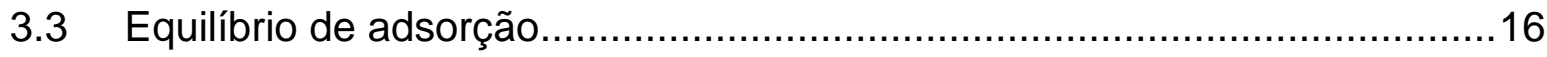

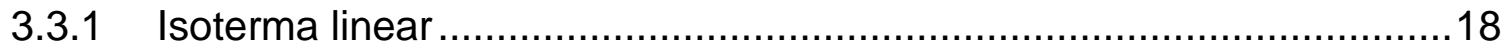

3.3.2 Isoterma de Langmuir ....................................................................

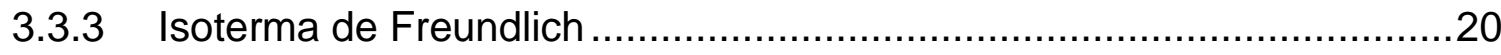

3.3.4 Isoterma de Langmuir-Freundlich ....................................................21

3.3.5 Isoterma de BET (Brunauer, Emmett, Teller, 1983).............................22

3.3.6 Isotermas multicomponentes ........................................................22

3.3.7 Termodinâmica da adsorção .........................................................24

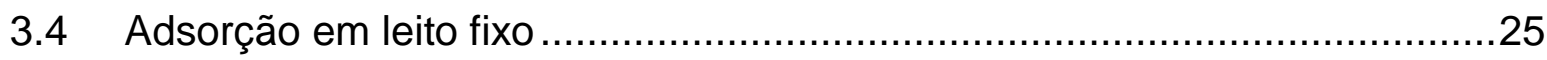

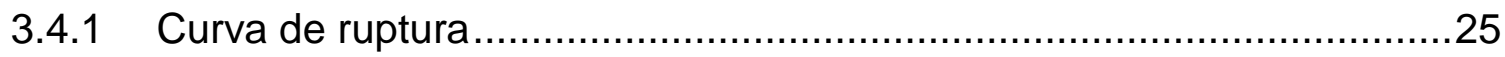

3.4.2 Capacidade de adsorção leito fixo .................................................27

3.4.3 Zona de transferência de massa ...................................................28

3.4.4 Estudo de aumento de escala ....................................................... 
3.5 Processos para remoção de compostos de enxofre por adsorção

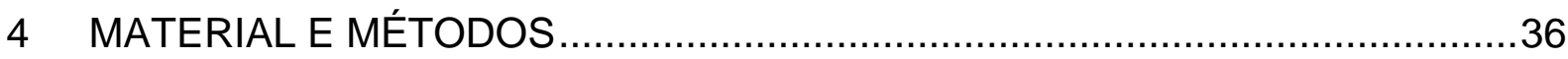

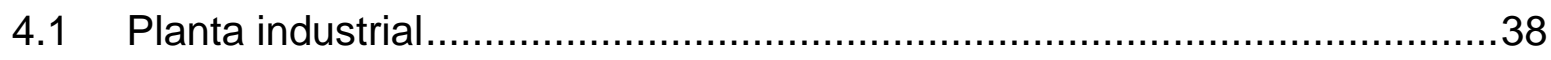

4.2 Caracterização do solvente .................................................................. 40

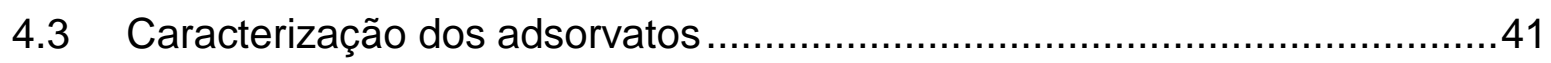

4.4 Obtenção das curvas de equilíbrio de adsorção ........................................42

4.4.1 Condicionamento do material adsorvente .........................................42

4.4.2 Preparação das soluções ............................................................. 42

4.4.3 Obtenção da isoterma de adsorção ..................................................4

4.5 Obtenção da curva de ruptura............................................................... 48

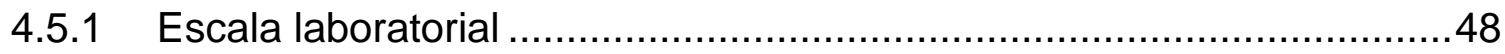

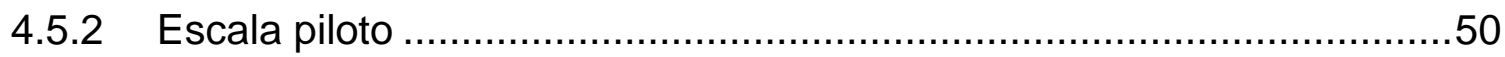

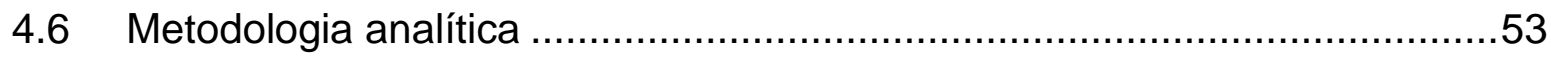

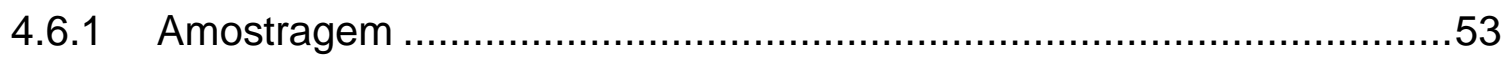

4.6.2 Análise de compostos de enxofre ....................................................

4.6.3 Análise de umidade - Karl Fischer …………..................................56

4.6.4 Análise de hidrocarbonetos - Cromatografia a gás ...............................57

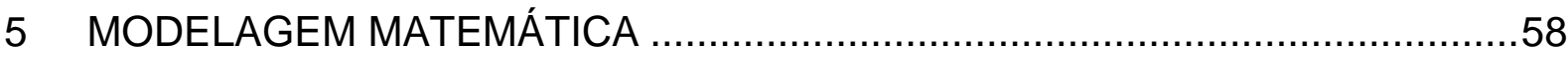

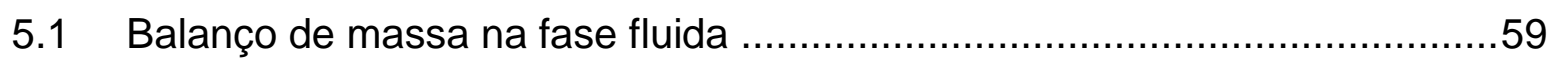

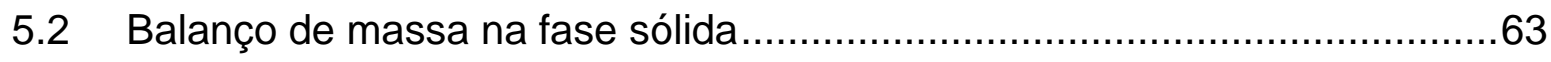

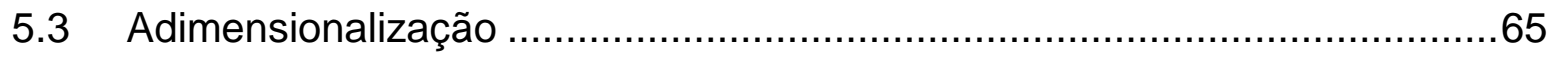

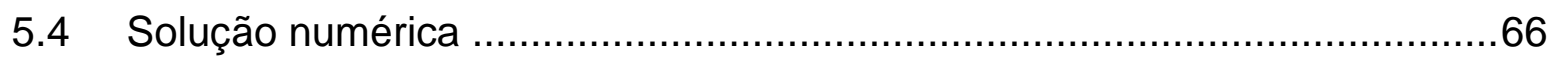

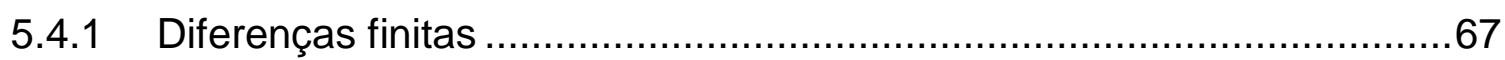

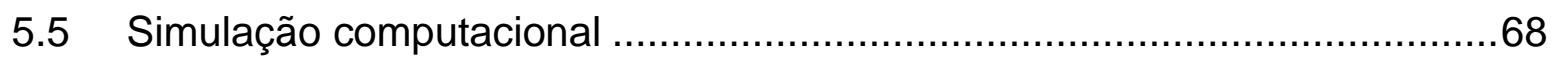

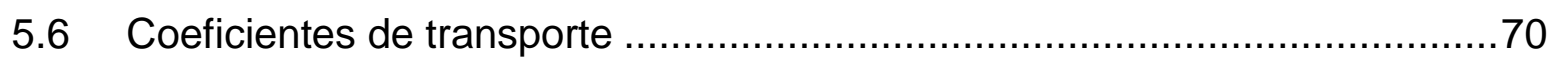

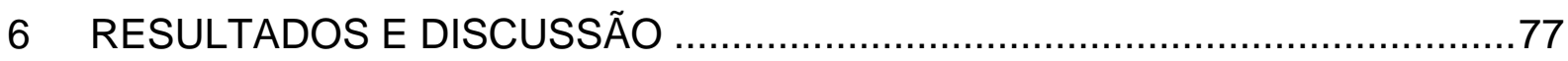




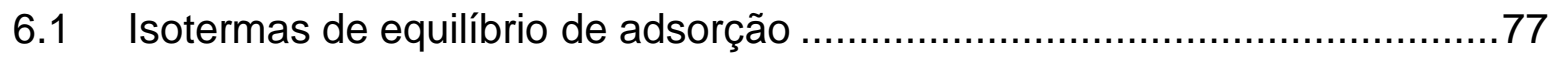

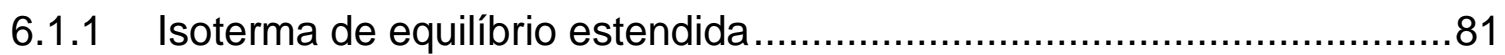

6.2 Curva de ruptura em escala laboratorial ................................................ 84

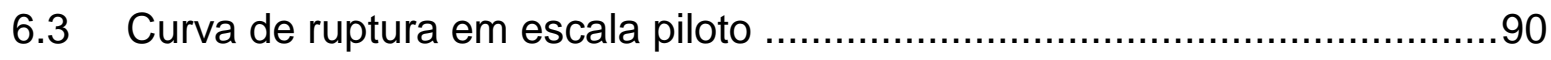

6.4 Estudo do modelo e simulação ............................................................92

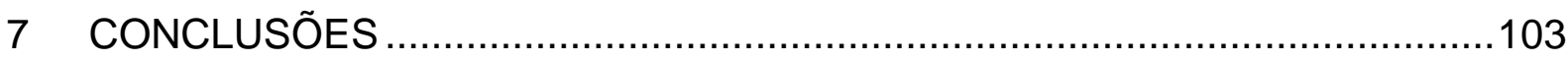

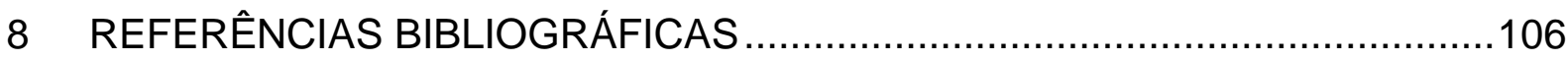




\section{INTRODUÇÃO}

O grande aumento na utilização dos hidrocarbonetos (butano/ propano) ou gás LP (Gases Liquefeitos de Petróleo), como propelentes na indústria de aerossol iniciou-se com a descoberta do buraco na camada de ozônio provocado pelos CFC's (Clorofluorcarbonos) em 1973. Atualmente, é o tipo de propelente mais utilizado no mundo, devido sobretudo ao seu baixo custo, à baixa toxicidade e ao seu odor agradável. Na América do Norte, sua utilização pode chegar até $82 \%$ de todos os aerossóis. Em 2014, mais de 1 bilhão de latas de aerossóis foram comercializadas no Brasil. (ABAS, 2014).

O gás LP é muito utilizado como combustível tanto na área industrial como doméstica e devido ao fato de ser inodoro, por questões de segurança, são adicionados compostos orgânicos sulfurados com forte poder odorífero, para permitir a sua detecção em vazamentos. Contudo, a adição destas substâncias impossibilita seu uso como propelente para produtos em aerossol em setores como o de cosméticos e de medicamentos.

Em 2011, a Liquigás Distribuidora iniciou no Brasil a produção de propelente dessulfurizado através da purificação destas correntes orgânicas por adsorção usando como adsorvente a zeólita 13X - uma vez que possui a habilidade de tratar soluções diluídas de maneira mais seletiva e eficiente comparada a outros métodos de separação, como destilação e absorção. (CUSSLER, 2009).

Dado que a adsorção é um método de separação fortemente dependente de dados experimentais e que a literatura especialmente para dessulfurização de gás LP, usando zeólitas 13X continua escassa desde as publicações de Shams et al (2008) e Weber et al (2005), a grande motivação deste trabalho foi promover maior conhecimento sobre este sistema a fim de possibilitar futuramente a otimização do processo industrial que envolve alto nível de complexidade, por se tratar de um processo de adsorção multicomponente em condições de temperatura e concentração de contaminantes variáveis.

Como ilustração da complexidade do comportamento das colunas industriais, apresenta-se a curva de ruptura ( $\mathrm{C} / \mathrm{C}_{0} \times$ tempo), na Figura 1.1, obtida através do 
acompanhamento das 4 colunas industriais, descritas no item 4.1, no período de 08/09/2014 à 19/11/2014.

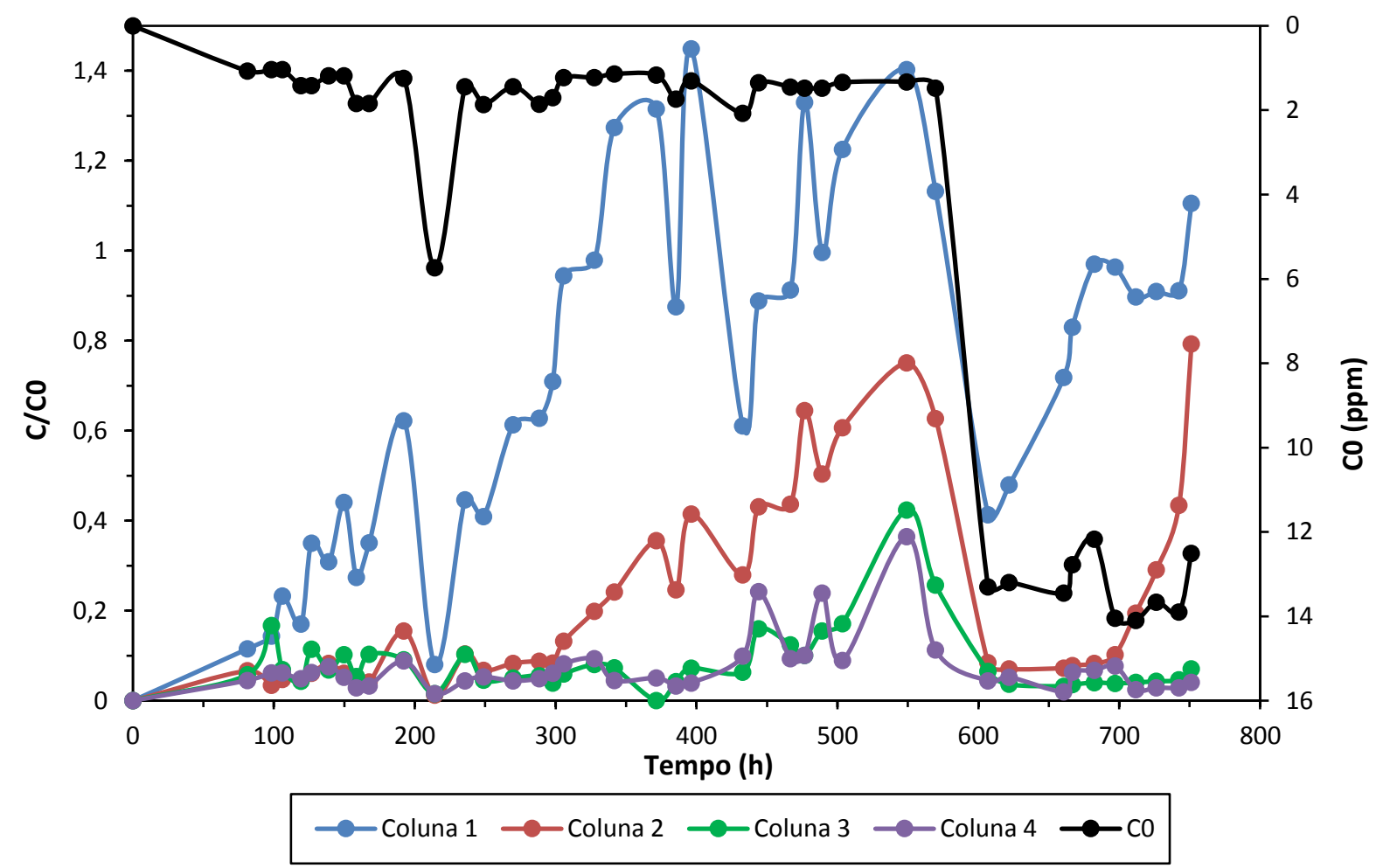

Figura 1.1. Curvas de ruptura das 4 colunas industriais de leito recheado com peneiras moleculares $13 \mathrm{X}$ novas e regeneradas. Sistema multicomponente.

Outros fatores que dificultam a utilização e análise destes dados para fins acadêmicos, estão descritos:

- No período entre as bateladas as colunas ficam preenchidas de líquido estático até o início da próxima produção. O tempo é considerável, podendo chegar a $30 \mathrm{~h}$. Neste momento as peneiras moleculares continuam adsorvendo os contaminantes até atingirem o equilíbrio em uma dada temperatura. Isso certamente interfere no tempo de vida útil do material adsorvente $\mathrm{e}$ consequentemente nas curvas de ruptura que, geralmente, baseiam-se em processos contínuos.

- O material adsorvente que preenche as colunas no processo industrial por vezes é regenerado e não novo. Como há dificuldade na avaliação da qualidade do material regenerado, a capacidade de adsorção do material regenerado pode ser menor que a das peneiras moleculares novas e ainda 
variável, conforme seu nível de saturação e as condições do processo de regeneração propriamente dita.

Alguns estudos científicos abordam a dessulfurização de gases (LUTZ, 1990; SOUZA, 2002) e de solventes líquidos (CERUTTI, 2007) através do processo de adsorção para fins ambientais em atendimento a regulamentos e normas ou otimização de processo como desativação de leito catalítico. Grande parte dos dados científicos para remoção de mercaptanas de combustíveis hidrocarbonetos, estudam o carvão ativado como adsorvente, como em Bashkova et al (2002), Bagreev et al (2002), Chiang et al (2000) e Sakano et al (1997).

O artigo de Shams et al (2008) que trata especificamente da modelagem e simulação do processo de dessulfurização de butano líquido através de peneiras moleculares 13X, equivale ao sistema investigado no presente trabalho e é utilizado como referência com algumas adaptações para a modelagem matemática e simulação computacional. 


\section{OBJETIVOS E ORGANIZAÇÃO DO TRABALHO}

\subsection{Objetivo geral}

O presente trabalho tem como objetivo principal estudar o processo de dessulfurização de butano no estado líquido utilizando peneiras moleculares 13X, para que seja possível aplicar estes conhecimentos na otimização do sistema em escala industrial, localizado em uma das unidades operacionais da Liquigás Distribuidora SA, conforme descrição no item 4.1.

\subsection{Objetivos específicos}

A previsão do comportamento dos diversos parâmetros do processo industrial é de extrema valia, no sentido em que permite o planejamento operacional e financeiro. Entretanto, o processo de adsorção é fortemente dependente de dados experimentais e complexo, pois é representado por equações que não são resolvidas analiticamente. Além disso, realizar experimentos em escala industrial é inviável devido às possíveis consequências como, por exemplo, uma contaminação do produto a ser comercializado. Assim, pretende-se:

- Estudar o equilíbrio de adsorção de diferentes compostos de enxofre (etilmercaptana, terc-butil-mercaptana e n-propil-mercaptana) e a influência da temperatura.

A etil-mercaptana é o composto de enxofre encontrado com maior frequência e teor no Butano como matéria-prima. Entretanto, há outros compostos como dissulfeto de carbono, sulfeto de carbonila e metil-mercaptana, que por serem gasosos nas condições ambientais há dificuldade no manuseio. Como se trata de um sistema multicomponente, o objetivo foi avaliar se haveria diferença na interação de diferentes componentes com a peneira molecular e se seria possível considerar a soma de todos como enxofre total para efeito de modelagem matemática do sistema. A seleção dos componentes: terc-butil-mercaptana e n-propil-mercaptana se deu pela disponibilidade de volume suficiente para os experimentos e pela facilidade no manuseio, uma vez que são líquidos à temperatura e pressão ambiente. 
- Implementar um modelo matemático que represente o processo de adsorção monocomponente e multicomponente em uma corrente líquida de butano, em leito fixo recheado de peneiras moleculares $13 \mathrm{X}$.

- Validar o modelo matemático de um sistema inicialmente monocomponente a partir da comparação com dados experimentais obtidos em escala laboratorial e piloto, que refletem condições análogas às existentes em escala industrial.

- Estudar a influência dos parâmetros operacionais: velocidade e concentração de compostos de enxofre no desempenho do sistema.

De acordo com o histórico de dados do laboratório de controle de qualidade da Liquigás, há variação da concentração inicial de enxofre total no Butano utilizado como matéria-prima. Por este motivo, é interessante a avaliação da influência deste parâmetro no comportamento das colunas de adsorção.

O estudo da velocidade é importante por estar associado à produtividade do processo industrial.

\subsection{Organização do trabalho}

Os Capítulos 1 e 2 apresentam uma breve introdução ao escopo e aos objetivos do presente estudo, respectivamente. $O$ Capítulo 3 aborda os principais fundamentos que envolvem o processo de adsorção, o material adsorvente em questão e a caracterização da mistura de hidrocarbonetos e dos solutos (compostos sulfurados).

No Capítulo 4, apresentam-se a descrição dos métodos empregados para o desenvolvimento dos ensaios experimentais, a saber: metodologia analítica utilizada para medição e controle das substâncias químicas, descrição dos equipamentos utilizados e da sua operação para os ensaios para obtenção das isotermas de adsorção e os ensaios contínuos de adsorção em leito fixo em escalas laboratorial e piloto e sua correlação com a planta industrial.

No Capítulo 5 apresentam-se os modelos para o estudo de adsorção e os respectivos equacionamentos, o desenvolvimento e implementação do modelo matemático e a solução computacional para os estudos de simulação. 
O Capítulo 6 refere-se aos resultados para o equilíbrio de adsorção, do estudo da influência de alguns parâmetros do processo em escala laboratorial e piloto e da modelagem matemática e simulação computacional das colunas de leito fixo comparando aos dados experimentais.

Apresentam-se, no Capítulo 7, as principais conclusões da dissertação e sugestões para trabalhos futuros.

Finalmente, no Capítulo 8, são listadas as referências bibliográficas que subsidiaram o cumprimento deste estudo. 


\section{REVISÃO BIBLIOGRÁFICA}

\subsection{Fundamentos da adsorção}

O processo de adsorção ocorre através de uma interação do tipo física ou química, seja em sistemas gás-sólido ou líquido-sólido. (CHEREMISINOFF, 1986). Na indústria, a adsorção é normalmente conduzida em um leito recheado de partículas sólidas porosas. A Figura 3.1 ilustra a fixação do adsorvato sobre o adsorvente.

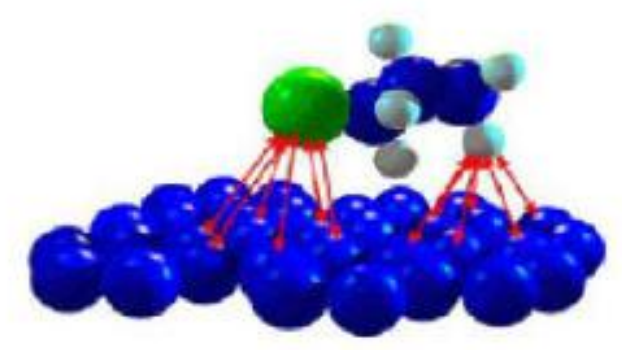

Figura 3.1 - llustração do fenômeno de adsorção. Fonte: (LUZ, 2006)

Os poros do adsorvente são geralmente muito pequenos, resultando em áreas superficiais que podem aproximar-se da ordem de $1000 \mathrm{~m} / \mathrm{g}$. Quando o líquido (eluente) escoa através do leito, o soluto (adsorbato) é adsorvido na superfície das partículas sólidas (adsorvente). A separação então ocorre por diferenças de massa molecular, forma ou polaridade, o que faz com que algumas moléculas sejam mais fortemente adsorvidas que outras.

Consideram-se basicamente dois tipos de adsorção: de natureza física (fisissorção) e natureza química (quimissorção). As duas são iniciadas quando as moléculas do líquido são atraídas pela superfície do sólido, superando assim a energia cinética do soluto. A fisissorção é principalmente ocasionada por forças entre as moléculas, geralmente fracas quando comparadas às ligações covalentes, chamadas de van der Waals, em homenagem ao físico holandês do século XIX que propôs primeiro sua existência. As mais importantes são: a interação dipolos permanentes (Força de Keesom), dipolo permanente e um polo induzido (Força de Debye) e dipolo induzido ou forças de dispersão de London. (RUSSEL, 1994)

Já a quimissorção é resultado de ligações químicas entre o material do sólido e as moléculas da substância adsorvida, que são muito mais fortes que a de natureza física 
e são acompanhadas de uma alta entalpia de adsorção. (CAVALCANTE, 1998). A Tabela 3-1 mostra um comparativo entre os diferentes tipos de adsorção.

Tabela 3-1 - Comparativo adsorção física e química. (CAVALCANTE, 1998)

\begin{tabular}{ll}
\hline Adsorção Física & Adsorção Química \\
\hline Baixa entalpia de adsorção & Alta entalpia de adsorção \\
Não específica & Altamente específica \\
Não há dissociação de espécies adsorvidas & Pode ocorrer dissociação \\
Somente significativa a baixas temperaturas & Possível em ampla variação de temperatura \\
Rápida, não-ativada, reversível & Ativada, pode ser lenta e irreversível \\
Sem transferência de elétrons, mesmo que & $\begin{array}{l}\text { Transferência de elétrons levando à } \\
\text { formação de ligação química entre soluto e } \\
\text { ocorra a polarização do soluto. }\end{array}$ \\
Monocamada ou multicamada & Somente monocamada \\
\hline
\end{tabular}

\subsection{Tipos de Adsorventes}

O desempenho do processo de adsorção depende do comportamento do sólido poroso no equilíbrio e cinética. Um sólido com boa capacidade de adsorção, mas baixa cinética não é uma boa escolha, já que a molécula de adsorvato leva muito tempo para atingir o interior da partícula. Isto significa longo tempo de residência na coluna e baixa taxa de transferência. Pelo outro lado, um sólido com alta cinética, mas baixa capacidade de adsorção também não é positivo, porque seria necessária uma grande quantidade de sólido para processar uma dada quantidade de solvente. Logo, um bom adsorvente deve prover boa capacidade adsortiva, assim como boa cinética através de uma grande superfície de pequenos poros e porosidade razoáveis.

A União Internacional de Química Pura e Aplicada (IUPAC) classifica o tamanho das aberturas ou poros, como segue na Tabela 3-2:

Tabela 3-2. Classificação do tamanho dos poros e microporos de peneiras moleculares. (IUPAC).

\begin{tabular}{ccc}
\hline Microporos & Mesoporos & Macroporos \\
\hline$<2 \mathrm{~nm}$ & 2 a $50 \mathrm{~nm}$ & $>50 \mathrm{~nm}$ \\
\hline
\end{tabular}

Em que os microporos por sua vez são classificados na Tabela 3.3: 
Tabela 3-3. Classificação por tamanho dos microporos de peneiras moleculares. (IUPAC).

\begin{tabular}{cccc}
\hline Poros Pequenos & Poros Médios & Poros Grandes & Poros Supergrandes \\
\hline$<0,4 \mathrm{~nm}$ & $0,4-0,6 \mathrm{~nm}$ & $0,6-2 \mathrm{~nm}$ & $>2 \mathrm{~nm}$ \\
\hline
\end{tabular}

Esta classificação foi desenvolvida baseada na adsorção do nitrogênio em sua temperatura de ebulição normal para uma ampla variedade de sólidos porosos.

Existem muitos tipos de adsorventes, sendo os mais importantes utilizados na indústria química, petroquímica, bioquímica, biológica e biomédica: a alumina ativada, zeólitas, sílica gel e carbono ativado.

\subsubsection{Alumina Ativada}

A alumina ativada é particularmente adequada para secagem de ar comprimido e de gases que possuem alta umidade relativa. Entre as razões para estas aplicações são o baixo custo, resistência química e física, possibilidade de regeneração e alta capacidade de reter água.

A matéria-prima convencional para obtenção da alumina ativada é a bauxita, que reagindo com soda cáustica transforma-se em aluminato de sódio via processo Bayer. Após a lavagem e separação, uma "lama vermelha" é removida, obtendo-se assim a gipsita através de calcinação de $400{ }^{\circ} \mathrm{C}$ a $600{ }^{\circ} \mathrm{C}$.

Seguem algumas características típicas de alumina ativada comercial, produzida pela AXENS na Tabela 3-4.

Tabela 3-4. Propriedades típicas alumina ativada comercial, fabricante AXENS.

\begin{tabular}{ll}
\hline Propriedades & Alumina Ativada \\
\hline Tipo & Axsorb A ou B \\
Massa específica, $\mathrm{kg} / \mathrm{m}^{3}$ & $785-840$ \\
Volume total de poro, $\mathrm{cm}^{3} / 100 \mathrm{~g}$ & 44 \\
Superfície específica, $\mathrm{m}^{2} / \mathrm{g}$ & $325-335$ \\
Resistência ao esmagamento, daN & $13-43$ \\
Diâmetro esfera, mm & $1,5-8$ \\
Capacidade adsorção (\% massa), umidade $0,1 \%$ & 7,5 \\
Capacidade adsorção (\% massa), umidade $0,6 \%$ & 21,5 \\
\hline
\end{tabular}

Fonte: Technical Data Sheet AXENS: www.axens.net 


\subsubsection{Sílica Gel}

A sílica gel pura, $\mathrm{SiO}_{2}$ é naturalmente um material apolar inativo quimicamente, como o quartzo, mas quando possui um grupo funcional hidróxido (silanol) torna-se muito polar. É produzida da coagulação de uma solução coloidal de ácido de sílica, seguida de uma desidratação controlada. O termo gel reflete a condição do material durante sua etapa de produção e não a natureza do produto final. A sílica gel é uma substância vítrea rígida. Este tipo de adsorvente é muito utilizado para remoção de água devido a sua alta capacidade hidrofílica. Segue a Tabela 3-5 contendo algumas características típicas da sílica gel:

Tabela 3-5. Características típicas sílica gel.

\begin{tabular}{lc}
\hline Propriedades & Sílica Gel \\
\hline Massa específica partícula, $\mathrm{kg} / \mathrm{m}^{3}$ & $700-1000$ \\
Porosidade & $0,5-0,65$ \\
Volume total de poro, $\mathrm{cm}^{3} / 100 \mathrm{~g}$ & $45-100$ \\
Superfície específica, $\mathrm{m}^{2} / \mathrm{g}$ & $250-900$ \\
\hline Fonte: $\mathrm{DO}, 1998$. &
\end{tabular}

Algumas aplicações da sílica gel estão descritas abaixo:

- Remoção de água do ar;

- Secagem de gases não-reativos e reativos;

- Adsorção de sulfeto de hidrogênio;

- Adsorção de vapores de óleo;

- Adsorção de álcoois.

\subsubsection{Carbono Ativado}

Entre os sólidos usados na indústria, o carbono ativado é um dos mais complexos, contudo o mais versátil por conta de sua enorme área superficial e volume de microporo. Existem mais de 100 tipos de carbonos ativados comerciais no mercado, com diferentes tamanhos de poros e específicas aplicações. 
O carbonos ativados são um conjunto de camadas de grafeno e possuem uma porosidade fechada por átomos de carbono. O tamanho do poro é da ordem de moléculas em formato de fendas. (MARSH, REINOSO, 2006).

Carbonos ativados são feitos a partir de matérias-primas usualmente ricas em oxigênio, tais como carvão, lignina, madeira, casca de coco e sistemas de macromoléculas sintéticas. O processo de ativação do carvão ativo, segundo Marsh e Reinoso (2006), pode ser realizado termicamente, fisicamente ou quimicamente.

\subsubsection{Zeólitas}

Há dois séculos, notou-se pela primeira vez a existência de zeólitas cristalinas. Sua habilidade de desprender água quando aquecida e adsorver quando resfriadas já eram conhecidas naquele tempo, mas sua capacidade seletiva não era reconhecida até 1920. Considerando que as zeólitas naturais possuem alta variabilidade química e física, estes produtos não eram viáveis economicamente. A partir de 1950 propagaram-se estudos para sintetizar adsorventes com desempenho consistente para serem utilizados comercialmente. (UOP, 2004). Em 2006, havia aproximadamente mais de 170 peneiras moleculares registradas na Structure Commission of the International Zeolite Association. Dessas, apenas 17 são produzidas comercialmente. (CEJKA, 2007)

A zeólita (nome grego zeo: ferver, lithos: pedra) é um aluminosilicatos cristalino com estrutura tridimensional, que forma tamanhos de poro de dimensão molecular uniformes. Toda estrutura zeolítica é composta pelo encadeamento de unidades $\mathrm{TO}_{4}$ $\left(\mathrm{SiO}_{4}\right.$ e $\left.\mathrm{AlO}_{4}\right)$, em que $\mathrm{T}$ é um átomo de silício ou alumínio, coordenado por quatro átomos de oxigênio em geometria tetraédrica com o emprego de uma pequena quantidade de argila para promover ajustes das propriedades mecânicas do material adsorvente. A composição de uma zeólita pode ser representada usando os três componentes: rede cristalina, cátions de compensação e fase adsorvida, conforme a fórmula: (PAYRA; DUTRA; 2003)

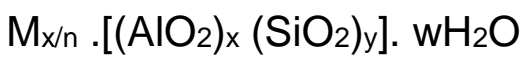


Em que $\mathrm{M}$ é o cátion de compensação de valência $\mathrm{n}$ (metais alcalinos como, $\mathrm{Na}, \mathrm{K}$, $\mathrm{Ca}, \mathrm{Mg}, \mathrm{Sr}, \mathrm{Ba}$, etc), w é o número de moléculas de água e $\mathrm{x}+\mathrm{y}$ é o número total de tetraedros $\mathrm{SiO}_{4}$ e $\mathrm{AlO}_{4}$ na cela unitária da estrutura zeolítica.

As zeólitas podem ser classificadas quanto à sua proporção Si/Al, conforme Tabela 3-6. As zeólitas naturais são de baixa sílica e eventualmente de sílica intermediária. Já as zeólitas de alta sílica são aquelas obtidas sinteticamente.

Tabela 3-6. Classificação quanto ao teor de sílica na rede de zeólitas. (PAYRA; DUTRA, 2003).

\begin{tabular}{lll}
\hline Quanto ao teor de sílica & Si/Al & Exemplo \\
\hline Baixa sílica & 1 a 1,5 & A e X natural e sintética \\
Intermediária sílica & 2 a 8 & Y sintética, modernita natural \\
Alta sílica & 10 a $<\infty$ & ZSM-5 sintética \\
\hline
\end{tabular}

A microporosidade natural destes sólidos, que é controlada pela estrutura cristalina, limita a entrada de moléculas cujas dimensões são maiores que um dado valor, que varia de um tipo a outro de zeólita, de acordo com seu processo de fabricação. Por esse motivo são também chamadas de peneiras moleculares.

Como são fabricadas por troca iônica, as peneiras moleculares possuem cargas polares nas superfícies que atraem compostos extremamente polares como água e sulfeto de hidrogênio. Ao contrário de outros dessecantes, as peneiras moleculares exibem uma taxa constante de adsorção e alta capacidade no equilíbrio de remoção de água a uma gama de umidades relativas.

As características especiais das peneiras moleculares incluem reversibilidade no processo de adsorção de vários componentes gasosos e vapores de água e uma rede de cavidades estreitas resultando numa grande área de superfície interna que pode variar entre 500 a $1000 \mathrm{~m}^{2} / \mathrm{g}$. (GUTIERREZ; 2004). Adicionalmente a isso, possuem alta capacidade de adsorção a baixas pressões e baixa capacidade em altas temperaturas.

Desde o trabalho pioneiro de Barrer e Milton, a técnica sintética hidrotérmica tem se tornado a rota básica para síntese de zeólitas. Esta técnica geralmente se refere a reações sob condições de alta temperatura e pressão (> $100^{\circ} \mathrm{C},>1$ bar) em solução 
aquosa e sistema fechado. (CEJKA, 2007). A água estabiliza os canais e cavidades da estrutura porosa controlando a dimensão dos poros formados. (MASCARENHAS, 2001).

Segue na Figura 3.2, um exemplo de produção comercial da empresa UOP. Silicato de sódio, alumina trihidratada e hidróxido de sódio são pesados e misturados em um tanque até que se tornem homogêneos. A mistura forma um gel que é bombeado até um tanque para cristalização sob condições controladas. Após a cristalização, um filtro rotativo separa e lava os cristais de zeólita.

Para troca catiônica ocorrer (cálcio, potássio ou outros cátions substituídos por sódio no cristal), o "bolo" filtrado é transferido para um tanque de aquecimento onde é adicionada uma solução com um sal de metal apropriado. Uma vez separados e lavados, o bolo é transferido para funis. Para formação de pellets de 1,6 mm e 3,2 mm ou esferas, o cristal é misturado com argila e depois alimentado a equipamentos para extrusão. As várias formas de produtos são, então, secas e empacotadas para evitar o contato com umidade.

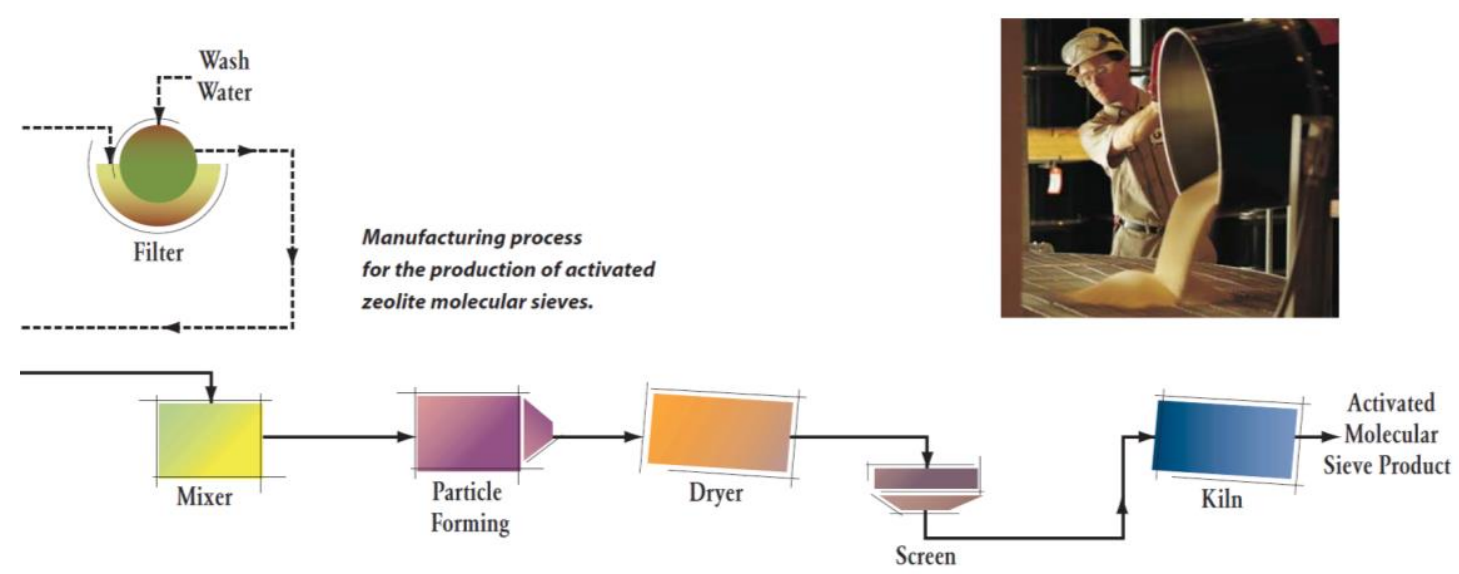

Figura 3.2. Processo de produção de peneiras moleculares da UOP.

\subsubsection{Zeólitas tipo $A$}

Aluminosilicato de sódio é a base da zeólita do tipo A com poros de 4 Å de diâmetro $\left(0,4 \mathrm{~nm}\right.$ ou $\left.4^{\star} 10^{-8} \mathrm{~cm}\right)$. Esta estrutura é representada quimicamente pela fórmula:

$\mathrm{Na}_{12}\left(\mathrm{AlO}_{2}\right)_{12}\left(\mathrm{SiO}_{2}\right){ }_{12}, \mathrm{x} \mathrm{H}_{2} \mathrm{O}$ 
A substituição de cátions de sódio por cálcio, altera a abertura dos poros para $5 \AA$ de diâmetro, o que corresponde a peneira molecular comercial $5 \mathrm{~A}$ e seguindo o mesmo raciocínio tamanhos de poro de $3 \AA$, correspondem a peneira molecular $3 \mathrm{~A}$, obtidas pela substituição do cátion sódio pelo potássio.

\subsubsection{Zeólitas tipo $X$ e $Y$}

As zeólitas sintéticas ou faujasitas $X$ e $Y$ e o mineral natural faujasita possuem a mesma armação, conforme mostrado na Figura 3.3. O canal resultante é bem aberto com cada cadeia conectada a outras através de 12 anéis de oxigênio com diâmetro livre em torno de 7,4 $\AA$. Moléculas grandes, tais como neopentano e terc-butil amina podem penetrar nestes poros. (RUTHVEN, 1984).

A diferença entre a zeólita $X$ e a $Y$ existe na razão Si/Al, com $X$ variando de $1-1,5$ e $Y$ de $1,5-3,0$. Assim, há a correspondência na complexidade de distribuição no número de cátions em cada uma das redes $\mathrm{X}$ e $\mathrm{Y}$. Isto resulta em diferenças de seletividade para algumas moléculas. Segue na Figura 3.3 a estrutura típica de uma zeólita do tipo $\mathrm{X}$ ou $\mathrm{Y}$.

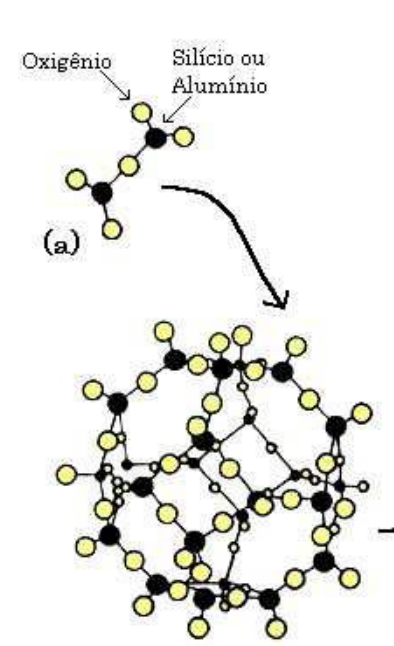

(b)

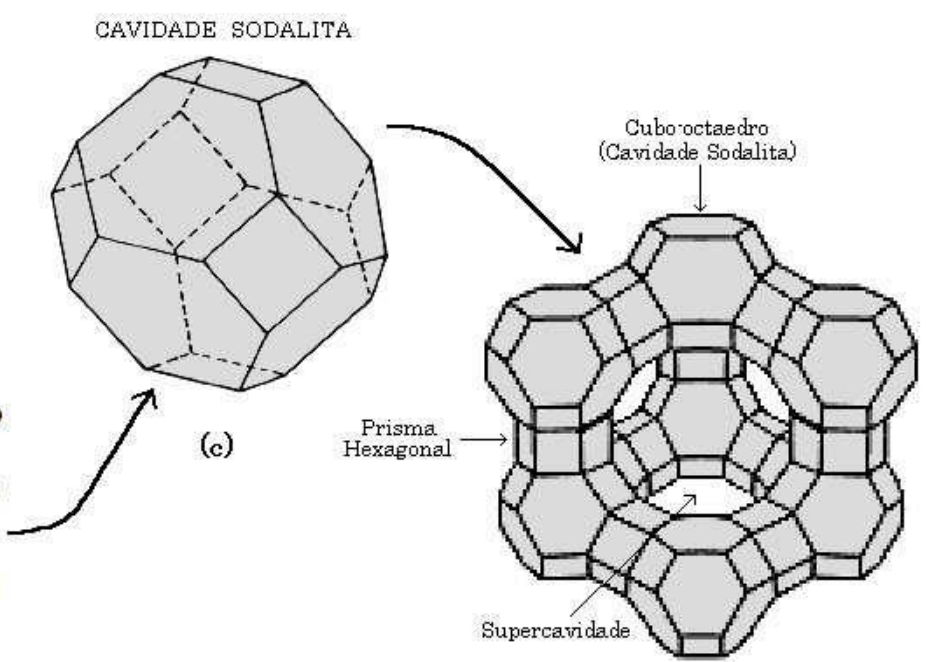

(d)

Figura 3.3. Estrutura de uma zeólita X ou Y. (b,c) Representação simplificada de um cubo octaedro, em que aparecem os átomos de oxigênio, silício e alumínio (a) Estes cubos octaedros unidos formam a zeólita faujasita (d) . Fonte: (CERUTTI, 2007) 
As zeólitas mais indicadas para a remoção de compostos sulfurados de gás natural e hidrocarbonetos líquidos são as do tipo $X$ com poros de $10 \AA$ e cátions de cálcio (MS13X). Para esta utilização as peneiras tendem a adsorver moléculas com maior polaridade devido a sua afinidade. Em razão de forças de Van der Waals, os materiais são adsorvidos nos poros da peneira molecular de maneira seletiva. A adsorção de água é a mais significativa, seguida de compostos de enxofre (mercaptanas e outros). Um pouco menos é a reação com hidrocarbonetos insaturados e por fim os saturados. (MONFORT, A. J; NARDINI, G, 2005)

O material adsorvente utilizado nos ensaios realizados no presente trabalho é composto por pellets de 1,6 mm de diâmetro, cuja composição apresenta silicato de sódio e alumínio: peneira molecular tipo 13X [Na86 $\left[\left(\mathrm{AlO}_{2}\right)_{86}\left(\mathrm{SiO}_{2}\right)_{106}\right] \cdot \mathrm{x} \mathrm{H}_{2} \mathrm{O}$. (MONFORT, A. J; NARDINI, G, 2005). Seguem algumas propriedades deste adsorvente na Tabela 3-7.

Tabela 3-7. Propriedades da Zeólita 13X. (CHEREMISINOFF, 1986).

\begin{tabular}{ll}
\hline Propriedades & Aluminosilicato Anidro \\
\hline Tipo & $13 \mathrm{X}$ \\
Densidade & $1,1 \mathrm{~g} / \mathrm{cm}^{3}$ \\
Estrutura do cristal & cúbico de corpo centrado \\
Porosidade da partícula & $0,23(\mathrm{LESSA}, 2012)-0,9$ (SHAMS et al, 2008) \\
Entalpia máxima de adsorção & $1000 \mathrm{cal} / \mathrm{g}$ \\
Tamanho do poro & 10 angstrons \\
Calor de adsorção & $1000 \mathrm{kcal} / \mathrm{kg}$ de água \\
Calor específico & $\mathrm{kcal}{ }^{\circ} \mathrm{C} / \mathrm{kg}$ \\
Temperatura de regeneração & $200-300{ }^{\circ} \mathrm{C}$ \\
\hline
\end{tabular}

As zeólitas $13 \mathrm{X}$ também podem ser utilizadas para remoção de $\mathrm{CO}_{2}$ e $\mathrm{N}_{2}$ de correntes de gases de exaustão resultantes de processos de combustão, conforme estudado por Dantas et al. (2008) através da obtenção de isotermas de adsorção a temperaturas de $28^{\circ} \mathrm{C}$ a $150^{\circ} \mathrm{C}$ obtidas por medidas gravimétricas e com resultados mais favoráveis para a seletividade da zeólitas $13 \mathrm{X}$ em comparação ao carvão ativado. Nesse trabalho 
foram determinados, através de experimentos, os valores de área superficial BET e volume de microporo para $\mathrm{N}_{2}$, conforme sumarizado na Tabela 3-8.

Tabela 3-8. Propriedades físicas do adsorvente 13X.

\begin{tabular}{|c|c|}
\hline Características Físicas & Zeólita 13X \\
\hline Área BET, $\mathrm{m}^{2} / \mathrm{g}$ & 585,5 \\
\hline Volume de microporo $\mathrm{cm}^{3} / \mathrm{g}$ & 0,245 \\
\hline $\mathrm{N}_{2}$ capacidade de microporo, $\mathrm{gN}_{2} / \mathrm{g}^{*}$ & 140 \\
\hline $\mathrm{N}_{2}$ capacidade total, $\mathrm{gN}_{2} / \mathrm{g}^{*}$ & 200 \\
\hline Densidade aparente, $\mathrm{g} / \mathrm{cm}^{3}$ & 1,94 \\
\hline Densidade verdadeira, $\mathrm{g} / \mathrm{cm}^{3}$ & 2,00 \\
\hline
\end{tabular}

Comercialmente também são usadas para secagem de ar (remoção simultânea de $\mathrm{H}_{2} \mathrm{O}$ e $\mathrm{CO}_{2}$ ), purificação de gás natural e gás LP (remoção de $\mathrm{H}_{2} \mathrm{~S}$ e mercaptanas). (SOUSA, 2002).

\subsection{Equilíbrio de adsorção}

O equilíbrio de adsorção é a informação mais importante no entendimento de um processo de adsorção. Não importa quantos componentes estão presentes no sistema, o conhecimento do equilíbrio de adsorção dos componentes puros é essencial para saber o quanto estes componentes podem ser acomodados pelos adsorventes sólidos. (DO, 1998).

A relação entre a quantidade de soluto adsorvida pelo adsorvente, $q$, e a pressão ou concentração deste soluto no fluido, $Y$, na condição de equilíbrio a uma dada temperatura, é chamada de isoterma de adsorção. (CHEREMISINOFF, 1986).

O equilíbrio de adsorção fornece-nos informações sobre a capacidade de adsorção, tipo de isoterma, propriedades da superfície e interação adsorvente-adsorbato.

Segundo a recomendação da IUPAC (1985) as isotermas podem ser classificadas, conforme apresentado na Figura 3.4. 


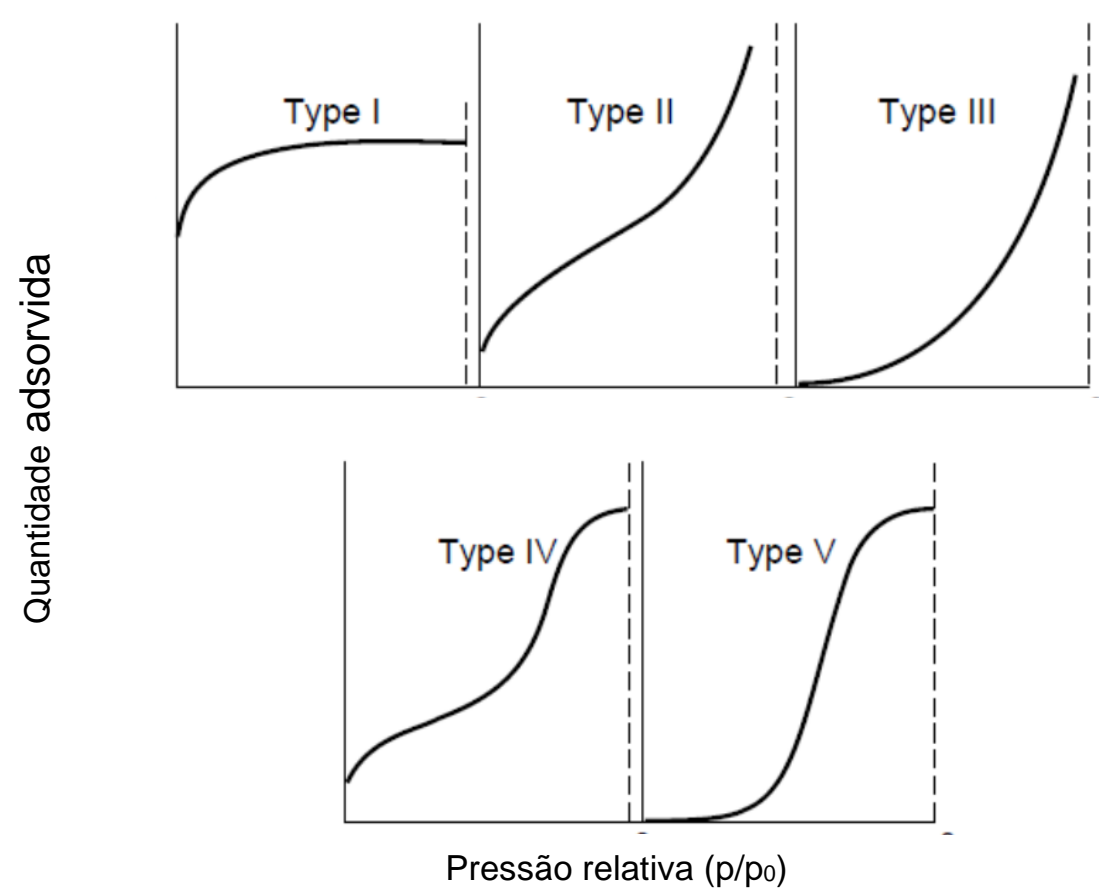

Figura 3.4. Tipos de isoterma, classificação IUPAC (União Internacional de Química Pura e Aplicada). (PERRY, 1999).

As isotermas do tipo I aplicam-se comumente a sólidos microporosos. A quantidade adsorvida tende para um valor limite quando $p_{\text {p }} \mathrm{p}_{0} \rightarrow 1$, dependendo do volume de microporos. (KARGE, WEITKAMP, 2008)

Isotermas do tipo II, com a curva ascendente são comuns aos sólidos macroporosos ou não porosos. O ponto de inflexão ocorre quando se completa a primeira camada de cobertura na superfície do material adsorvente.

Isotermas do tipo III são raras. O processo de adsorção é lento e originam-se em situações em que as moléculas do adsorvato tem maior afinidade uma pelas outras que pela superfície do adsorvente. (KARGE, WEITKAMP, 2008)

Isotermas do tipo IV e V são obtidas com adsorventes mesoporosos. A primeira inflexão corresponde à cobertura de uma monocamada. Já a segunda, mostra a adsorção devido à condensação capilar. Outra característica é que apresentam o fenômeno de histerese (curvas de adsorção e dessorção distintas). (RUTHVEN, 1997)

As isotermas de adsorção podem ser classificadas ainda, segundo McCabe et al (2001) como ilustra a Figura 3.5. 
A isoterma com perfil linear está descrita no item 3.3.1. A curva identificada como favorável, mostra um rápido aumento do componente adsorvido na fase sólida no sentido positivo da pressão, de modo que é especialmente efetiva em soluções diluídas. Já a curva convexa é desfavorável por não apresentarem boa capacidade de adsorção a baixas concentrações do soluto no fluído.

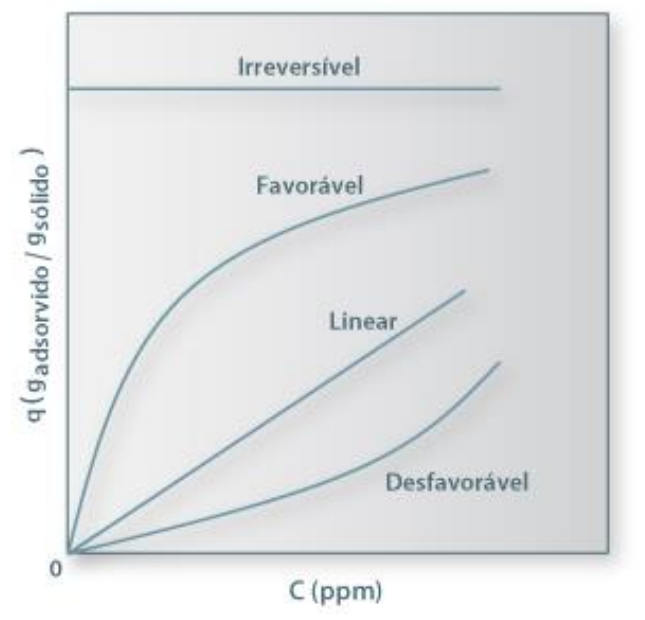

Figura 3.5. Isotermas típicas. Fonte: Acesso em 01/06/2014:

http://labvirtual.eq.uc.pt/siteJoomla/index.php?Itemid=450\&id=188\&option=com content\&task=view

\subsubsection{Isoterma linear}

A relação mais simples entre a concentração na fase sólida e a concentração na fase líquida é representada pela isoterma linear. Considera-se, neste caso, uma superfície ideal com solução infinitamente diluída e para baixas pressões. A relação de equilíbrio pode ser representada pela equação (1):

$$
q=H Y
$$

Em que, $\mathrm{H}$ representa a constante de Henry, q é a massa de soluto adsorvido por massa de adsorvente e $\mathrm{Y}$ é a concentração de equilíbrio do soluto na fase fluida.

A constante da lei de Henry proporciona uma medida direta da interação entre a molécula de adsorvato e o adsorvente, e representa a isoterma mais favorável, quando comparável aos demais modelos. Entretanto, a forma da isoterma de equilíbrio a altas concentrações de adsorvato é sensível a inúmeros efeitos como, interação adsorvato-adsorvato e a heterogeneidade energética. 
Alguns sistemas seguem o modelo de isoterma linear como n-heptano - zeólita 13X e gases nobres (Ar, Kr e Xe) - zeólita 5A. (RUTHVEN, 1997)

\subsubsection{Isoterma de Langmuir}

O modelo teórico mais utilizado para adsorção em monocamada, o de Langmuir (1918), foi originalmente desenvolvido para representar a quimissorção em um conjunto de sítios de adsorção localizados e distintos. As principais considerações em que o modelo se baseia são (CUSSLER, 2009):

- As moléculas são adsorvidas em um número fixo de sítios localizados bem definidos (a superfície é completamente uniforme);

- Cada sítio pode reter uma única molécula do adsorvato;

- A superfície é homogênea, ou seja, todos os sítios são equivalentes energeticamente;

- Não há interação entre moléculas adsorvidas e há probabilidade de adsorção em um sítio, independe de sítios vizinhos estarem ou não ocupados.

Neste modelo a isoterma é expressa pela equação (2):

$$
q=\frac{q_{m} K \mathrm{Y}}{1+K \mathrm{Y}}
$$

Em que q é a concentração do soluto no adsorvente, $K=k_{a} / k_{d}$ é uma constante de equilíbrio empírica e está relacionada com a energia livre de adsorção, ( $k_{a}$ e kd são, respectivamente, as constantes de taxa de adsorção e dessorção), Y é a concentração do soluto na fase fluida em equilíbrio com a fase sólida e $q_{m}$ é a constante que representa a cobertura de adsorvato em uma monocamada, isto é, a capacidade de adsorção máxima do adsorvente.

Para encontrar os parâmetros $\mathrm{K}$ e q da isoterma, é necessário linearizar a equação, que fica com a forma representada por (3):

$$
\frac{1}{q}=\frac{1}{q_{s}}+\frac{1}{q_{s} K Y}
$$


Para obedecer a isoterma de Langmuir o coeficiente angular deve permanecer constante em uma ampla faixa de concentrações e temperaturas.

Exemplos de adsorção em sistemas gasosos em sólidos porosos que obedecem a equação de Langmuir são $\mathrm{CH}_{4}$ - sodalita, $\mathrm{Ar}$ - sodalita, $\mathrm{C}_{3} \mathrm{H}_{8}$ - zeólita $5 \mathrm{~A}$ e outros sistemas gasosos. (CRITTENDEN, THOMAS, 1998)

\subsubsection{Isoterma de Freundlich}

Para alguns sistemas, observa-se um declínio na entalpia de adsorção em magnitude logarítmica com o aumento da extensão da adsorção, o que implica que os sítios adsortíveis sejam distribuídos exponencialmente em relação à energia de adsorção. Essa hipótese foi considerada por Zeldovich em 1935 para representar um tipo de isoterma muito comum, chamada de isoterma de Freundlich e é dada pela equação (4):

$$
q=K^{\prime} Y^{n}
$$

Em que $K^{\prime}$ e n são constantes empíricas de Freundlich dependentes da temperatura, $q$ é a quantidade de soluto por massa de adsorvente e $Y$ é a concentração do soluto na fase fluida. Nos casos em que a isoterma é favorável, $n$ é menor que 1.

A equação de Freundlich é popularmente usada na descrição da adsorção de compostos orgânicos de correntes aquosas em carvão ativado (CRITTENDEN, THOMAS, 1998). É também aplicável em sistemas gasosos tendo superfícies heterogêneas, desde que a faixa de pressão não seja demasiada grande, pois esta equação isotérmica não tem um comportamento apropriado para lei de Henry a baixa pressão e não tem limite finito quando a pressão é suficientemente alta.

Os parâmetros da equação de Freundlich podem ser encontrados plotando-se o log (q) versus log $(Y)$, produzindo uma linha reta com inclinação de1/n e interceptando o eixo em $\log _{10} K$.

$$
\log _{10} q=\log _{10} K+\frac{1}{n} \log _{10} Y
$$




\subsubsection{Isoterma de Langmuir-Freundlich}

Por conta da limitação do modelo de Langmuir em prever equilíbrio de misturas, muitos autores modificaram as equações de Langmuir através da introdução de equações expandidas tanto para sistemas com um e dois componentes:

No caso de um componente, tem-se:

$$
\frac{q}{q_{m}}=\frac{b Y^{n}}{1+b Y^{n}}
$$

No caso de misturas binárias, tem-se:

$$
\begin{gathered}
\frac{q_{1}}{q_{m 1}}=\frac{b_{1} Y_{1}^{n_{1}}}{1+b_{1} Y_{1}^{n_{1}}+b_{2} Y_{2}^{n_{2}}} \\
\frac{q_{2}}{q_{m 2}}=\frac{b_{2} Y_{2}^{n_{2}}}{1+b_{1} Y_{1}+b_{2} Y_{2}^{n_{2}}}
\end{gathered}
$$

Sendo: Y a concentração do adsorvato na fase sólida ( $\mathrm{mg} / \mathrm{L}), b=k_{a d} / k_{d}$, a constante de equilíbrio de adsorção, $k_{a d}$ : constante de adsorção, $k_{d}$ : constante de dessorção, $\mathrm{n}$ a constante do modelo, q: quantidade adsorvida de adsorvato pela massa de adsorvente, qm: o limite de saturação da monocamada.

Embora não seja termodinamicamente consistente, estas expressões representam uma razoável correlação empírica para equilíbrios binários para dados de gases em peneiras moleculares e são amplamente utilizadas com o propósito de projeto de leitos fixos. (Ruthven, 1997)

Linearizando a equação de equilíbrio monocomponente, obtém-se:

$$
\frac{1}{q}=\left(\frac{1}{b q_{m}}\right) \frac{1}{Y^{1 / n}}+\frac{1}{q_{m}}
$$

Então, plotando o gráfico de $1 / q$ versus $1 / Y^{1 / n}$, obteremos o valor de $1 / q_{m}$ e o valor de $1 /$ bqm será dado pela inclinação da curva. 


\subsubsection{Isoterma de BET (Brunauer, Emmett, Teller, 1983)}

A formação de multicamadas de adsorvato nos sítios ativos da superfície do sólido está implícita na teoria proposta por Brunauer, Emmet e Teller (1983) que, em conformidade com a isoterma de Langmuir, demonstra que a taxa de condensação na superfície é igual à taxa de evaporação da primeira camada de adsorvato. Assim, a isoterma de BET é expressa pela equação:

$$
q=\frac{q_{m} k \mathrm{Y}}{\left(Y_{m}-Y\right)\left[1+(k-1) \frac{Y}{Y_{m}}\right]}
$$

Em que k é uma constante relacionada com a saturação dos sítios ativos em todas as camadas, $q_{m}$ representa a cobertura da primeira camada e $Y_{m}$ é a concentração do soluto na saturação de todas as camadas. (KARGE, WEITKAMP, 2008)

É importante pontuar as hipóteses inerentes ao modelo: (a) não há interação das moléculas adsorvidas na vizinhança (b) cada molécula de uma camada apresenta-se como possível sítio ativo para outra de camada adjacente (c) o calor envolvido durante o preenchimento da segunda e subsequentes camadas de moléculas é igual à entalpia de condensação. (CRITTENDEN, THOMAS, 1998)

A isoterma de BET tem sido largamente utilizada como uma ferramenta para a determinação da área específica de materiais adsorventes, pelo acompanhamento da adsorção de nitrogênio líquido sob condições controladas.

\subsubsection{Isotermas multicomponentes}

O comportamento da isoterma de equilíbrio considerando um sistema monocomponente é bem mais simples que o comportamento das isotermas que envolve uma mistura de vários componentes. A quantidade de cada substância adsorvida em equilíbrio com a solução em geral diminui com o aumento da concentração de qualquer outro componente adsorvido. Este fato ilustra o caráter competitivo do fenômeno de adsorção. Assim, as isotermas multicomponentes são também chamadas de isotermas competitivas. Os compostos que são mais fortemente adsorvidos tendem a excluir os demais. (RUTHVEN, 1997) 
Muitos pesquisadores têm desenvolvido técnicas para estimar o equilíbrio de adsorção multicomponente. Uma delas é proposta por Ruthven (1997) e conhecida como o modelo geral estatístico que prediz isotermas multicomponentes muito bem, particularmente para zeólitas.

A Figura 3.6 mostra o comportamento da adsorção em um sistema competitivo. É possível observar duas moléculas de espécies diferentes (preta e vermelha) competindo pelo mesmo sítio.

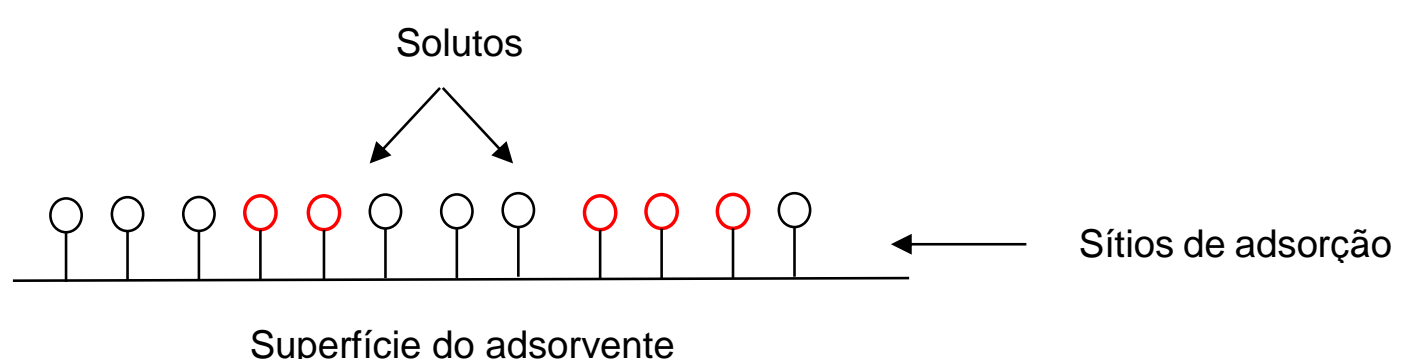

Figura 3.6. Esquema do comportamento de adsorção em um sistema multicomponente ou competitivo na superfície do adsorvente.

A isoterma de Langmuir, segundo Ruthven (1997), pode ser estendida para sistemas binários ou multicomponentes, resultando nas seguintes expressões:

$$
\begin{aligned}
& \frac{q_{1}}{q_{m 1}}=\frac{b_{1} Y_{1}}{1+b_{1} Y_{1}+b_{2} Y_{2}+\cdots+b_{m} Y_{m}} \\
& \frac{q_{2}}{q_{m 2}}=\frac{b_{2} Y_{2}}{1+b_{1} Y_{1}+b_{2} Y_{2}+\cdots+b_{m} Y_{m}} \\
& \frac{q_{n}}{q_{m n}}=\frac{b_{n} Y_{n}}{1+b_{1} Y_{1}+b_{2} Y_{2}+\cdots+b_{m} Y_{m}}
\end{aligned}
$$

Ruthven (1997) apresenta os estudos de Kemball, et al (1948) e independentemente de Broughton que tem mostrado que para serem termodinamicamente consistentes: $q_{m 1} \cong q_{m 2}$. Para adsorção física de moléculas com tamanhos muito diferentes a utilização deste modelo não se aplica. Se a equação de Langmuir é considerada como uma descrição analítica mais que um modelo físico, o uso de diferentes valores de $q_{m n}$ para cada componente se torna permissível, contudo a equação não deve, então, 
ser aplicável sobre outras faixas de concentração e deve ser extrapolada com precaução.

Shams et al (2008) utilizou a isoterma de Langmuir para representar o equilíbrio no sistema multicomponente $\mathrm{H}_{2} \mathrm{~S}$ e $\mathrm{CH}_{3} \mathrm{SH}$ em zeólita $13 \mathrm{X}$ para validar o modelo matemático proposto com sucesso, já que obtém como resultado uma aproximação entre a simulação e os dados experimentais de $15 \%$, conforme descrito no item 3.5 .

\subsubsection{Termodinâmica da adsorção}

Para avaliação termodinâmica do processo de adsorção, calcula-se a entropia e a energia livre de Gibbs, conforme equação (14). Sendo que, altos valores negativos de Gibbs indicam uma adsorção favorável e altamente energética. (MARTINS et al., 2015)

$$
\Delta G=\Delta H-T \Delta S
$$

Entretanto, torna-se necessário primeiramente determinar a entropia e a entalpia de adsorção através da equação (15) de Van't Hoff, plotando-se $\ln (\rho K)$ versus a temperatura $(1 / \mathrm{T})$ :

$$
\ln (\rho K)=-\frac{\Delta H}{R T}+\frac{\Delta S}{R}
$$

Sendo:

$\Delta G=$ variação da energia de Gibbs, $(\mathrm{J} / \mathrm{mol})$

$\Delta H=$ entalpia de adsorção, $(\mathrm{J} / \mathrm{mol})$

$\Delta S=$ entropia do sistema, $(\mathrm{J} / \mathrm{mol} \mathrm{K})$

$R=$ constante universal dos gases $(8,314 \mathrm{~J} / \mathrm{mol} \mathrm{K})$

$\rho=$ massa específica do solvente, $\left(\mathrm{kg} / \mathrm{m}^{3}\right)$

$\mathrm{K}=$ constante de adsorção obtida pelo modelo de Langmuir, $\left(\mathrm{m}^{3} / \mathrm{kg}\right)$ 


\subsection{Adsorção em leito fixo}

Processos de adsorção geralmente são associados a uma coluna recheada, isto porque, segundo Cussler (2009), a adsorção em leito fixo normalmente promove uma separação mais eficiente que em tanques agitados. Em um processo de adsorção, o sólido é usualmente mantido em um leito fixo, enquanto o fluído contendo a substância a ser removida, passa continuamente através do leito até que o sólido é saturado com tal substância, ou seja, sua capacidade de reter o soluto é extinta. O fluxo então é direcionado para um segundo leito e o primeiro é substituído ou regenerado.

A maioria dos adsorventes é constituída de materiais porosos e a adsorção ocorre primeiramente nas paredes dos poros ou em específicos sítios dentro da partícula.

O tamanho do leito adsorvente é determinado pelo fluxo do líquido ou gás e o tempo de ciclo desejado. Geralmente, o diâmetro é calculado para levar a uma velocidade superficial (velocidade do fluido em qualquer seção reta perpendicular ao escoamento, como se não houvesse o meio poroso) em torno de 0,15 a $0,45 \mathrm{~m} / \mathrm{s}$. (MCCABE, SMITH, HARRIOTT; 2001).

\subsubsection{Curva de ruptura}

Para o projeto de colunas de adsorção, é de extrema importância a obtenção da curva de ruptura em pequena escala para estimar sua performance em larga escala, através do conhecimento do comprimento da zona de transferência de massa. Assim, dados experimentais são essenciais, porque os efeitos da isoterma e da dispersão não podem ser previstos facilmente.

Em leitos fixos, a concentração da fase fluida muda com o tempo e com a posição na coluna. Se a adsorção for completamente eficiente, a concentração do efluente na saída da coluna tende a zero durante um longo período. Então, no ponto de ruptura a concentração de saída subitamente iguala-se ao valor da concentração da alimentação. Nesse momento, o leito estaria completamente saturado. Naturalmente esta é uma situação ideal, representada pela curva da Figura 3.7. 


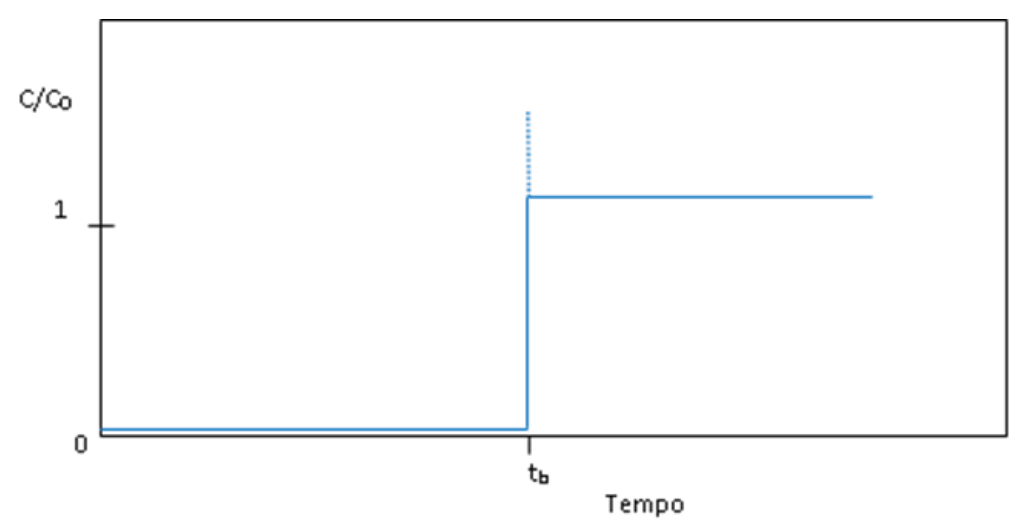

Figura 3.7 Curva de ruptura ideal.

$\mathrm{Na}$ realidade, a concentração do efluente de saída permanece nula por um longo período, já que a transferência de massa ocorre no início do leito ao contato com a primeira porção de adsorvente, até que se torna significativo no tempo tb, que normalmente equivale à $5 \%$ da concentração inicial de alimentação, e aumenta exponencialmente até que finalmente atinge a concentração de entrada no tempo de exaustão do leito te, formando uma curva em formato de $S$, conforme ilustrado na Figura 3.8.

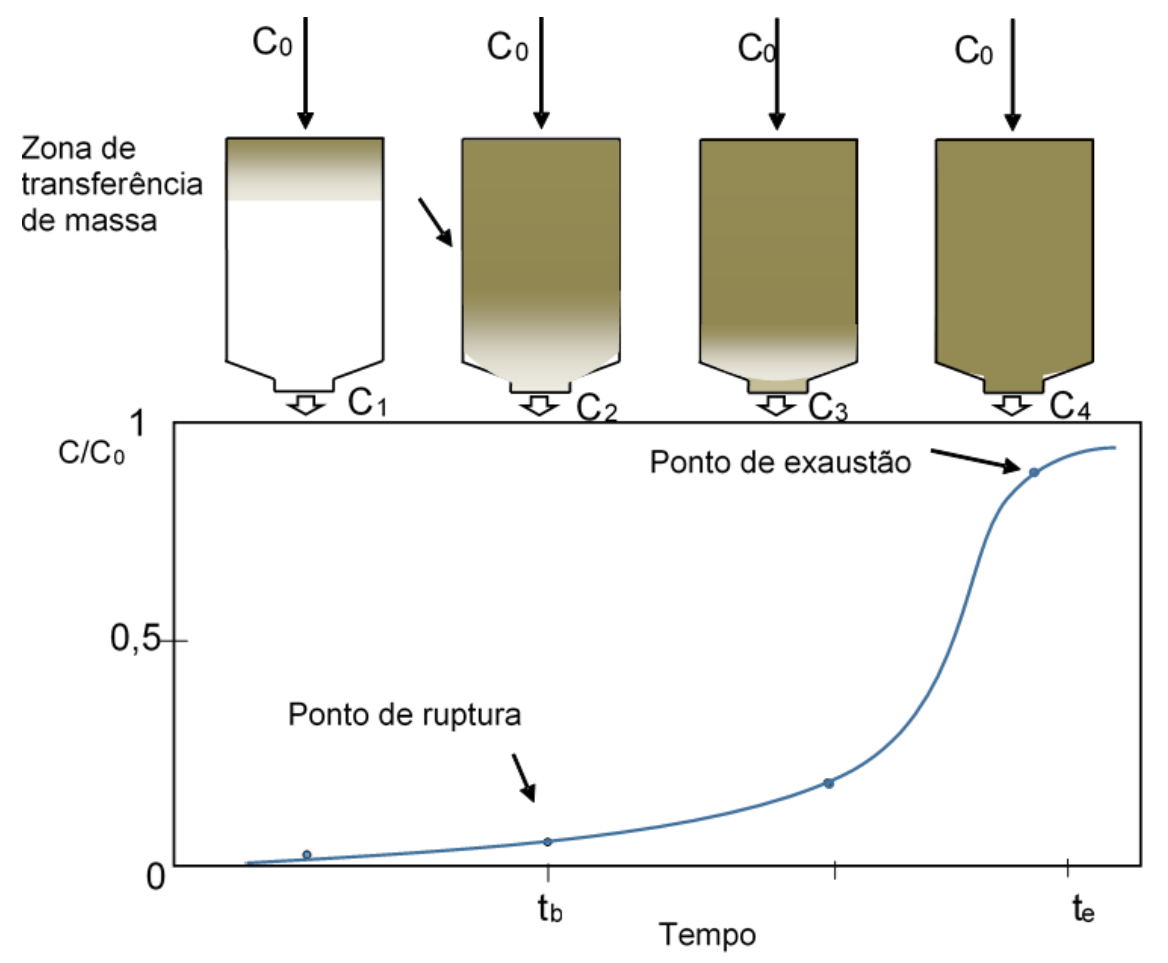

Figura 3.8 Curva de ruptura geral.

Em poucos casos, a real curva de ruptura será semelhante a ideal. Em grande parte dos casos, a ascensão da curva será mais gradual, sendo te maior que tb em torno de 
$30 \%$ a 100\%. Isto porque, segundo Cussler (2009), existem quatro fenômenos importantes que são responsáveis pela dispersão da curva de ruptura:

- Difusão axial. Obviamente, o soluto difundirá na direção do fluxo, afinal está sendo alimentado com uma concentração de uma substância em um leito inicialmente com concentração nula. Entretanto, geralmente a difusão axial não é significante em escala industrial.

- Dispersão. Esse efeito pode ocorrer basicamente por dois motivos: um relacionado ao descuido no enchimento da coluna empacotada que pode conter espaços vazios ou distribuição desigual de sólidos. E o outro resulta do mecanismo Taylor-Aris, que envolve o acoplamento entre o fluxo axial que alarga o fronte, e a difusão radial que tende a reduzi-lo.

- Cinética de adsorção. Se a taxa de adsorção é lenta, a curva de ruptura irá expandir-se. A causa principal está mais ligada à transferência de massa por difusão do soluto no interior do poro, do que pela velocidade de adsorção.

- Isotermas de equilíbrio de adsorção. Isoterma de adsorção linear e desfavoráveis dispersam a curva de ruptura, enquanto que as favoráveis são mais acentuadas.

Realmente, a maioria das curvas de ruptura representa um balanço entre os efeitos favoráveis, que aproximam seu perfil ao comportamento ideal e dos que causam a dispersão.

Assim, os fatores que afetam o comportamento da curva de ruptura podem ser divididos em termodinâmicos - aqueles que determinam a distribuição (equilíbrio) do soluto entre a fase fluida e sólida; cinéticos - determinam a velocidade de transferência de massa local em todo o sistema e fluidodinâmicos. (ALMEIDA, 2012)

\subsubsection{Capacidade de adsorção leito fixo}

A partir do balanço de massa na coluna de adsorção e das curvas de ruptura experimentais, pode-se determinar a quantidade total de soluto adsorvido, através do balanço de massa expresso pela equação (14): 


$$
Q C_{0} t_{t}=m_{\text {liq }} C_{0}+m_{\text {pen }} q_{m}
$$

Onde $\mathrm{Q}$ é a vazão $(\mathrm{kg} / \mathrm{h})$ de fluido alimentado à coluna, $\mathrm{C}_{0}$ a concentração de entrada $(\mathrm{mg} / \mathrm{kg}), m_{\text {pen }}=$ massa da zeólita $(\mathrm{kg}), m_{\text {liq }}=$ massa de líquido no interior do pellet $(\mathrm{kg})$. Considerando que $m_{l i q} C_{0}$ é desprezível, pois a concentração no liquido é muito baixa temos que:

$$
q_{m}=\frac{Q C_{0} t_{t}}{m_{\text {pen }}}
$$

\subsubsection{Zona de transferência de massa}

Durante o processo de adsorção, uma zona de transferência de massa é formada na entrada da coluna, conforme Figura 3.8, até que uma zona de saturação é obtida com um aumento na concentração até atingir a concentração de alimentação, observada na parte frontal ao final do processo. A transferência de massa entre as fases fluida e sólida ocorre nesta região chamada zona de transferência de massa (ZTM).

Para calcular a ZTM, é necessário calcular primeiramente os tempos equivalentes à capacidade útil da coluna ( $\mathrm{tb}_{\mathrm{b}}$ e o tempo de exaustão ou saturação ( $\mathrm{t}_{\mathrm{e}}$ ). Realizando um balanço de massa na coluna pode-se obter facilmente a razão de saturação do leito, através da integração numérica da curva de ruptura. Considerando-se uma curva de ruptura com tempo de ruptura tb, em que o eixo y: $C / C_{0}=0,05$ e, terminando no tempo de exaustão te, conforme Figura 3.9, o tempo equivalente à capacidade útil do leito (tu) pode ser calculado pela equação (18):

$$
t_{u}=\int_{0}^{t_{b}}\left(1-\frac{C}{C_{0}}\right) d t
$$

Da mesma forma, o tempo equivalente à quantidade de soluto trocada se todo o leito estivesse em equilíbrio com a alimentação $\left(\mathrm{t}_{\mathrm{t}}\right)$, pode ser obtido pela equação:

$$
t_{t}=\int_{0}^{\infty}\left(1-\frac{C}{C_{0}}\right) d t
$$


A partir do tempo adimensional, $\theta$, é possível obter quantitativamente o comprimento da ZTM do leito. O parâmetro, $\theta=t_{u} / t_{t}$, corresponde à fração do comprimento útil da coluna até o ponto de exaustão, conforme a equação (20):

$$
\theta=\frac{\begin{array}{l}
\text { Total adsorvido até } \\
\text { Total adsorvido até } \\
\text { o tempo de exaustão }
\end{array}}{\text { temptura }}
$$

Assim a altura útil da coluna $\left(L_{u}\right)$ e a ZTM é dada por:

$$
\begin{gathered}
L_{u}=\theta \times L \\
L=L_{u}+Z T M
\end{gathered}
$$

Sendo:

$\mathrm{L}=$ altura da coluna de leito fixo $(\mathrm{m})$. Logo, a ZTM $(\mathrm{m})$ que corresponde à diferença entre a altura total e útil do leito pode ser calculada pela seguinte expressão:

$$
Z T M=(1-\theta) \times L
$$

Já a quantidade de massa adsorvida até o ponto de ruptura qu pode ser calculada pela equação (24):

$$
M_{u}=t_{u} Q C_{0}
$$

Sendo, $Q$ a vazão volumétrica em m³/h e $C_{0}$ a concentração do adsorvato em $\mathrm{kg} / \mathrm{m}^{3}$.

Para sistemas com isotermas favoráveis, o perfil de concentração da zona de transferência de massa adquire uma forma e largura que não mudam conforme a zona de transferência se movimenta pela coluna. Assim, testes com diferentes comprimentos de coluna apresentam curvas de ruptura com a mesma forma, mas em leitos maiores a zona de transferência representa uma menor fração do total da coluna. Portanto, leitos mais longos são mais eficientes que os curtos, segundo Cussler (2009). O entendimento deste parâmetro obtido experimentalmente é a chave para otimização da eficiência do processo de adsorção. 


\subsubsection{Estudo de aumento de escala}

Segundo Crittenden e Thomas (1998), duas abordagens podem ser usadas para o projeto de colunas recheadas: uma envolve a solução de equações que consideram a conservação de massa, o transporte de massa e termodinâmica; a outra usa técnicas baseadas em dados de escala laboratorial, piloto e industrial.

No estudo de experimentos em pequena escala que possam representar um processo industrial, atenção especial deve ser dada à escolha do comprimento, diâmetro do leito e velocidade, já que afetam a hidrodinâmica e as características de dispersão.

Se os estudos são baseados em dados de curva de ruptura, é importante obter um padrão constante de zona de transferência de massa na coluna de menor escala. Esse padrão pode ser obtido se a isoterma de adsorção é favorável. Nos casos em que a isoterma é desfavorável e o sistema for multicomponente e/ou não adiabáticos, mais de uma zona de transferência de massa ocorrerá para diferentes tipos de isoterma, por isso é prudente assegurar que o comprimento do leito para pequena e larga escala é o mesmo.

A hidrodinâmica e a dispersão são fatores que devem ser levados em conta desde o princípio, garantindo que o leito recheado é preenchido de modo que não haja má distribuição do fluxo. Carberry (1976) sugere que para condições isotérmicas a razão entre o comprimento e diâmetro da coluna deve ser maior que 20 , enquanto o comprimento da coluna em relação ao diâmetro da partícula é menor que 50. Além disso, a fim de manter o fluxo para condições não isotérmicas a razão entre o comprimento do leito e o diâmetro da partícula deve ser maior que 150.

Le Van e Vermeulen (1984) reportam que para evitar fluxos preferenciais, a razão entre o diâmetro da coluna e da partícula deve ser maior que 20. (CRITTENDEN; THOMAS, 1998)

O aumento de escala pode ser obtido simplesmente através da manutenção da mesma velocidade superficial tanto na escala laboratorial, quanto na industrial e aumento da área seccional do fluxo pelo aumento do número de leitos operando em paralelo, ou aumentando o diâmetro de uma única coluna. 
Para utilização dos dados experimentais a fim de otimizar o processo de adsorção, seguem alguns métodos: obtenção e análise do comprimento ou massa de leito inutilizado (CLI), comprimento da zona de transferência de massa (ZTM), tempo de residência do leito, unidade de transferência e capacidade até o ponto de ruptura. (CRITTENDEN; THOMAS, 1998)

O método do comprimento do leito inutilizado (CLI) requer um padrão de comportamento constante que só é obtido para sistemas diluídos com um único componente e que apresenta isoterma favorável e depende somente da combinação adsorvato-adsorvente, da temperatura e da velocidade superficial. O sistema infinitamente diluído implica em condições isotérmicas.

$$
C L I=\left(1-\frac{t_{b}}{t_{e}}\right) L
$$

O comprimento da zona de transferência de massa aumenta na medida em que aumenta a resistência à transferência de massa.

\subsection{Processos para remoção de compostos de enxofre por adsorção}

Muitos estudos acerca de dessulfurização utilizando materiais adsorventes têm como objetivo a remoção de $\mathrm{SO}_{2}$ de gases combustíveis ou de gases resultantes da combustão, para fins ambientais.

Um exemplo de estudos com finalidade ambiental é realizado por Gollakota e Chriswell (1988), que avaliaram o desempenho dos materiais adsorventes: silicalita e zeólita ZSM-5 da Mobil e carvão ativo da Amoco, através de curvas de ruptura, usando uma coluna de aço inoxidável com dimensões de $6,3 \mathrm{~mm}$ de raio e $50 \mathrm{~mm}$ de comprimento, para a remoção de $\mathrm{SO}_{2}$ de gases de combustão e concluíram que a capacidade de adsorção da silicalita (37,9 mg SO$/ 2 / g$ de adsorvente) é maior que a da zeólita ZSM-5 (20,9 mg de SO $2 / \mathrm{g}$ de adsorvente) e do carvão ativo (16,7 mg de SO/2/g de adsorvente).

Lu e Do (1991) estudaram a remoção de gases poluentes, como $\mathrm{SO}_{2}$ e $\mathrm{NO}_{x}$ a partir de um adsorvente carbonáceo preparados com rejeitos de carvão, usando hélio como solvente $(95 \%)$ e verificaram elevadas capacidades de adsorção (aproximadamente $30 \mathrm{mg}$ de $\mathrm{SO}_{2}$ e $40 \mathrm{mg}$ de $\mathrm{NO}$ por grama de carvão). 
Tantel et al (1995) obtiveram dados sobre a cinética e adsorção de $\mathrm{SO}_{2}$ e vapor de água em zeólitas do tipo mordenita e pentasil, usando curvas de ruptura, e assim constataram um decréscimo nas capacidades de adsorção com o incremento da razão $\mathrm{SiO}_{2} / \mathrm{Al}_{2} \mathrm{O}_{3}$ e que a zeólita pentasil apresenta maior capacidade de adsorção para $\mathrm{SO}_{2}$ que a do tipo modernita.

Kopac (1999) realizou um estudo utilizando a técnica de cromatografia de pulso não isobárica para buscar as propriedades de adsorção de dióxido de enxofre sobre zeólita 13X e carvão ativado. Os resultados mostraram que há grande influência da temperatura na adsorção de $\mathrm{SO}_{2}$ nos dois adsorventes $13 \mathrm{X}$ e carvão ativo, com calores de adsorção de $12 \mathrm{kcal} / \mathrm{mol}$ e $8,99 \mathrm{kcal} / \mathrm{mol}$, respectivamente.

Também com caráter ambiental, visando ao atendimento das normas regulamentadoras, há muitos trabalhos que discutem a adsorção de componentes sulfurados, como $\mathrm{H}_{2} \mathrm{~S}$, mercaptanas e tiofeno de combustíveis fósseis, como gasolina e gás natural.

$\mathrm{Na}$ dissertação de Souza (2002), por exemplo, estudou-se um processo de dessulfurização de gás natural comparando a performance dos materiais adsorventes: zeólitas 5A, 13X, um óxido de zinco e um sólido denominado comercialmente de SLFT. Foram determinadas isotermas de adsorção para o $\mathrm{H}_{2} \mathrm{~S}$ nas temperaturas de $25{ }^{\circ} \mathrm{C}$ e $76 \stackrel{\circ}{\circ}$, sendo características do tipo I as isotermas de zinox, 5A, SZ5 e $13 \mathrm{X}$ e do tipo IV a do material $5 \mathrm{~A} 522$. Em todas as amostras um incremento da temperatura resultou em uma menor quantidade adsorvida e saturação em um tempo menor, sugerindo que o método TSA (Temperature Swing Adsorption) pode ser usado para regeneração do leito.

A isoterma obtida para a zeólitas $13 \mathrm{X}$ apresentou a capacidade de adsorção máxima de $53 \mathrm{mg} \mathrm{H} 2 \mathrm{~S} / \mathrm{g}$ de adsorvente, conforme pode ser verificado na Figura 3.9. 


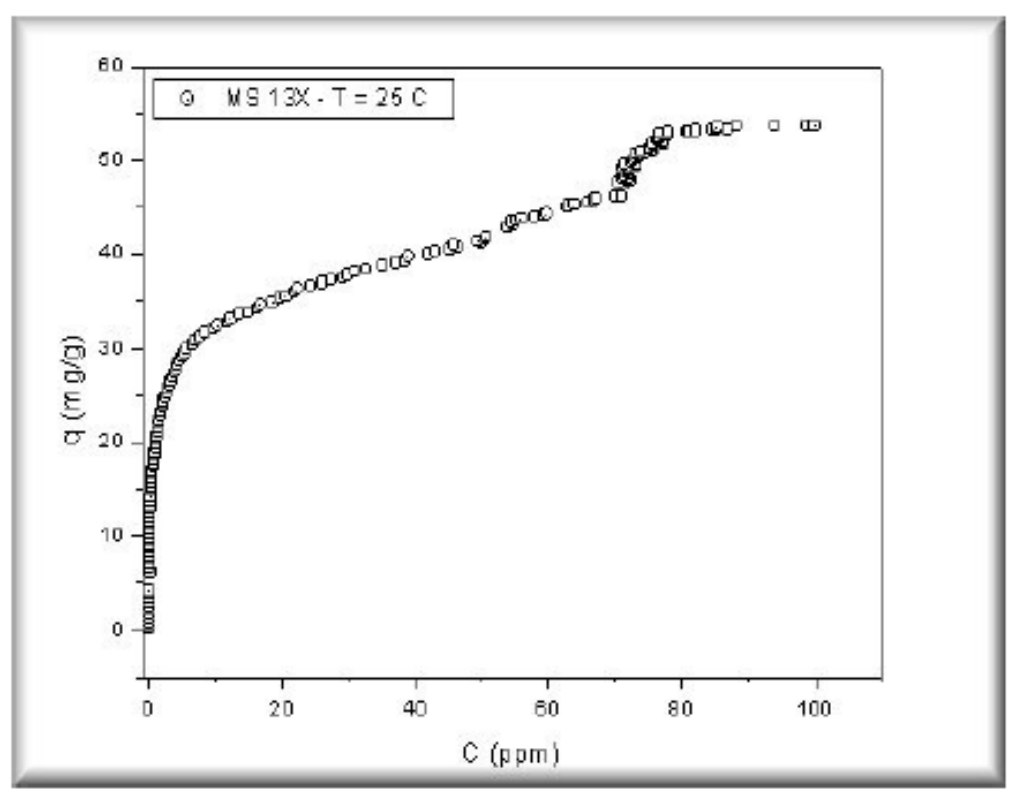

Figura 3.9. Isoterma de adsorção de $\mathrm{H}_{2} \mathrm{~S}$ para a amostra $13 \mathrm{X}$ a $\mathrm{T}=25^{\circ} \mathrm{C}$. (Souza, 2002)

A Tabela 3-9 apresenta a comparação das quantidades máximas adsorvidas de $\mathrm{H}_{2} \mathrm{~S}$ em todos os tipos de adsorventes avaliados.

Tabela 3-9. Quantidades máximas ( $\mathrm{mg} \mathrm{H} \mathrm{H}_{2} \mathrm{~S} / \mathrm{g}$ adsorvente) adsorvidas em gás natural por adsorvente. (SOUZA, 2002)

\begin{tabular}{cccccc}
\hline Temperatura (ㅇ) & Unidade & Zinox & 13X & MS SZ5 & MS 522 \\
\hline $\mathbf{2 5}$ & $\mathrm{mg} \mathrm{H} 2 \mathrm{~S} / \mathrm{g}$ ads & 9,25 & 53,61 & 2,5 & 0,57 \\
$\mathbf{7 6}$ & $\mathrm{mg} \mathrm{H} 2 \mathrm{~S} / \mathrm{g}$ ads & 6,04 & - & 0,81 & 0,48 \\
\hline
\end{tabular}

Trata-se no estudo de Salem (1997) da remoção de compostos de enxofre de nafta, usando zeólita 13X e 5A. Como resultado foi identificada alta capacidade de adsorção para zeólita 13X, enquanto a zeólita 5A mostrou um comportamento desfavorável.

No trabalho de Shams et al (2007), é estudado um processo semelhante ao sistema apresentado nesta dissertação. É abordada a modelagem e simulação do processo de dessulfurização de butano líquido através de peneira molecular 13X. A principal diferença é que se trata de um sistema multicomponente e de diferentes tipos de compostos de enxofre $\left(\mathrm{H}_{2} \mathrm{~S}\right.$ e $\left.\mathrm{CH}_{3} \mathrm{SH}\right)$, enquanto que, nesta dissertação, estuda-se individualmente o comportamento da etil-mercaptana, n-propil-mercaptana e tercbutil-mercaptana em butano líquido, usando o mesmo tipo de material adsorvente. 
O modelo matemático proposto leva em consideração os efeitos de dispersão axial, a resistência à transferência de massa inter e intra-partícula e condições de operação isotérmicas. Para resolver simultaneamente o conjunto de equações diferenciais ordinárias da partícula e do leito, foram usados os métodos de colocação ortogonal e Gill's Runge-Kutta de $4^{a}$ ordem. Os resultados da simulação do modelo matemático foram comparados aos dados obtidos de uma planta industrial de uma petroquímica iraniana, cujo leito de adsorção possui 1,7 m de diâmetro e 5,06 m de altura com concordância razoável de cerca de $15 \%$ de diferença nos valores da concentração.

Contudo, analisando o balanço de massa do leito, foi identificado um equívoco especificamente na velocidade do termo convectivo. A velocidade usada, conforme Figura 3.10, foi a superficial e não a intersticial, já que não considera a porosidade do leito. Esta consideração torna-se expressiva, na medida em que a velocidade intersticial é significativamente maior que a superficial. Isso impacta diretamente na curva de ruptura obtida, uma vez que se trata de um parâmetro relevante na análise do processo de adsorção.

$$
\begin{aligned}
\frac{\partial C_{i}}{\partial t}+U \frac{\partial C_{i}}{\partial z}-D_{\mathrm{L} i} \frac{\partial^{2} C_{i}}{\partial z^{2}}+\left(\frac{1-\epsilon_{\mathrm{b}}}{\epsilon_{\mathrm{b}}}\right) \frac{\partial q_{i}}{\partial t}=0 \\
\left(i=\mathrm{CH}_{3} \mathrm{SH}(1) \text { and } \mathrm{H}_{2} \mathrm{~S}(2)\right)(1)
\end{aligned}
$$

(a)

Table 3. Specification of the Fixed Bed

\begin{tabular}{|ll|}
\hline packed bed height, $L(\mathrm{~m})$ & 5.06 \\
bed diameter, $d_{\mathrm{B}}(\mathrm{m})$ & 1.7 \\
feed temperature, $T(\mathrm{~K})$ & 311 \\
operating pressure $(\mathrm{bar})$ & 15.5 \\
\hline superficial velocity, $U(\mathrm{~m} / \mathrm{s})$ & 0.0139 \\
\hline Reynolds number of bed & 89000 \\
porosity of bed, $\epsilon_{\mathrm{b}}$ & 0.36 \\
porosity of the zeolite, $\epsilon_{\mathrm{p}}$ & 0.9 \\
radius of the zeolite particle $(\mathrm{m})$ & 0.0016
\end{tabular}

(b)

Figura 3.10. (a) Equação do balanço de massa retirada do artigo referência. (pag. 571).(b) Tabela com parâmetros do leito considerados na simulação do artigo (pag.573). (SHAMS et al, 2007). 
E, embora haja dúvida quanto à confiabilidade dos resultados, segue avaliação dos autores quanto à influência do número de Reynolds, número de Peclet, diâmetro da partícula, concentração inicial dos compostos de enxofre e temperatura, mantendo sempre os demais parâmetros constantes e variando somente o que é foco do estudo:

- Um aumento do número de Reynolds de $144 \%$ causa uma redução no tempo de ruptura de $41,6 \%$ e a curva de ruptura torna-se mais íngreme, devido à redução no tempo de residência do fluido que não é suficiente para atingir o equilíbrio de adsorção. Sob altas velocidades, reduz-se a resistência à transferência de massa externa e tornando a curva de ruptura mais íngreme. Além disso, a dispersão axial do fluído é elevada com o aumento do número de Reynolds, o que reduz a inclinação da curva de ruptura. Observa-se que a curva de ruptura é mais sensível.

- Já uma elevação do número de Peclet de 1.820 para 3.640, com o intuito de avaliar a influência da altura do leito, tem como consequência um aumento no tempo de ruptura de 5,88 h para 11,64 h, acompanhado de uma redução da inclinação da curva. Este comportamento indica que a inclinação da curva de ruptura é fortemente dependente da altura do leito.

- Reduzindo o diâmetro da partícula de adsorvente pela metade (de 1,6 mm para $0,8 \mathrm{~mm}$ ) tem-se a diminuição do tempo de ruptura em $14 \%$ e pode afetar o tempo total do ciclo de adsorção.

- O efeito do aumento na concentração inicial de enxofre de $13 \mathrm{mg} / \mathrm{kg}$ para 25 $\mathrm{mg} / \mathrm{kg}$ de enxofre total na curva de ruptura é a redução do tempo de ruptura de $12 \mathrm{~h}$ para $6,48 \mathrm{~h}$, já que os sítios das zeólitas são rapidamente preenchidos na condição de altas concentrações iniciais.

- Outro parâmetro que chama atenção pela significativa influência na curva de ruptura é a temperatura. Uma elevação de temperatura de apenas $19{ }^{\circ} \mathrm{C}$ causa uma redução de aproximadamente $54 \%$ no tempo de ruptura. Este comportamento é esperado considerando que o processo de adsorção é exotérmico, assim quando a temperatura de operação aumenta, a concentração de equilíbrio no sólido diminui. 


\section{MATERIAL E MÉTODOS}

Este capítulo tem como objetivo apresentar a descrição dos métodos empregados para o desenvolvimento dos ensaios experimentais, a saber: metodologia analítica utilizada para medição e controle das substâncias químicas, descrição dos equipamentos utilizados e da sua operação para os ensaios para obtenção das isotermas de adsorção e os ensaios contínuos de adsorção em leito fixo em escalas laboratorial e piloto e sua correlação com a planta industrial.

O método experimental compreendeu 5 etapas, que resumidamente foram:

- A primeira etapa consiste na preparação das soluções de compostos de enxofre (etil-mercaptana, terc-butil-mercaptana e n-propil-mercaptana) em butano líquido pressurizado e do material adsorvente (zeólita 13X).

Considerando que o fluido tratado industrialmente apresenta tipos distintos de compostos de enxofre, é de interesse compreender se há diferenças de comportamento com a peneira molecular $13 \mathrm{X}$ e se seria possível considerar a soma dos contaminantes como enxofre total. A escolha dos componentes dá-se pelos seguintes motivos: a etil-mercaptana por ser o tipo de componente que apresenta maior incidência e teor na matéria-prima processada industrialmente. Os demais foram escolhidos pela disponibilidade em quantidade suficiente para os ensaios e pela facilidade de manuseio, uma vez que são líquidos à temperatura e pressão ambientes. Apesar de não serem detectados altos níveis destes compostos no fluido processado industrialmente.

- A segunda refere-se ao levantamento das curvas de equilíbrio de adsorção monocomponentes dos seguintes tipos de compostos de enxofre a $25 \stackrel{\circ}{\circ}$ : etilmercaptana, tercbutil-mercaptana e normal-propil-mercaptana. E, para a $n$ propil-mercaptana obteve-se a isoterma de adsorção também para a temperatura de $10 \stackrel{\circ}{\circ}$ e $25 \stackrel{\circ}{\circ}$.

O processo industrial real é desprovido de isolamento térmico, estando sujeito à temperatura ambiente. É de interesse, portanto, avaliar como as variações do clima durante $\mathrm{o}$ ano interferem no comportamento do sistema. A escolha dos valores de 
temperatura deu-se pela média encontrada no período de inverno $\left(10^{\circ} \mathrm{C}\right)$ e de grande parte do ano $\left(25^{\circ} \mathrm{C}\right)$.

- Na terceira etapa experimental obtiveram-se as curvas de ruptura para n-propilmercaptana em uma coluna leito fixo recheado com peneira molecular 13X em escala laboratorial, para 3 concentrações de entrada distintas $(81 \mathrm{mg} / \mathrm{kg}, 174$ $\mathrm{mg} / \mathrm{kg}$ e $315 \mathrm{mg} / \mathrm{kg}$ ), mantendo a velocidade similar à industrial constante. $\mathrm{E}$, para diferentes velocidades $(0,0039 \mathrm{~m} / \mathrm{s}, 0,006 \mathrm{~m} / \mathrm{s}$ e $0,0077 \mathrm{~m} / \mathrm{s})$, mantendo a mesma concentração inicial.

A concentração de contaminantes (enxofre total) na matéria-prima fornecida para tratamento no processo industrial varia de $2 \mathrm{mg} / \mathrm{kg}$ a $30 \mathrm{mg} / \mathrm{kg}$. A ideia, então, seria escolher teores de concentração nesta faixa para avaliação. No entanto, estes valores são incompatíveis com a estrutura dos experimentos, de modo a inviabilizá-los pelo tempo despendido que provavelmente superaria $48 \mathrm{~h}$ e por exceder a quantidade de cilindros disponíveis para armazenamento do butano. Logo, a escolha das concentrações iniciais de contaminantes visou obter tempos menores que $24 \mathrm{~h}$ e volumes de até $80 \mathrm{~kg}$.

Tendo em vista que a alta produtividade é sinônimo de eficiência, a velocidade de produção é uma característica importante a ser estudada. Há interesse em conhecer o impacto do aumento de velocidade nas curvas de ruptura do processo de adsorção.

- A quarta etapa contemplou a obtenção das curvas de ruptura para a coluna leito fixo recheado com peneira molecular $13 \mathrm{X}$ em escala piloto com diferentes tipos de compostos de enxofre e velocidades, como referência para validação do modelo matemático.

Como o objetivo dos experimentos estava relacionado à validação do modelo matemático, a definição dos parâmetros foi ligada à viabilidade de realização do experimento, pois em escala piloto o controle das variáveis torna-se ainda mais complexo. A velocidade, por exemplo, dependeu unicamente da capacidade da bomba instalada em cada caminhão utilizado e o tipo e concentração do composto de enxofre foi estabelecido, pela disponibilidade da substância em volumes acima de 200 $\mathrm{mL}$. 


\subsection{Planta industrial}

Uma das linhas de produção de propelente da unidade da Liquigás Distribuidora SA, localizada em Capuava, cidade de Mauá, de acordo com a Figura 4.1. e dados da Tabela 4.1, é composta de 3 pré-filtros em paralelo com tela metálica para remoção de particulados e 4 colunas em série com leito recheado de zeólita 13X do fabricante Axens. O fluido é bombeado para a parte inferior da coluna, percorre toda sua extensão e sai pela parte superior.

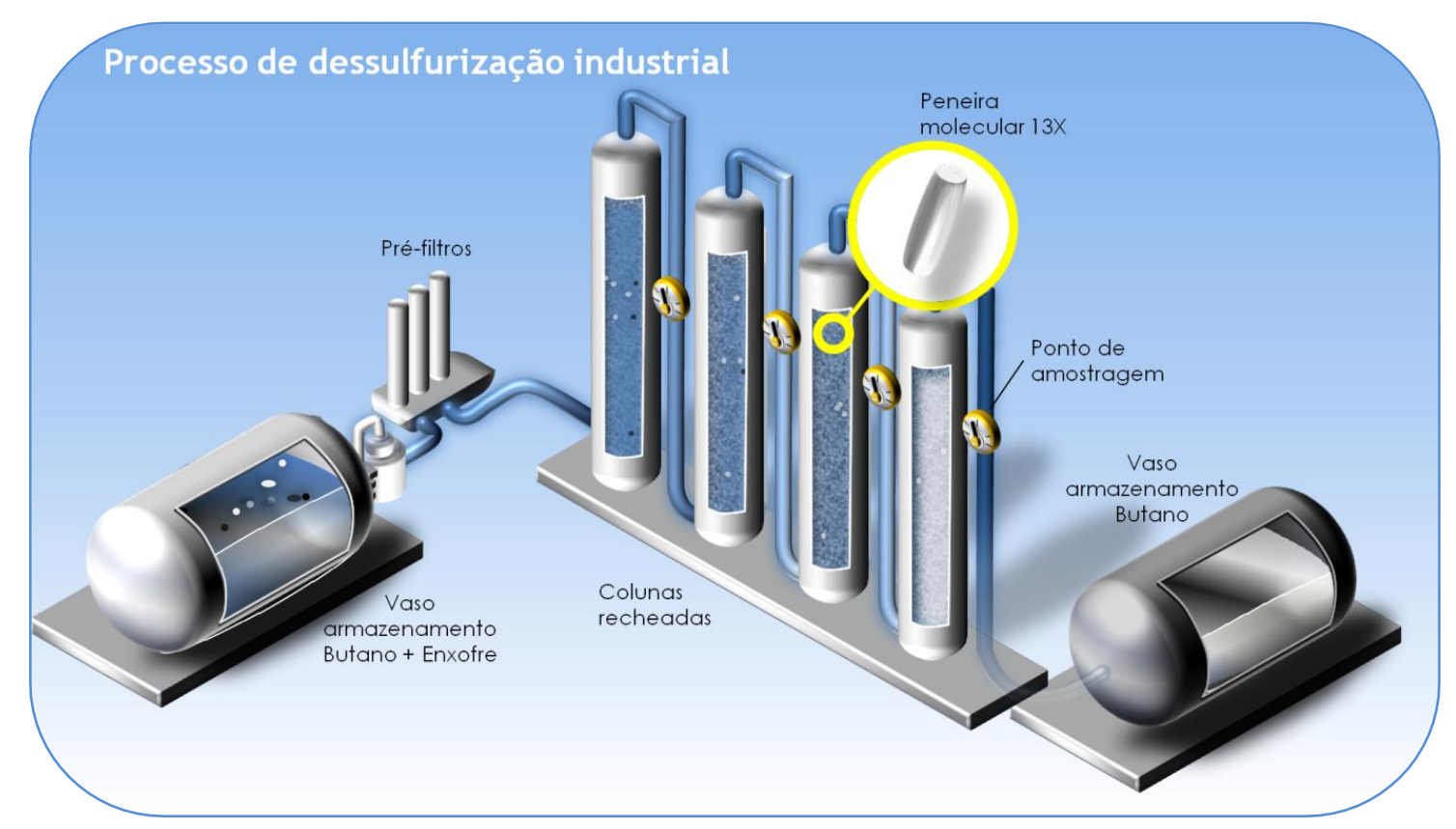

Figura 4.1. Esquema processo industrial de adsorção utilizando peneira molecular 13X.

Tabela 4-1. Características do processo industrial de dessulfurização de butano.

\begin{tabular}{lcc}
\hline Características do leito & Valor & Unidade \\
\hline Altura da coluna & 3,8 & $\mathrm{~m}$ \\
Diâmetro externo coluna & 0,61 & $\mathrm{~m}$ \\
Total de Colunas & 4 & - \\
Diâmetro equivalente da partícula & 2,48 & $\mathrm{~mm}$ \\
Porosidade estimada do leito & 0,35 & - \\
Massa de zeólita por coluna & 500 & $\mathrm{~kg}$ \\
\hline
\end{tabular}

A vazão permanece constante durante operação e é monitorada por medidores de fluxo do tipo vortex, fabricante Yokogawa, e controlada através da abertura e fechamento automatizado de válvulas de controle tipo globo do fabricante GE 
(General Eletrics) posicionadas na tubulação de saída das colunas recheadas com zeólita. Os demais parâmetros do processo de adsorção são somente monitorados:

- Composição do fluido de entrada;

As principais características da matéria-prima fornecida para produção de propelente para aerossol estão resumidas na Tabela 4-2. Os dados foram obtidos do histórico de análises realizadas pelo laboratório de controle de qualidade da Liquigás Distribuidora no período de setembro de 2015 a julho de 2016.

Em relação aos contaminantes são encontrados mais de 12 tipos diferentes de compostos sulfurados, sendo 4 deles os mais recorrentes e que se apresentam em maior teor nas correntes de Butano: etil-mercaptana, dissulfeto de carbono, sulfeto de carbonila e metil-mercaptana.

Tabela 4-2. Composição média da matéria-prima Butano processada na planta industrial da Liquigás Distribuidora.

\begin{tabular}{lcc}
\hline Principais componentes Butano & Valores médios & Unidade \\
\hline Soma iso-butano + n-butano & $90,0-98,0$ & $\%$ massa \\
Propano & $2,0-6,0$ & $\%$ massa \\
Soma insaturados (propeno, 1- & $0,4-1,0$ & $\%$ massa \\
buteno, iso-buteno, 2-buteno) & $0,4-0,8$ & $\%$ massa \\
Pentanos + pesados & $5-30$ & $\mathrm{mg} / \mathrm{kg}$ \\
\hline
\end{tabular}

- Composição de enxofre total no fluido entre as colunas durante o processo.

Para obtenção da curva ruptura, a composição do fluido entre as colunas é monitorada até o ponto de ruptura da $4^{a}$ coluna. As coletas de amostra são feitas em cilindros de amostragem, conforme procedimento descrito no item 4.6.1, em pontos localizados nas tubulações entre as torres durante o processo e, são posteriormente analisadas em laboratório utilizando as metodologias descritas no item 4.6.2. Um exemplo de acompanhamento da curva de ruptura industrial está ilustrado na Figura 1.1. 


\subsection{Caracterização do solvente}

O Butano Especial, comercializado pela Petrobrás, é um composto orgânico saturado que pode ser obtido do petróleo através de craqueamento e destilação ou de unidades de processamento de gás natural (UPGN). Entretanto, somente a última fonte atende as especificações requeridas para utilização como propelente para aerossol.

O solvente usado nos experimentos foi extraído do processo em escala industrial, sendo, conforme descrito no item 4.1., uma mistura rica de hidrocarbonetos isômeros normal-butano e iso-butano, totalizando cerca de $94 \%$ em massa. O restante da solução consiste de uma pequena quantidade (máximo 1\% massa) de olefinas (propeno, 1-buteno, iso-buteno, trans-buteno e cis-buteno) e de propano (em média $4 \%$ massa). Esta mistura multicomponente será denominada Butano, pois são os componentes presentes em maior quantidade. A composição completa da mistura de hidrocarbonetos utilizada foi realizada no laboratório de controle de qualidade da Liquigás Distribuidora, através da metodologia descrita no item 4.6.4.

Para efeito de obtenção de suas propriedades físico-químicas, a mistura líquida estudada pode ser considerada uma solução ideal. (SMITH, 2007)

Na Tabela 4-3 apresentam-se a estrutura molecular e as propriedades físico-químicas dos principais constituintes do Butano.

Tabela 4-3. Propriedades físico-químicas do butano. (DENNY, LUXON; 1962)

\begin{tabular}{lccc}
\hline Propriedades Físico-Químicas & Unidade & Iso-Butano & N-Butano \\
\hline & & & \\
Fórmula Química & & ${ }_{4} \mathrm{H}_{8}$ & \\
& & Orgânico & Orgânico \\
Natureza & - & 58,12 & 58,12 \\
Massa Molecular & $\mathrm{g} / \mathrm{gmol}$ & $5,110^{-8}$ & $5,610^{-8}$ \\
Diâmetro aproximado molécula & $\mathrm{Cm}$ & 204 & 112 \\
Pressão de vapor $20^{\circ} \mathrm{C}$ & $\mathrm{MPa}$ & $-159,4$ & $-138,3$ \\
Ponto de Fusão & ${ }^{\circ} \mathrm{C}$ & $-11,7$ & $-0,5$ \\
Ponto de Ebulição & ${ }^{\circ} \mathrm{C}$ & 563 & 584 \\
Massa Específica (fase líquida $15,5^{\circ} \mathrm{C}$ ) & $\mathrm{kg} / \mathrm{m}^{3}$ & 2 & 2 \\
Massa Específica (fase gás $15,5^{\circ} \mathrm{C}$ ) & $\mathrm{kg} / \mathrm{m}^{3}$ & & \\
\hline
\end{tabular}




\subsection{Caracterização dos adsorvatos}

Os compostos sulfurados são adicionados ao Butano para garantir os níveis na faixa de detecção e alerta, em caso de vazamento deste produto para o meio ambiente. Para possibilitar sua utilização como propelente para produtos em aerossol a presença dos compostos sulfurados é indesejável, logo são considerados contaminantes e devem ser removidos até níveis em torno de 0,1 ppm massa.

Os principais odorantes são constituídos de compostos orgânicos sulfurados, em que se destacam as famílias das mercaptanas e dos sulfetos. Quanto a algumas características importantes, apresentam:

- Características olfativas distintas;

- Baixa toxicidade;

- Forte odor desagradável em baixas concentrações;

- Baixa reatividade e adsorção em contato com materiais da rede;

- Permeabilidade no solo;

- Miscibilidade e volatilidade ao fluxo de gás LP;

- Insolubilidade em água.

Conforme descrito no item 2.2, a seleção dos componentes: terc-butil-mercaptana e n-propil-mercaptana se deu pela disponibilidade de volume suficiente para os experimentos e pela facilidade no manuseio, uma vez que são líquidos à temperatura e pressão ambiente. A etil-mercaptana por estar presente em maior teor e frequência no Butano Especial utilizado no processo industrial.

A Tabela 4-4 apresenta as características dos compostos de enxofre utilizados nos testes de obtenção da isoterma monocomponente.

Tabela 4-4. Características dos compostos sulfurados.

\begin{tabular}{lcccc}
\hline Composto de Enxofre & Fórmula & $\begin{array}{c}\text { Massa Molecular } \\
\text { (g/gmol) }\end{array}$ & $\begin{array}{c}\text { Pureza } \\
\text { (\%) }\end{array}$ & Fabricante \\
\hline Etil-mercaptana & $\mathrm{C}_{2} \mathrm{H}_{5}-\mathrm{SH}$ & 62,1 & 98 & Chemservice \\
N-propil-mercaptana & $\mathrm{C}_{3} \mathrm{H}_{7}-\mathrm{SH}$ & 76,1 & 98 & Sigma Aldrich \\
Terc-butil mercaptana & $\left(\mathrm{CH}_{3}\right)_{3} \mathrm{C}-\mathrm{SH}$ & 90,2 & 99 & Sigma Aldrich \\
\hline
\end{tabular}




\subsection{Obtenção das curvas de equilíbrio de adsorção}

Os ensaios para obtenção dos dados de equilíbrio termodinâmico entre o adsorvato e o adsorvente compreendem o levantamento das curvas de adsorção monocomponentes de alguns tipos de compostos de enxofre.

Os ensaios foram realizados em duplicata para garantir a repetibilidade e confiabilidade dos resultados. Todas as etapas descritas a seguir foram realizadas no laboratório de controle de qualidade de gases liquefeitos de petróleo da Liquigás Distribuidora, localizado na cidade de Mauá - SP.

\subsubsection{Condicionamento do material adsorvente}

Devido à característica hidrofílica das peneiras moleculares $13 \mathrm{X}$, há risco de adsorção da umidade do ar e consequente ocupação dos espaços livres adsortíveis antes do início dos testes. Por este motivo, antes de cada ensaio experimental as amostras passaram por um tratamento prévio que consistiu na secagem, através de colocação do material em estufa na Figura 4.2 (b), do fabricante Quimis, modelo Q317M, a 120 ${ }^{\circ} \mathrm{C}$ durante 8 horas. Após este tempo, manteve-se o cadinho em dessecador, conforme Figura 4.2 (a), com sílica gel até seu uso nos ensaios.
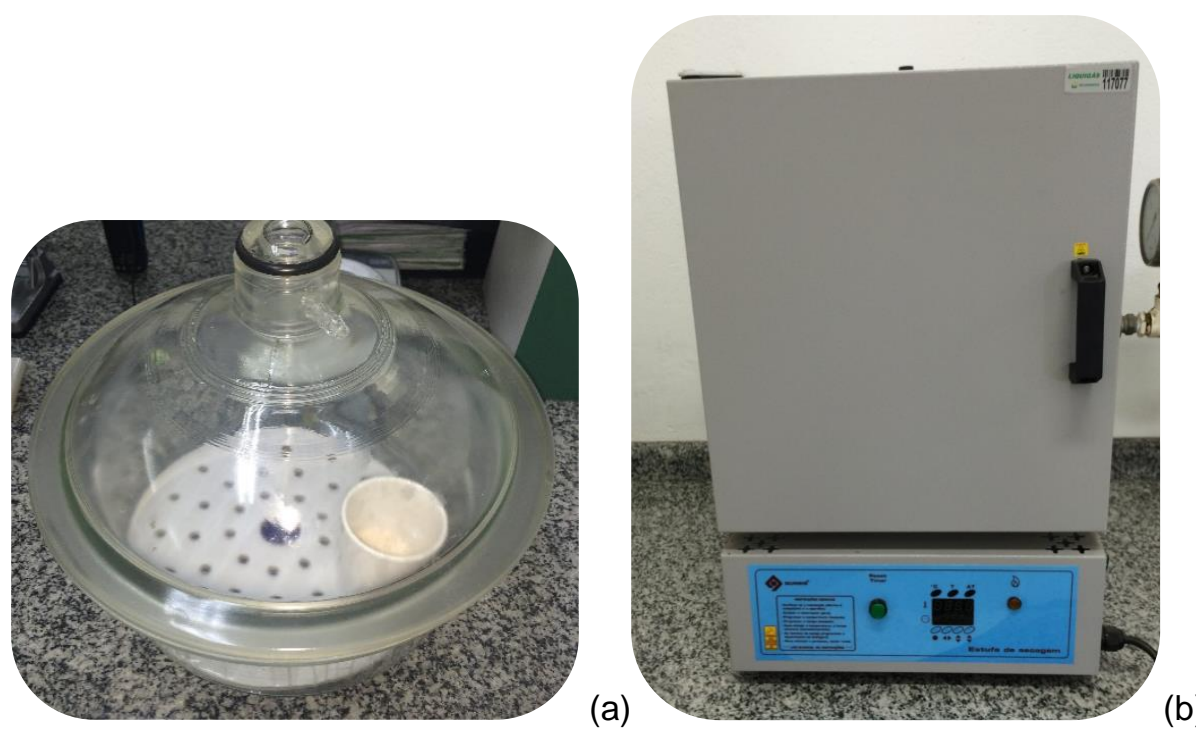

Figura 4.2. (a) Foto do dessecador com sílica gel. (b) Foto da estufa modelo Q317M do fabricante Quimis.

\subsubsection{Preparação das soluções}

A preparação das soluções foi conduzida em duas etapas: 
- Coleta do butano dessulfurizado;

- Adição da molécula de enxofre.

O Butano proveniente da fonte produtora apresenta concentração variada de componentes sulfurados e até mesmo umidade, impossibilitando sua utilização para avaliação do equilíbrio monocomponente. Por conta disso, o butano empregado para realização dos testes laboratoriais foi dessulfurizado pelo processo industrial de adsorção com peneira molecular 13X, para que posteriormente fosse possível a adição da molécula de enxofre objeto de estudo.

O butano dessulfurizado foi amostrado e acondicionado em estado líquido pressurizado em cilindros de aço inox e com capacidade para aproximadamente 1 litro, ilustrado na Figura 4.3.

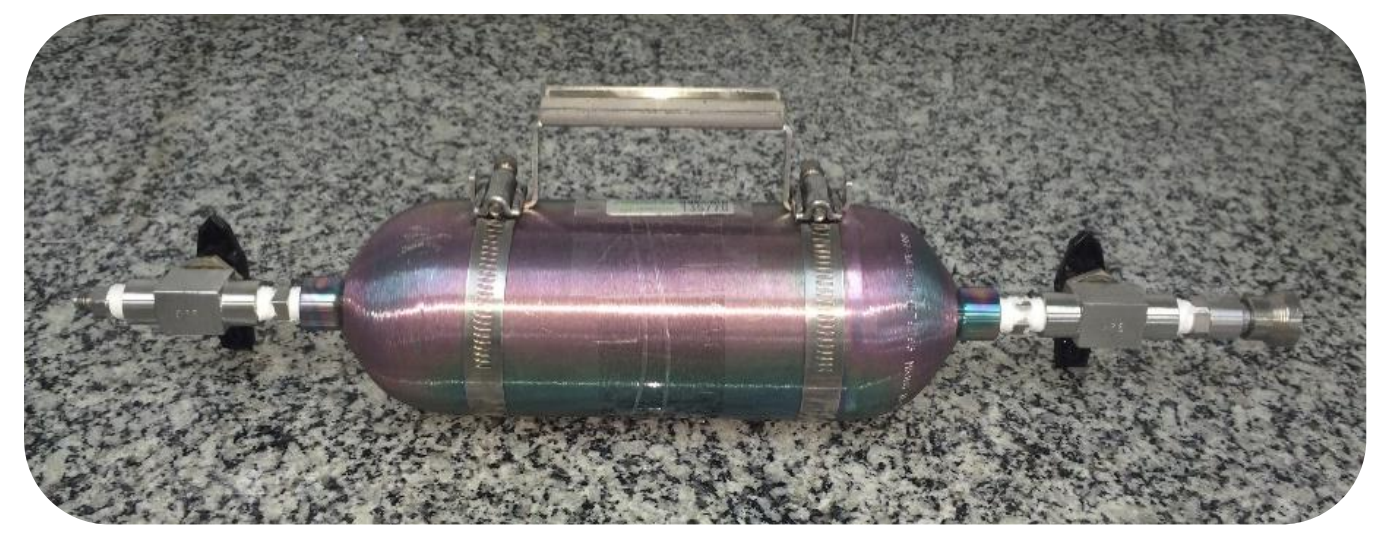

Figura 4.3. Cilindro de aço inox com sulfinert e capacidade para 1 litro.

Em seguida, a amostra foi analisada no cromatógrafo, marca Agilent Technologies, modelo 7890A, com detector SCD (Sulfur Chemiluminscence Detector - método ASTM D5404) para confirmar a isenção de enxofre total, no medidor de umidade Karl Fischer, da Metrohm para medição do teor de água e no cromatógrafo, marca Agilent Technologies, modelo 7890A, com detector FID (Flame lonization Detector - método ASTM D2163) para obtenção dos teores de hidrocarbonetos. 
Para obtenção da solução concentrada separou-se outro cilindro de aço inox de 1L, com revestimento em Sulfinert ${ }^{1}$, para evitar adsorção de enxofre na superfície interna do cilindro, para inserção de uma alíquota do composto de enxofre líquido com auxílio de uma seringa. Após a colocação do enxofre, o cilindro foi fechado para introdução do solvente líquido pressurizado. Então, o cilindro foi pesado, homogeneizado e as análises de cromatografia SCD/FID e Karl Fischer repetidas. Caso necessário, a solução poderia ser diluída.

\subsubsection{Obtenção da isoterma de adsorção}

Para o estudo de equilíbrio, o levantamento das isotermas foi realizado variando-se a concentração inicial de enxofre em butano e a quantidade de peneira molecular $13 \mathrm{X}$ de acordo com o comportamento do adsorvato envolvido. A tarefa de encontrar a relação quantidade adsorvida $x$ concentração de equilíbrio foi inicialmente um tanto complexa, pela ausência de referências na literatura científica. Assim sendo, iniciouse o experimento com quantidades arbitrárias de peneira molecular e concentração de enxofre inicial e a partir da obtenção dos primeiros pontos da curva de adsorção, estimou-se os demais considerando capacidades de adsorção similares as previamente obtidas e um teor de enxofre total ao final do experimento igual ou superior a $1 \mathrm{mg} / \mathrm{kg}$.

Para realização dos ensaios de maneira segura e confiável, desenvolveu-se um cilindro especial para este fim, que permitisse a visualização da solução em contato com as partículas sólidas, a remoção/colocação do material adsorvente de maneira prática e a amostragem e análise somente da fase fluida ao final do experimento. Uma foto do cilindro de $300 \mathrm{~mL}$ (fabricante Piccolo), é apresentada na Figura 4.5.

Para controlar duas variáveis fundamentais do experimento, a temperatura e a agitação, devido à baixa difusividade do soluto na fase líquida, foi necessário o desenvolvimento de um agitador, conforme ilustrado na Figura 4.4, com capacidade

\footnotetext{
${ }^{1}$ A técnica do tratamento em Sulfinert ${ }^{\circledR}$, realizada pela empresa Restek, liga uma camada inerte de sílica na superfície do aço, prevenindo compostos ativos de reagir com ou serem adsorvidos no aço. Fonte: http://www.restek.com/pdfs/500-05-001.pdf . Acesso em 27/11/2016.
} 
para 6 cilindros, acoplado a um banho termostatizado, fabricante Quimis, modelo Q214M2, com função de aquecimento e resfriamento.

Para realização os ensaios de equilíbrio, foram adicionados de $0,20 \mathrm{~g}$ a $5,00 \mathrm{~g}$ de peneira molecular $13 \mathrm{X}$ a aproximadamente $50,00 \mathrm{~g}$ a $90,00 \mathrm{~g}$ de butano com teores de compostos de enxofre previamente preparados, de acordo com a descrição do item 4.4.2. Como a quantidade de solução preparada foi em torno de $1000 \mathrm{~mL}$, utilizou-se este volume para obtenção de diferentes pontos da curva de adsorção, variando-se as quantidades de peneira molecular. Por este motivo alguns experimentos aparecem com teores de enxofre inicial idêntico.

O tempo do teste foi estabelecido através de ensaios de cinética com os 6 cilindros com a mesma quantidade de butano e peneira. Com $64 \mathrm{~h}$ o resultado de todos os cilindros foi semelhante, então, acrescentou-se mais $8 \mathrm{~h}$ de ensaio como margem de segurança para o alcance do estado de equilíbrio. Os cilindros foram, então, imersos no interior do banho térmico, onde permaneceram em agitação durante $72 \mathrm{~h}$.

Após este tempo as amostras foram analisadas. Para assegurar a qualidade dos resultados, os testes foram realizados em duplicata.

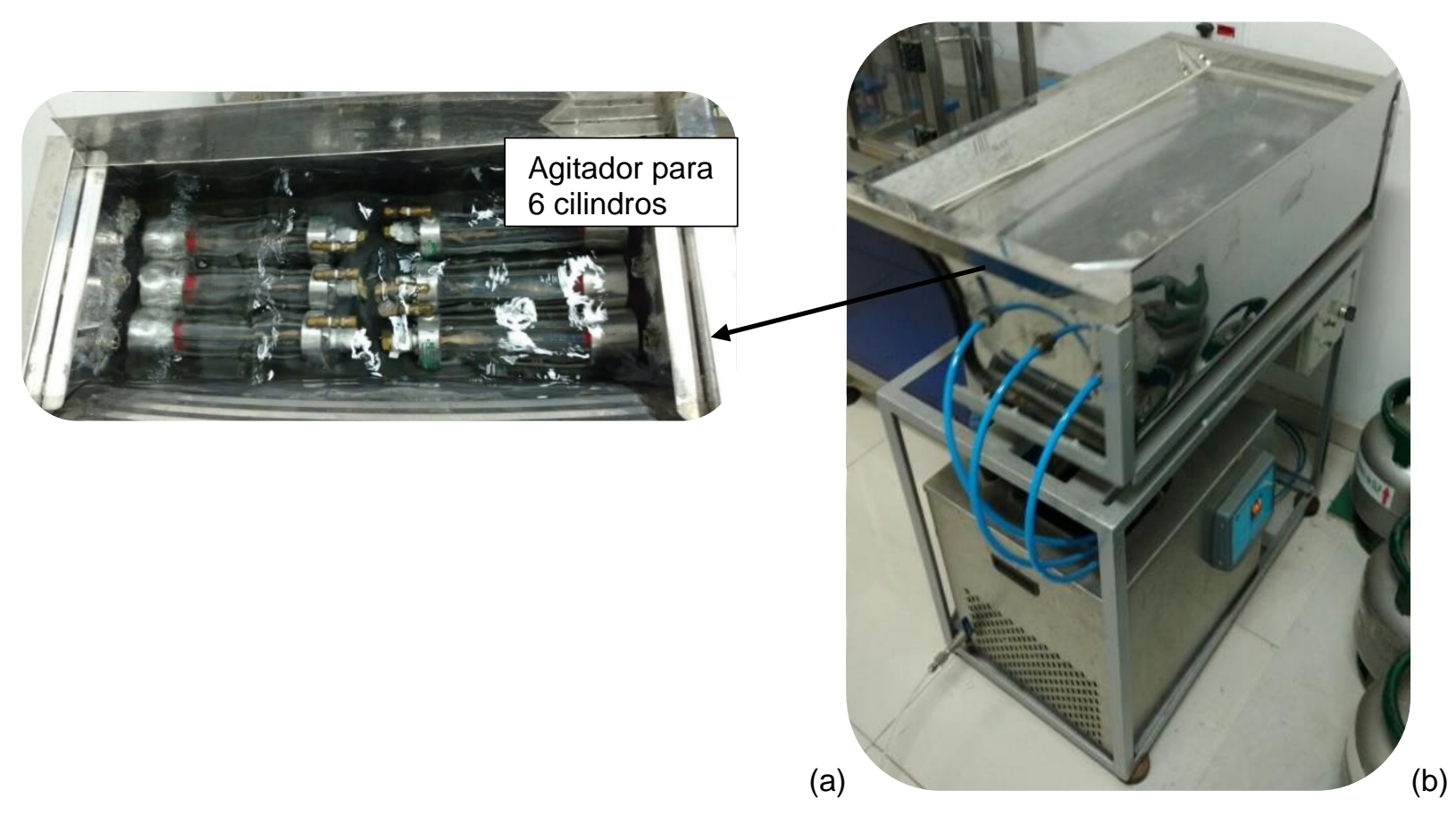

Figura 4.4. (a) Foto ampliada do tanque agitador com os 6 cilindros imersos em água (b) Foto do agitador desenvolvido, acoplado a um banho termostatizado. 

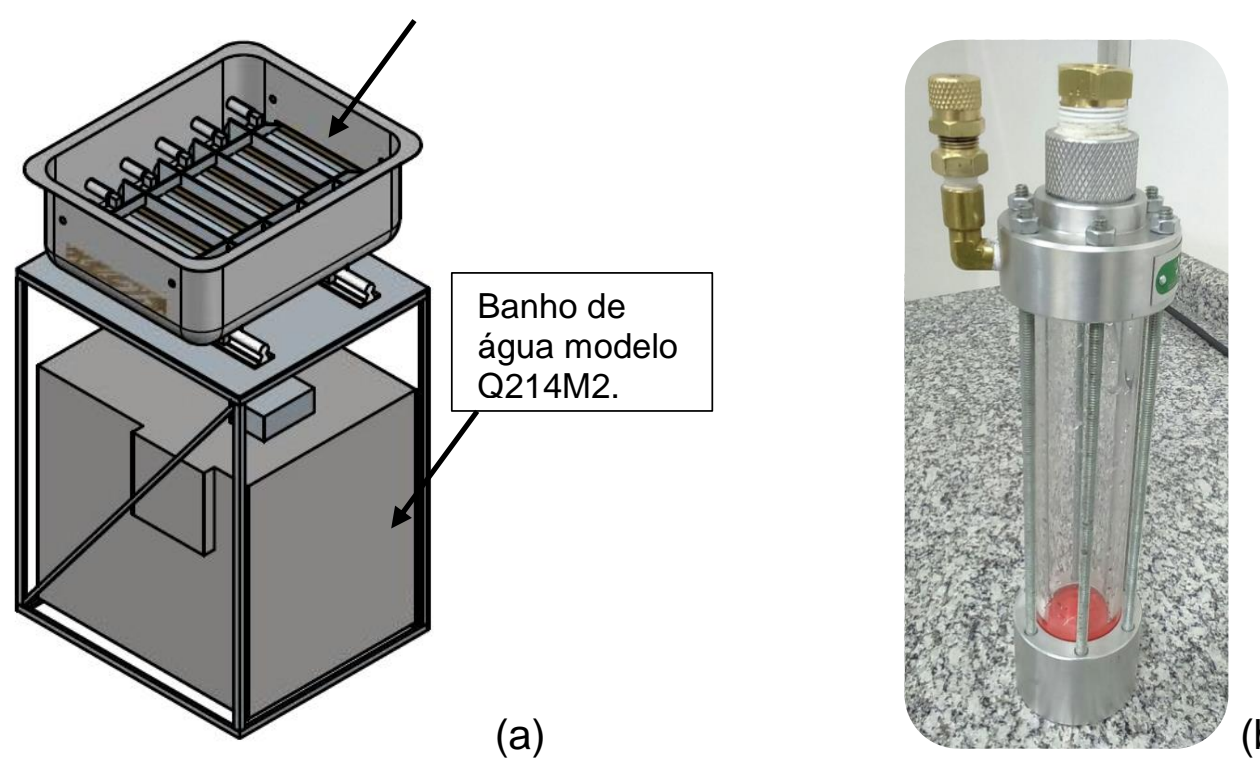

(b)

Figura 4.5 (a) Esquema do projeto do agitador desenvolvido. (b) Foto do cilindro de $300 \mathrm{~mL}$ de alumínio e acrílico desenvolvido para testes de adsorção.

Seguem nas Tabelas 4.5 a 4.8 , as condições iniciais dos testes realizados para obtenção das isotermas de adsorção para os diferentes compostos de enxofre. A massa de peneira foi obtida após a remoção de umidade. A partir das determinações das concentrações dos compostos de enxofre no solvente ao final do ensaio, calculam-se as quantidades adsorvidas. Dessa forma, obtém-se a curva de equilíbrio.

Tabela 4-5. Experimento para obtenção isoterma de equilíbrio a $25 \stackrel{\circ}{\mathrm{C}}$ tercbutil-mercaptana em butano com peneira molecular $13 \mathrm{X}$.

\begin{tabular}{ccccc}
\hline Amostra & $\begin{array}{c}\text { Massa de } \\
\text { Peneira (g) }\end{array}$ & $\begin{array}{c}\text { Teor de } \\
\text { Enxofre Inicial } \\
(\mathbf{m g} / \mathbf{k g})\end{array}$ & $\begin{array}{c}\text { Massa de } \\
\text { Solvente (g) }\end{array}$ & $\begin{array}{c}\text { Tempo de } \\
\text { Teste (h) }\end{array}$ \\
\hline $\mathbf{1}$ & 3,5 & 103,5 & 49,99 & 72 \\
$\mathbf{2}$ & 2,0 & 103,5 & 52,85 & 72 \\
$\mathbf{3}$ & 3,5 & 37,3 & 50,86 & 72 \\
$\mathbf{4}$ & 2,5 & 248 & 51,26 & 72 \\
$\mathbf{5}$ & 3,5 & 248 & 54,50 & 72 \\
$\mathbf{6}$ & 1,75 & 114 & 50,86 & 72 \\
\hline
\end{tabular}


Tabela 4-6. Experimento para obtenção isoterma de equilíbrio a $25 \stackrel{\circ}{ } \mathrm{C}$ etil- mercaptana em butano com peneira molecular $13 \mathrm{X}$.

\begin{tabular}{ccccc}
\hline Amostra & $\begin{array}{c}\text { Massa de } \\
\text { Peneira (g) }\end{array}$ & $\begin{array}{c}\text { Teor de } \\
\text { Enxofre Inicial } \\
(\mathbf{m g} / \mathbf{k g})\end{array}$ & $\begin{array}{c}\text { Massa de } \\
\text { Solvente } \mathbf{( g )})\end{array}$ & $\begin{array}{c}\text { Tempo de } \\
\text { Teste }(\mathbf{h})\end{array}$ \\
\hline $\mathbf{1}$ & 3,5 & 201 & 50,13 & 72 \\
$\mathbf{2}$ & 2,0 & 201 & 51,70 & 72 \\
$\mathbf{3}$ & 3,0 & 46 & 90,18 & 72 \\
$\mathbf{4}$ & 0,2 & 201 & 53,42 & 72 \\
$\mathbf{5}$ & 0,5 & 201 & 51,56 & 72 \\
$\mathbf{6}$ & 3,0 & 322 & 49,62 & 72 \\
$\mathbf{7}$ & 1,3 & 301 & 54,59 & 72 \\
$\mathbf{8}$ & 1,0 & 322 & 50,81 & 72 \\
\hline
\end{tabular}

Tabela 4-7. Experimento para obtenção isoterma de equilíbrio a $25{ }^{\circ} \mathrm{C}$ n-propil-mercaptana em butano com peneira molecular $13 \mathrm{X}$.

\begin{tabular}{ccccc}
\hline Amostra & $\begin{array}{c}\text { Massa de } \\
\text { Peneira (g) }\end{array}$ & $\begin{array}{c}\text { Teor de } \\
\text { Enxofre Inicial } \\
(\mathbf{m g} / \mathbf{k g})\end{array}$ & $\begin{array}{c}\text { Massa de } \\
\text { Solvente (g) }\end{array}$ & $\begin{array}{c}\text { Tempo de } \\
\text { Teste (h) }\end{array}$ \\
\hline $\mathbf{1}$ & 2,0 & 174 & 51,62 & 72 \\
$\mathbf{2}$ & 1,75 & 174 & 52,83 & 72 \\
$\mathbf{3}$ & 2,5 & 109 & 52,74 & 72 \\
$\mathbf{4}$ & 3,0 & 511 & 48,95 & 72 \\
$\mathbf{5}$ & 2,0 & 511 & 52,12 & 72 \\
$\mathbf{6}$ & 6,0 & 511 & 48,63 & 72 \\
$\mathbf{7}$ & 5,0 & 217 & 52,58 & 72 \\
$\mathbf{8}$ & 3,5 & 511 & 89,58 & 72 \\
\hline
\end{tabular}


Tabela 4-8. Experimento para obtenção isoterma de equilíbrio a $10 \stackrel{\circ}{C} \mathbf{n}$-propil-mercaptana em butano com peneira molecular $13 \mathrm{X}$.

\begin{tabular}{ccccc}
\hline Amostra & $\begin{array}{c}\text { Massa de } \\
\text { Peneira (g) }\end{array}$ & $\begin{array}{c}\text { Teor de } \\
\text { Enxofre Inicial } \\
(\mathbf{m g} / \mathbf{k g})\end{array}$ & $\begin{array}{c}\text { Massa de } \\
\text { Solvente (g) }\end{array}$ & $\begin{array}{c}\text { Tempo de } \\
\text { Teste (h) }\end{array}$ \\
\hline $\mathbf{1}$ & 2,0 & 317 & 60,73 & 72 \\
$\mathbf{2}$ & 2,0 & 576 & 60,73 & 72 \\
$\mathbf{3}$ & 0,5 & 472 & 55,03 & 72 \\
$\mathbf{4}$ & 0,8 & 472 & 50,27 & 72 \\
$\mathbf{5}$ & 0,3 & 462 & 49,49 & 72 \\
$\mathbf{6}$ & 1,0 & 462 & 50,45 & 72 \\
$\mathbf{7}$ & 1,3 & 462 & 57,70 & 72 \\
$\mathbf{8}$ & 0,9 & 511 & 49,58 & 72 \\
\hline
\end{tabular}

\subsection{Obtenção da curva de ruptura}

Parte essencial do estudo é a operação de uma planta piloto e de uma coluna em escala laboratorial com material adsorvente idêntico ao da coluna industrial, a peneira molecular 13X. O objetivo dos testes com os protótipos é a obtenção da curva de ruptura para avaliar a influência dos parâmetros: velocidade e concentração de contaminantes no processo de adsorção, sem haver impacto no processo industrial e por consequência na qualidade do produto final comercializado. Além disso, esperase através deste ensaio validar o modelo matemático proposto.

\subsubsection{Escala laboratorial}

O protótipo em escala laboratorial consiste em uma coluna de leito fixo recheada com zeólita 13X conectada a cilindros com capacidade de $5 \mathrm{~kg}$ a $45 \mathrm{~kg}$, contendo solução de butano líquido (com concentração conhecida do teor de enxofre total). Sendo a válvula de entrada posicionada na extremidade superior e válvula de saída, na extremidade inferior do recipiente.

Para promover o fluxo do butano líquido através do leito fixo, o cilindro é pressurizado com nitrogênio a 15 bar pela válvula de entrada e o solvente é impulsionado para entrada da coluna recheada com material adsorvente, de acordo com esquema da Figura 4.6. A vazão é mantida constante pelo controle da abertura ou fechamento de 
uma válvula agulha e monitorada por um rotâmetro (medidor de vazão de área variável).

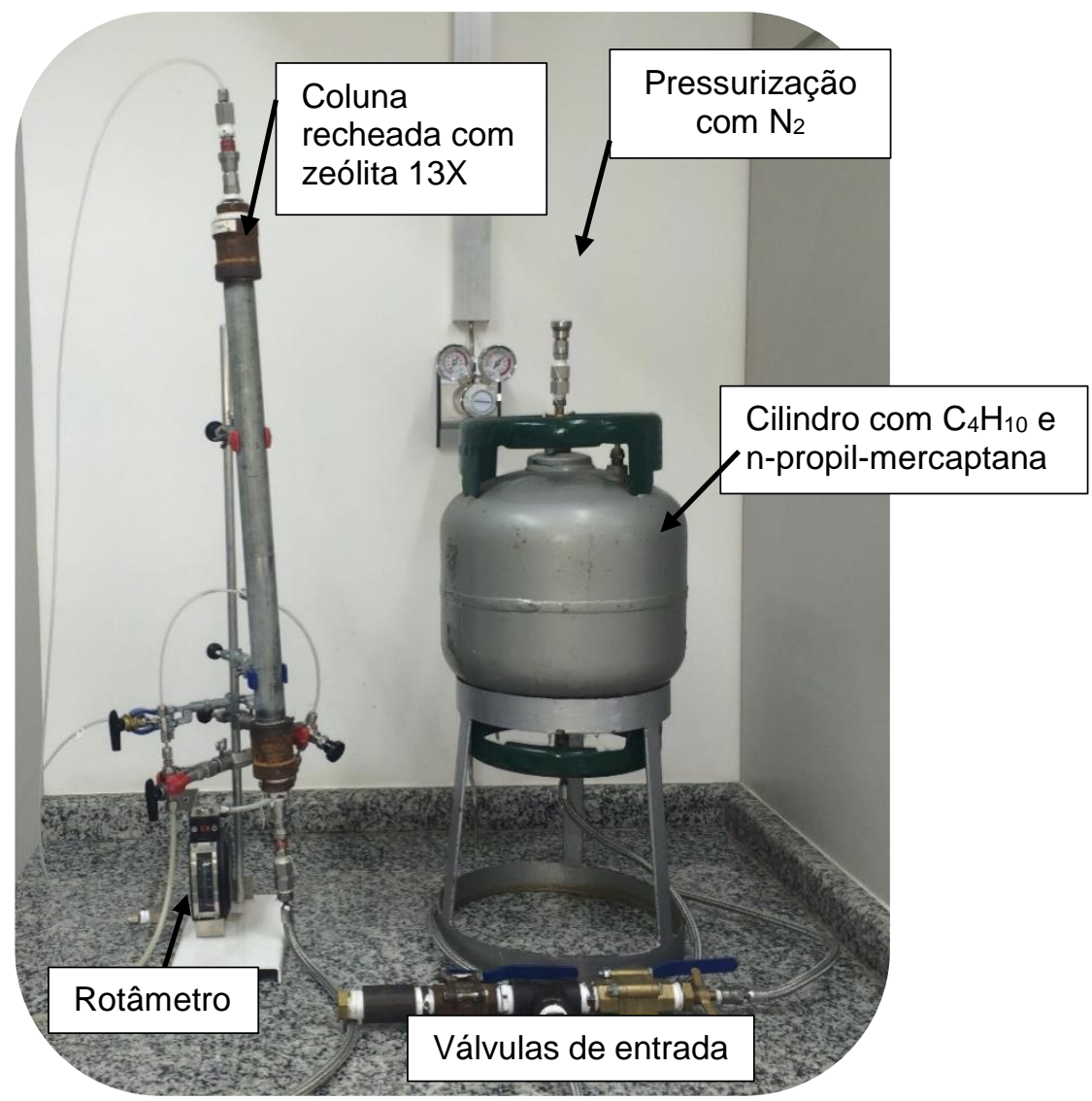

Figura 4.6. Esquema do protótipo laboratorial para obtenção das curvas de ruptura.

As características do protótipo estão resumidas na Tabela 4-9.

Tabela 4-9. Características do protótipo utilizado para testes em escala laboratorial.

\begin{tabular}{lcc}
\hline Características do leito & Valor & Unidade \\
\hline Altura da coluna & 0,58 & $\mathrm{~m}$ \\
Diâmetro interno da coluna & 0,027 & $\mathrm{~m}$ \\
Diâmetro equivalente da partícula & 2,48 & $\mathrm{~mm}$ \\
Porosidade da partícula & 0,67 & - \\
Porosidade do leito & 0,35 & - \\
Massa zeólita por coluna & 0,23 & $\mathrm{~kg}$ \\
\hline
\end{tabular}

Realizaram-se ensaios de adsorção com cada amostra de butano contaminada com um único composto sulfurado: n-propil-mercaptana. Embora este composto de enxofre não seja muito comum na matéria-prima processada industrialmente, havia 
disponibilidade suficiente do componente para os experimentos em escala laboratorial e piloto, é de fácil manuseio por ser líquido nas condições ambiente e possibilita desta maneira atingir o objetivo de avaliar a influência dos parâmetros concentração e velocidade, além da validação do modelo matemático, já que foram obtidos os dados de equilíbrio para este componente.

A seleção das velocidades está associada à reprodução da velocidade da planta industrial $(0,0039 \mathrm{~m} / \mathrm{s})$ e na observação do comportamento do sistema quando este parâmetro é aumentado. A escolha das concentrações de enxofre iniciais teve como premissa o tempo máximo do experimento de $24 \mathrm{~h}$, pois dificultaria seu acompanhamento. E, muito embora não sejam usuais no processo industrial, é relevante avaliar sua influência nos experimentos realizados em escala laboratorial. As condições experimentais estão sumarizadas na Tabela 4-10.

Tabela 4-10. Condições experimentais da adsorção em coluna em escala laboratorial.

\begin{tabular}{cccccc}
\hline $\begin{array}{c}\text { Teste } \\
\text { Lab }\end{array}$ & Tipo de Enxofre & $\begin{array}{c}\mathbf{C}_{\mathbf{0}} \\
(\mathbf{m g} / \mathbf{k g})\end{array}$ & $\begin{array}{c}\mathbf{T}\left({ }^{\circ} \mathbf{C}\right) \\
\mathbf{m e ́ d i a}\end{array}$ & $\begin{array}{c}\text { Vazão } \\
\text { Média } \\
(\mathbf{k g} / \mathbf{h})\end{array}$ & $\begin{array}{c}\mathbf{v} \\
(\mathbf{m} / \mathbf{s})\end{array}$ \\
\hline $\mathbf{1}$ & Npropil-mercaptana & 81 & 25 & 4,70 & 0,0039 \\
$\mathbf{2}$ & Npropil-mercaptana & 174 & 25 & 4,61 & 0,0039 \\
$\mathbf{3}$ & Npropil-mercaptana & 315 & 25 & 4,61 & 0,0040 \\
$\mathbf{4}$ & Npropil-mercaptana & 170 & 25 & 7,0 & 0,0060 \\
$\mathbf{5}$ & Npropil-mercaptana & 174 & 25 & 9,15 & 0,0077 \\
\hline
\end{tabular}

\subsubsection{Escala piloto}

A planta piloto consiste em quatro colunas de 1,02 m de altura de aço carbono conectadas em série, conforme Figura 4.7. No entanto, somente a primeira coluna é usada no experimento, porque havia restrição acerca do tempo máximo de experimento que não poderia ultrapassar as $24 \mathrm{~h}$ por dificultar o acompanhamento e pela inviabilidade em manter dois caminhões fora de sua atividade de comercialização de gás LP. As características do protótipo estão sumarizadas na Tabela 4-11.

Para realizar o teste foram utilizados dois caminhões, com capacidade para nove toneladas de butano, acoplados à entrada e à saída das colunas recheadas com peneira molecular 13X. O fluxo de butano através das colunas foi transferido por uma 
bomba instalada no caminhão ligado à entrada da $1^{\text {a }}$ coluna. Segue esquema 0 sistema piloto na Figura 4.7.

Caminhão 1

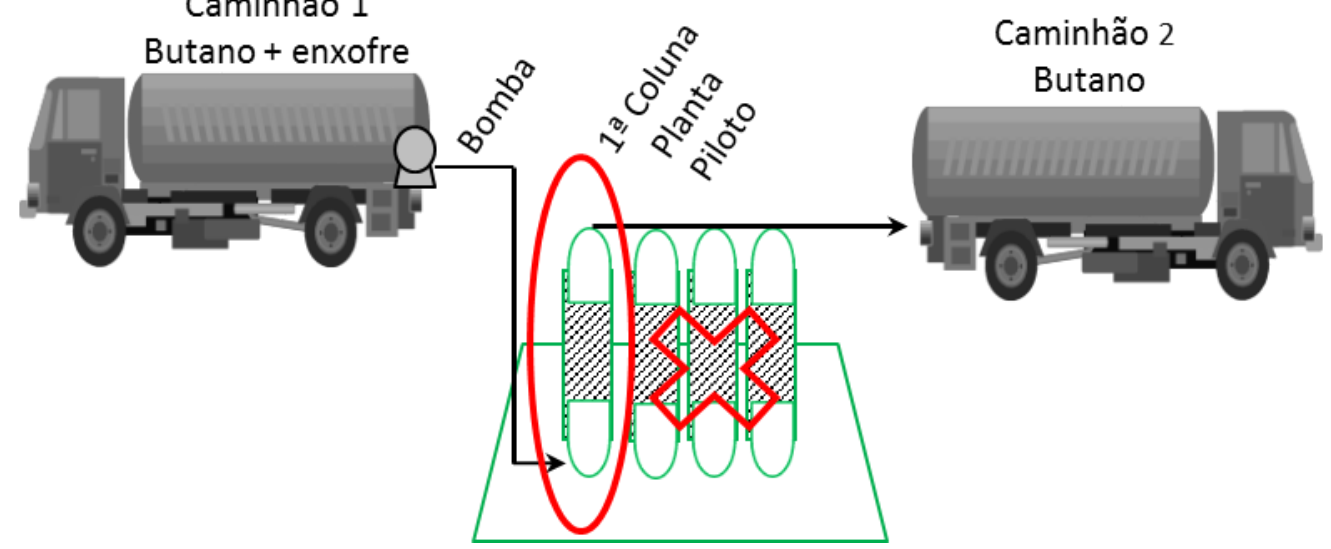

Figura 4.7. Esquema do teste realizado em planta piloto com dois caminhões conectados. Somente a primeira coluna de adsorção é utilizada no experimento.

Tabela 4-11. Características do protótipo utilizado para testes em escala piloto.

\begin{tabular}{lcc}
\hline Características do leito & Valor & Unidade \\
\hline Altura da coluna & 1,02 & $\mathrm{~m}$ \\
Diâmetro coluna & 0,14 & $\mathrm{~m}$ \\
Total de Colunas & 4 & - \\
Porosidade do leito & 0,35 & - \\
Massa Zeólita por coluna & 11,3 & $\mathrm{~kg}$ \\
\hline
\end{tabular}

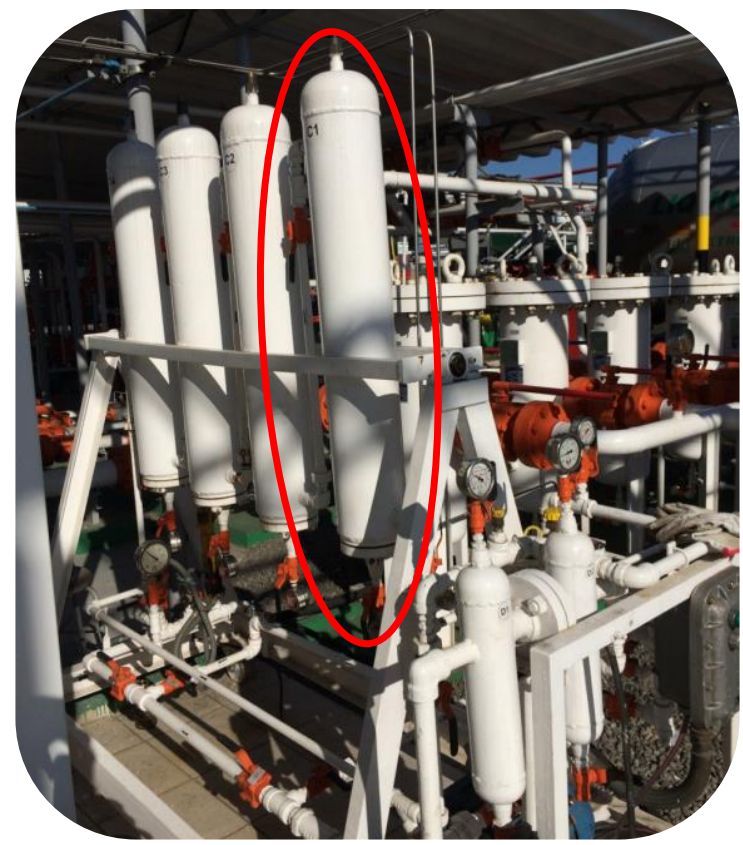

Figura 4.8. Foto do protótipo utilizado para testes em escala piloto, sendo que somente a $1 \stackrel{\text { a }}{\text { coluna é }}$ utilizada. 
Não foi possível a realização dos ensaios em condições isotérmicas, pois a instalação estava exposta às condições ambientais. A temperatura foi monitorada através de um sensor infravermelho, Figura 4.9 (a) modelo Scantemp ST600.2, fabricante Incoterm direcionado na superfície externa das colunas periodicamente. A vazão foi verificada por um medidor de fluxo totalizador instalado próximo à saída da $4^{\underline{a}}$ coluna, série Aluminum Eletronic Digital Fuel Meters, fabricante GPI - Great Plains Industries. Segue foto do medidor na Figura 4.9. (b). A velocidade se manteve constante durante todo o experimento, utilizando a capacidade máxima da bomba instalada no caminhão, entretanto, não foi possível pré-determinar o valor desejado.

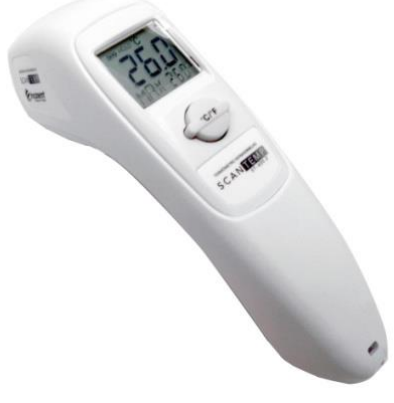

(a)

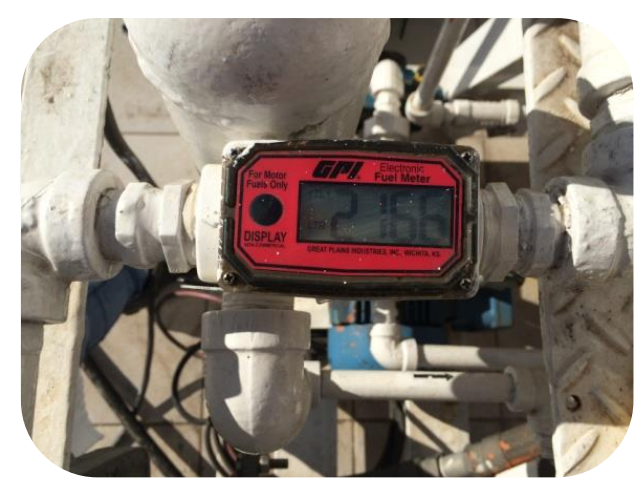

(b)

Figura 4.9. (a) Sensor de temperatura modelo Scanterm ST600.2, fabricante Incoterm. (b) Medidor de fluxo série, fabricante GPI utilizado para medição da vazão do processo.

Para garantir a concentração uniforme no fluido, o butano líquido foi contaminado com composto de enxofre na tubulação de carregamento do caminhão e a mistura foi, então, homogeneizada através da circulação do produto por sistema de bombeamento.

Foram realizados 3 experimentos, de acordo com as condições sumarizadas na Tabela 4-12. Após início do fluxo, observou-se um aquecimento das colunas para cerca de $45^{\circ} \mathrm{C}$, já que o processo de adsorção é exotérmico. Contudo, a temperatura ambiente foi estabelecida logo após aproximadamente 10 minutos, e variou cerca de $3 \stackrel{\circ}{ } \mathrm{C}$ durante todo o experimento. A coleta de amostra na saída da primeira coluna foi realizada imediatamente após 10 minutos do início e as demais ocorreram de $30 \mathrm{em}$ 30 minutos. A partir do ponto de ruptura o tempo de coleta passou a ser de hora em hora, já que a elevação do teor do composto de enxofre passou a ser demasiadamente lenta. Este fenômeno ocorre, provavelmente, porque a partir do preenchimento inicial 
dos espaços disponíveis nos sítios ativos das peneiras moleculares, começa a ser mais significativo o efeito de dispersão da curva de ruptura.

A ideia inicial para seleção do teor de enxofre foi a de simular concentrações iniciais análogas ao processo industrial. Entretanto, o tempo de duração dos experimentos foi demasiadamente longo (estima-se aproximadamente 24h para saturação do leito), o que inviabilizou seu acompanhamento até o ponto de saturação. Escolheu-se diferentes tipos de compostos sulfurados, porque haveria possibilidade de validação do modelo matemático, considerando que foram obtidas as isotermas de adsorção para cada um deles e também porque foi necessário dispor de grande quantidade de composto de enxofre líquido para contaminação do volume de butano nos caminhões e não havia disponibilidade. Assim, optou-se por realizar o experimento com concentração inicial de enxofre maior que os testes 7 e 8, para n-propil-mercaptana, no intuito de possibilitar o acompanhamento do experimento até um ponto próximo ao final da curva de ruptura em menos tempo.

As coletas de amostra seguiram o procedimento descrito no item 4.6.1.

Tabela 4-12 Experimentos realizados em escala piloto para obter as curvas de ruptura com butano e peneira molecular $13 \mathrm{X}$.

\begin{tabular}{cccccc}
\hline $\begin{array}{c}\text { Teste } \\
\text { Piloto }\end{array}$ & Tipo de enxofre & $\begin{array}{c}\mathbf{C}_{0} \\
(\mathbf{m g} / \mathbf{k g})\end{array}$ & $\begin{array}{c}\mathbf{T}(\mathbf{o} \mathbf{C}) \\
\text { média }\end{array}$ & $\begin{array}{c}\text { Vazão } \\
\text { Média } \\
(\mathbf{k g} / \mathbf{h})\end{array}$ & $\begin{array}{c}\mathbf{v} \\
(\mathbf{m} / \mathbf{s})\end{array}$ \\
\hline $\mathbf{7}$ & Tercbutil-mercaptana & 12,1 & 26 & 414 & 0,0132 \\
$\mathbf{8}$ & Isopropil-mercaptana & 13,0 & 25 & 418 & 0,0134 \\
$\mathbf{9}$ & Npropil-mercaptana & 91,8 & 25 & 530 & 0,0169 \\
\hline
\end{tabular}

\subsection{Metodologia analítica}

\subsubsection{Amostragem}

O processo de amostragem de petróleo e derivados tem como premissa preservar a representatividade do produto armazenado. É baseado nas normas ASTM D1265 05 - Standard Practice for Sampling Liquefied Petroleum (LP) Gases, Manual Method e ISO 4257 - Liquefied Petroleum (LP) Gases, Method of Sampling. 
As amostras são coletas no estado líquido pressurizado em cilindros apropriados conforme ilustrado na Figura 4.3.

\subsubsection{Análise de compostos de enxofre}

Para identificação e quantificação do enxofre são utilizados dois métodos: o de quimiluminescência por cromatografia gasosa e/ou o de fluorescência que mede 0 enxofre total da amostra.

\subsubsection{Método Quimiluminescência}

Nesta técnica analítica, baseada na norma ASTM D-5504-08, os compostos de enxofre são separados através de uma coluna de cromatografia gasosa pela sua afinidade com a fase fixa, que deve ser inerte para compostos de enxofre. Seguem os parâmetros do método na Tabela 4-13:

Tabela 4-13. Parâmetros do método de análise de enxofre por Quimiluminescência.

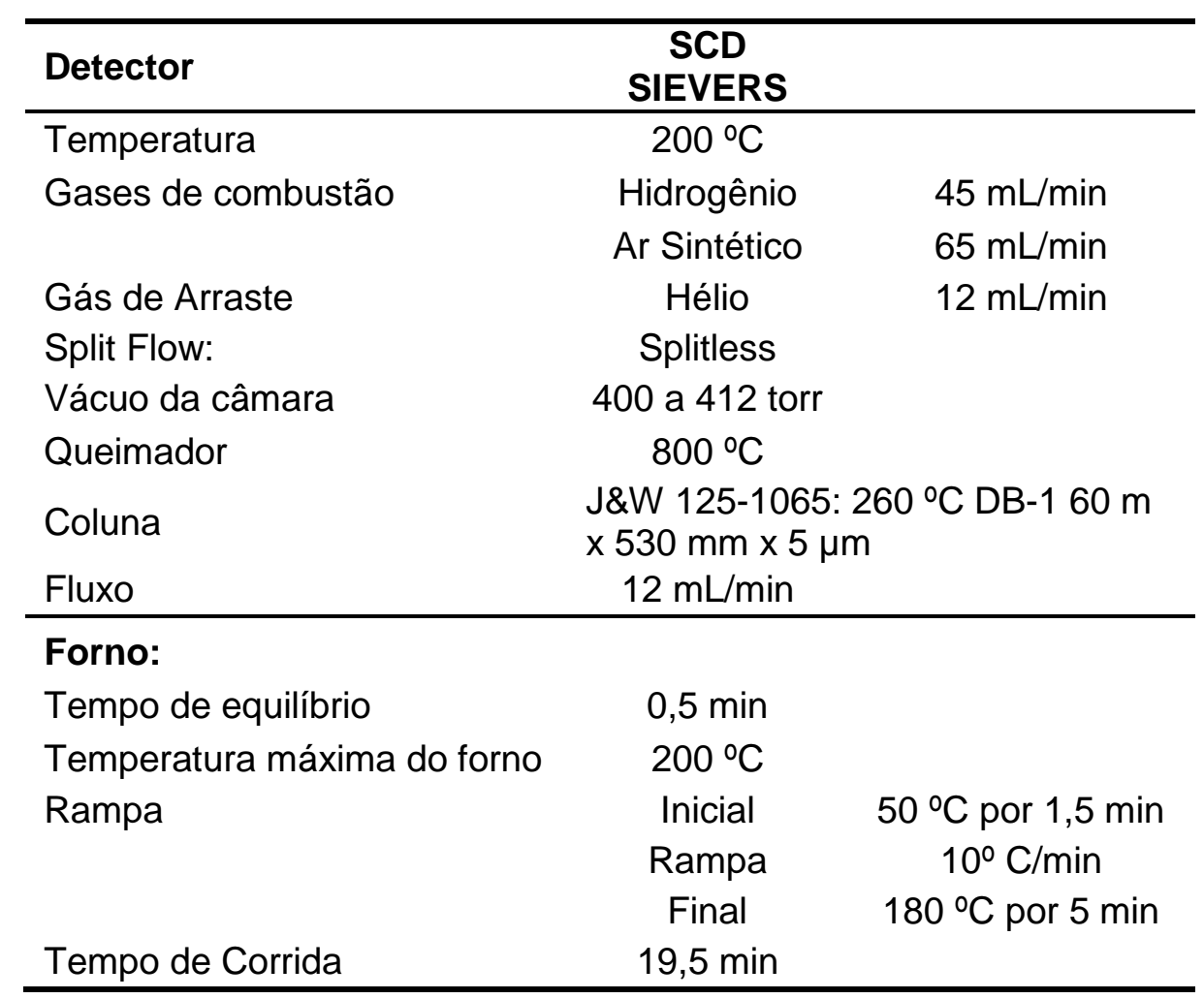

O cromatógrafo utilizado é da marca Agilent Technologies, modelo 7890A, módulo Dual Plasma e o detector é o SCD (Sulfur Chemiluminescence Detector), conforme ilustrado na Figura 4.10. 
Após serem eluídos, os compostos são transferidos para o SCD, que em excesso de ozônio presente na câmara reage com o enxofre liberando uma luz ultravioleta. O tubo fotomultiplicador é sensível à luz emitida e a amplifica por meio do software, apresentando o gráfico do cromatograma.

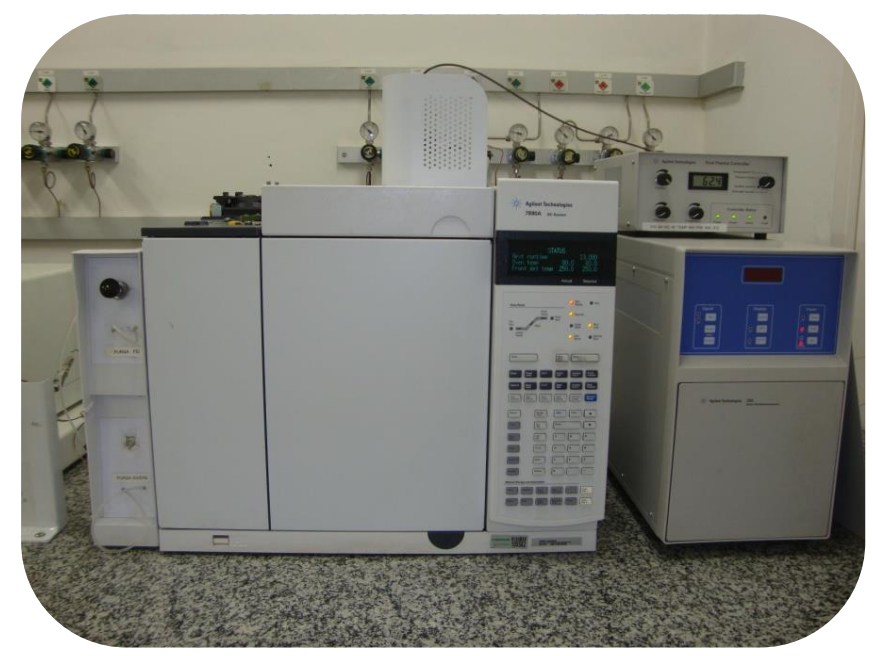

Figura 4.10 Cromatógrafo Gasoso Agilent - Modelo 7890A. Detector SCD e FID.

\subsubsection{Método Fluorescência}

A análise de concentração de enxofre total também foi obtida por uma técnica analítica instrumental no equipamento Multitek da marca Antek, na Figura 4.11, que se baseia na fluorescência de ultravioleta ou UVF (Ultra Violet Fluorescence). Nesse método, a amostra de gás entra em um tubo de pirólise com alta temperatura de combustão entre $1.050{ }^{\circ} \mathrm{C}$ a $1.100^{\circ} \mathrm{C}$. Dessa forma, os compostos de enxofre presentes na amostra reagem formando dióxido de enxofre e outros produtos da combustão, devido a uma atmosfera rica em oxigênio. Seguem parâmetros do método analítico na Tabela 4-14:

Tabela 4-14. Parâmetros da análise de enxofre total por Fluorescência.

\begin{tabular}{lcc}
\hline Detector: & Fluorescência UV & \\
\hline Controle de fluxo de gases & Ar Sintético/Hélio & $100 \mathrm{~mL} / \mathrm{min}$ \\
LLS Carrier & Oxigênio & $40 \mathrm{~mL} / \mathrm{min}$ \\
Carrier & Oxigênio & $25 \mathrm{~mL} / \mathrm{min}$ \\
Auxiliar & Hélio & $48 \mathrm{~mL} / \mathrm{min}$ \\
Forno & & $1050 \stackrel{\circ}{ }$ \\
\hline
\end{tabular}


A ASTM (American Society for Testing and Materials) padroniza a técnica de avaliação de compostos de enxofre voláteis em seu método ASTM D-6667-04 (2010).

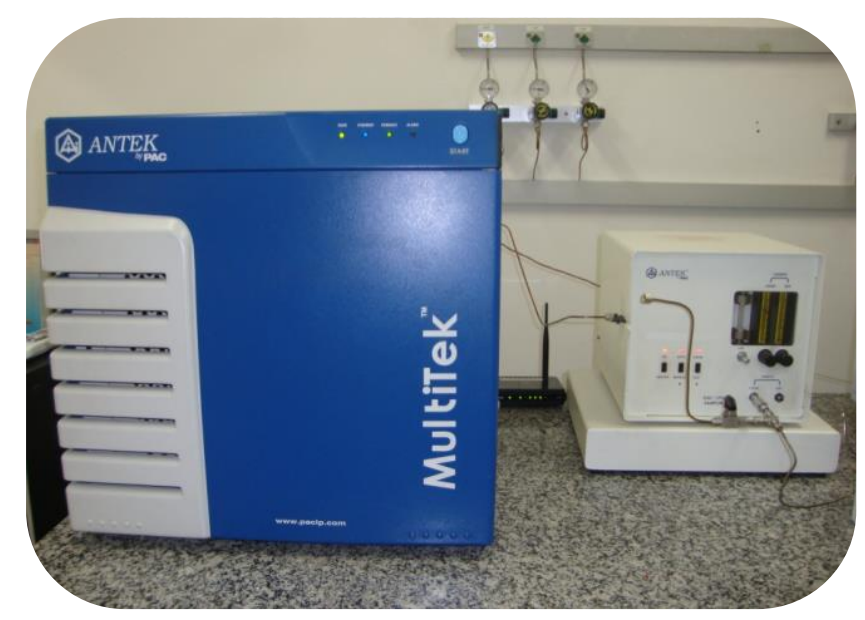

Figura 4.11. Analisador de Enxofre Total Antek

\subsubsection{Análise de umidade - Karl Fischer}

O método analítico Karl Fischer, na foto da Figura 4.12, por coulometria é utilizado para a determinação de água presente em uma amostra de Butano.

O princípio da determinação de umidade pelo método Karl Fischer é deduzido a partir da reação do $\mathrm{I}_{2}$ com a $\mathrm{H}_{2} \mathrm{O}$. O método consiste numa medição indireta a partir da corrente utilizada para produzir $\mathrm{I}_{2}$ no cátodo, que reage estequiometricamente com a água podendo medir sua quantidade em solução. O eletrodo duplo de platina é o responsável pela determinação do ponto final da reação.

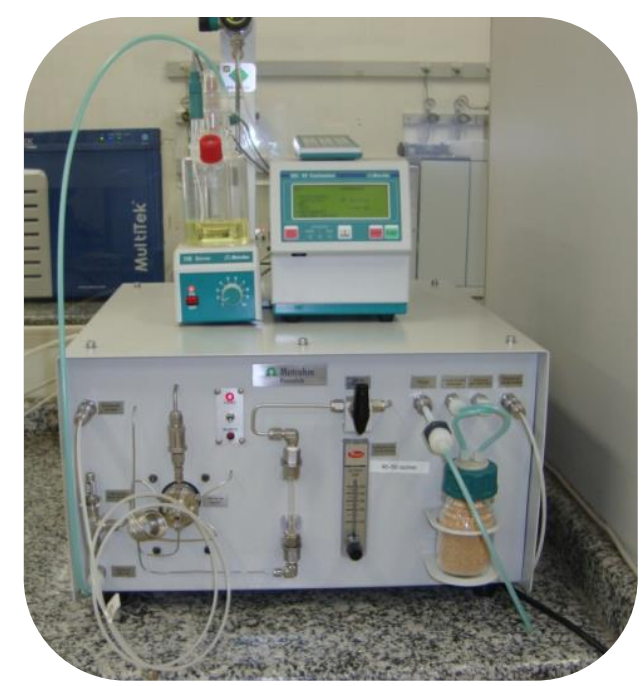

Figura 4.12. Analisador de Umidade Karl Fischer Metrohn. 


\subsubsection{Análise de hidrocarbonetos - Cromatografia a gás}

O procedimento consiste em injetar a amostra líquida em um cromatógrafo da Agilent Technologies, modelo 7890A, utilizando-se um detector FID (Flame Ionization Detector), que detecta os hidrocarbonetos que estão entre a faixa do metano até aqueles com até 6 carbonos na cadeia.

A norma atendida para essa análise é a ASTM D2163, e por isso alguns requisitos são seguidos conforme parâmetros a seguir na Tabela 4-15.

Tabela 4-15. Parâmetros para análise de hidrocarbonetos por cromatografia a gás.

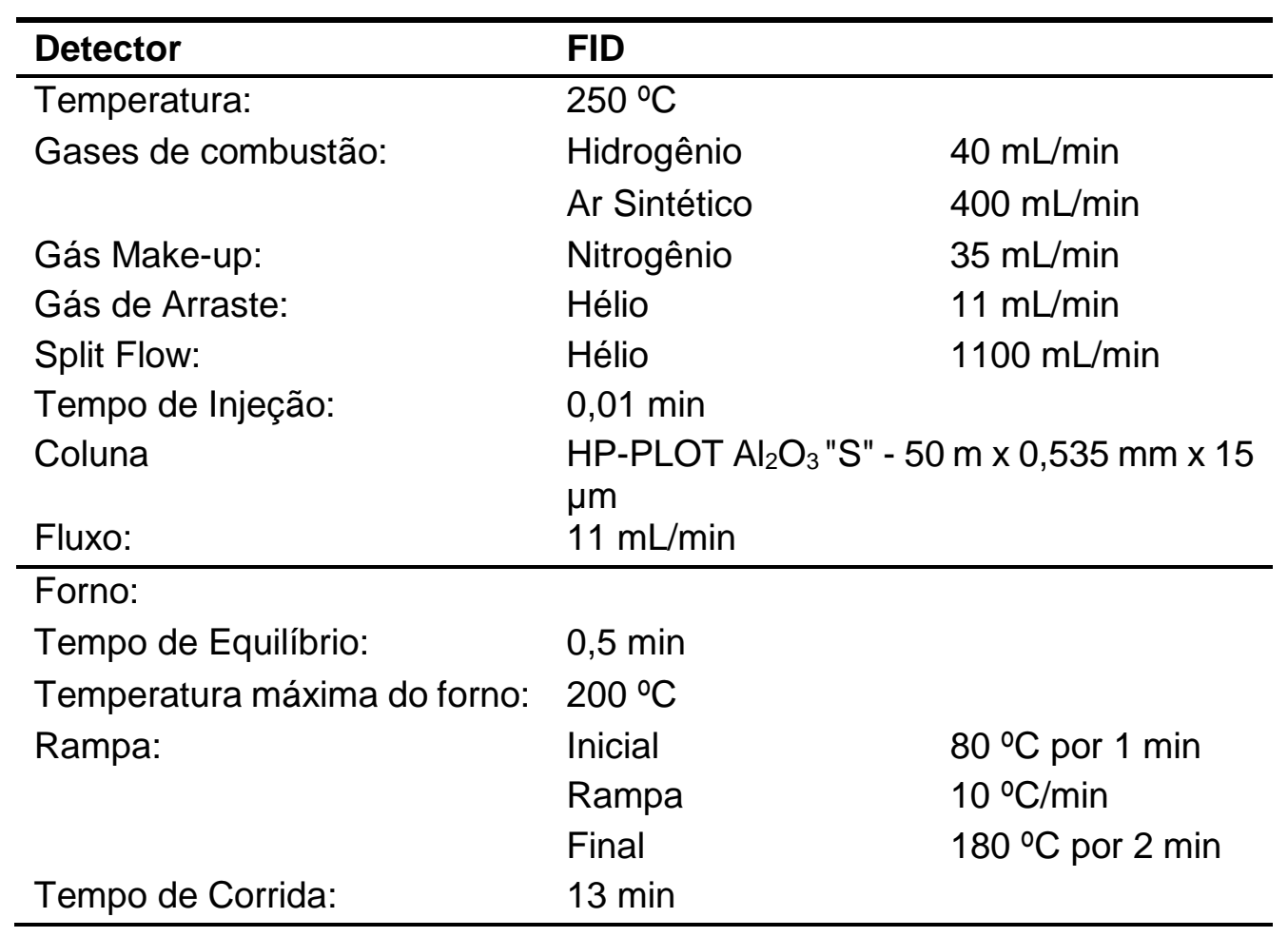




\section{MODELAGEM MATEMÁTICA}

A modelagem do processo de adsorção em leito fixo e o tratamento matemático das equações envolvidas são um campo de contínua evolução, pois os refinamentos dos métodos estão sendo acompanhados pela rapidez e capacidade das ferramentas computacionais. A operação de adsorção é complexa, pois envolve problemas difusionais, termodinâmicos e cinéticos em uma interface fluido/sólido que resultam em uma série de parâmetros e variáveis a serem estudadas.

O processo de adsorção de um soluto na superfície de um adsorvente pode ser decomposto em etapas elementares sucessivas. Cada uma destas etapas podendo controlar o fenômeno global dentro das condições dadas.

Considerando uma partícula de adsorvente porosa colocada no seio do fluído. A adsorção do soluto sobre o adsorvente segue as seguintes etapas (FOGLER, 2009):

i. Transferência de massa (difusão) dos solutos do interior da fase fluida para a superfície externa da partícula do adsorvente;

ii. Difusão do soluto a partir da entrada do poro para a vizinhança da superfície adsorvente interna;

iii. Adsorção do soluto na superfície adsorvente;

Diversos modelos, de maior ou menor complexidade, têm sido usados para prever o comportamento dinâmico de uma coluna de adsorção em leito fixo. A adsorção para um único componente é modelada com êxito por diversos trabalhos científicos como em Cerutti (2007), Gupta (2002) e Lutz (1990), utilizando o modelo agrupado de difusão nos poros. Deste modo, o modelo matemático fenomenológico proposto pretende obter uma aproximação do comportamento dinâmico da concentração de interesse em uma coluna de adsorção em leito fixo utilizando a mesma abordagem além de dados experimentais de equilíbrio entre o soluto e a zeólita. As equações apresentadas são preparadas para extensão a um sistema multicomponente.

A publicação de trabalhos considerando a modelagem multicomponente aplicada a processos industriais não é tão abundante quanto à monocomponente, mas é apresentada em Olafadehan; Susu (2004) e Siahpoosh et al (2009) com bons 
resultados para a validação do modelo. Seu comportamento difere significativamente dos sistemas com um único soluto e tem como principais dificuldades a maior robustez do software para simulação e a predição do equilíbrio de adsorção (RUTHVEN, 1982).

Quando se trata especificamente do estudo da dessulfurização de uma corrente líquida (butano) usando a zeólita 13X, foi encontrado somente o trabalho científico de Shams et al (2008). Entretanto, para o adsorvente carbono ativado encontrou-se estudos de modelagem como em Coelho (2009); Gomes (2010) e Weber (2005).

\subsection{Balanço de massa na fase fluida}

O modelo matemático pretende descrever a adsorção do adsorvato de um fluxo líquido ascendente em um leito fixo recheado com zeólitas tipo 13X, considerando: difusão axial e resistência global à transferência de massa externa.

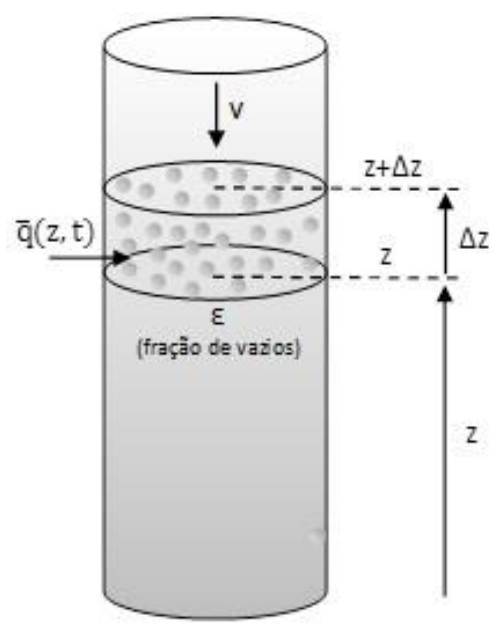

Figura 5.1. Volume de controle macroscópico. Coluna recheada com peneira molecular 13X.

As hipóteses adotadas para este sistema estão listadas abaixo:

a) Regime transiente;

b) Solução infinitamente diluída;

c) Condições isotérmicas;

d) Fluido incompressível, $\rho=$ constante;

e) Coeficientes de dispersão e transferência de massa externa e interna independentes da variação da composição da mistura; 
f) Porosidade do leito uniforme;

g) Fluxo unidimensional axial, ou seja, variação radial da velocidade do fluido no leito desprezível;

h) Partículas esféricas;

i) Tamanho e porosidade uniformes.

Então, aplicando-se o princípio de conservação de massa, o balanço diferencial de massa aplicado a cada componente do fluxo líquido na coluna (macrosistema), ilustrado na Figura 5.1 conduz às seguintes equações:

Taxa de massa entrando:

Taxa de massa saindo:

$$
\left[A_{L} N\right]_{Z}
$$

$$
\left[A_{L} N\right]_{z+\Delta z}
$$

Taxa de massa acumulada na fase líquida:

$$
\frac{\partial\left(V C_{i}\right)}{\partial t}=V \frac{\partial C_{i}}{\partial t}=\varepsilon_{b} A_{L} d z \frac{\partial C_{i}}{\partial t}
$$

Taxa de massa transferida para a fase sólida:

$$
\left(1-\varepsilon_{b}\right) \frac{\partial q_{i}}{\partial t}
$$

Considerando:

$$
\begin{aligned}
& A_{L}=\text { área da seção transversal do leito; }\left(\mathrm{m}^{2}\right) \\
& \mathrm{z}=\text { posição axial } \\
& \mathrm{L}=\text { comprimento da coluna, }(\mathrm{m}) \\
& \mathrm{V}=\text { volume da coluna: } \mathrm{Adz},\left(\mathrm{m}^{3}\right) \\
& \mathrm{N}=\text { fluxo mássico total da espécie química, }\left(\mathrm{kg} / \mathrm{m}^{2} . \mathrm{s}\right) \\
& \mathrm{t}=\text { tempo dimensional, }(\mathrm{s}) \\
& \varepsilon_{b}=\text { porosidade do leito, } \text { Volume }_{\text {vazios }} / \text { Volume }_{\text {total }}
\end{aligned}
$$


$C_{i}=$ Concentração do soluto na fase líquida externa ao poro, $\left(\mathrm{kg} / \mathrm{m}^{3}\right)$

$q_{i}=$ quantidade do soluto na fase líquida do sólido, $\left(\mathrm{kg} / \mathrm{m}^{3}\right)$

ENTRA - SAI = ACÚMULO + GERAÇÃO $/$ CONSUMO

$$
\left[A_{L} N\right]_{z}-\left[A_{L} N\right]_{z+\Delta z}=\varepsilon_{b} A_{L} d z \frac{\partial C_{i}}{\partial t}+\left(1-\varepsilon_{b}\right) A_{L} d z \frac{\partial q_{i}}{\partial t}
$$

Dividindo-se a equação por $A_{L} d z$ e pela porosidade do leito, $\varepsilon_{b}$, tem-se para o limite de $d z \rightarrow 0$, temos:

$$
\frac{\partial C_{i}}{\partial t}+\frac{\partial N}{\varepsilon_{b} \partial z}+\left(\frac{1-\varepsilon_{b}}{\varepsilon_{b}}\right) \frac{\partial q_{i}}{\partial t}=0
$$

Sabendo-se que o fluxo mássico total da espécie química, N, na direção z, leva em conta a contribuição convectiva e difusiva e a dispersão representada pelo coeficiente de dispersão axial no leito, $D\left\llcorner\left(\mathrm{~m}^{2} / \mathrm{s}\right)\right.$.

$$
N=v_{0} \frac{\partial C_{i}}{\partial z}-\varepsilon_{b} D_{L i} \frac{\partial^{2} C_{i}}{\partial z^{2}}
$$

Substituindo-se $\mathrm{N}$ na equação diferencial de conservação de massa na fase fluida para a espécie química:

$$
\frac{\partial C_{i}}{\partial t}+v \frac{\partial C_{i}}{\partial z}-D_{L i} \frac{\partial^{2} C_{i}}{\partial z^{2}}+\left(\frac{1-\varepsilon_{b}}{\varepsilon_{b}}\right) \frac{\partial q_{i}}{\partial t}=0 \quad\left(i=C_{3} H_{7} S H\right)
$$

Sendo que a velocidade superficial, $v_{0}(\mathrm{~m} / \mathrm{s})$, foi substituída pela velocidade intersticial, $v(\mathrm{~m} / \mathrm{s})$, conforme segue:

$$
v=\frac{v_{0}}{\varepsilon_{b}}
$$

O último termo da equação pode ser substituído pelo modelo Linear Driving Force (LDF) a fim de descrever a transferência de massa:

Esse modelo é frequentemente utilizado com sucesso para análise de colunas de adsorção como em Hansen (2015), porque é simples, analítico e fisicamente consistente (SIRCAR, 2000). Na aproximação por LDF, a transferência de massa é considerada a pequenas distâncias na camada limite ou filme adjacente à interface: 


$$
\frac{\partial q_{i}}{\partial t}=a_{p}\left(C_{i}-Y_{i}\right)_{R=R_{p}}=\frac{3 k_{f i}}{R_{p}}\left(C_{i}-\mathrm{Y}_{i}\right)_{R=R_{p}}
$$

Sendo:

$a_{p}=$ área interfacial das partículas, que é $3 / R_{p}$, para uma esfera, onde $\mathrm{R}_{\mathrm{p}}(\mathrm{m})$ é o raio equivalente da partícula, $\left(\mathrm{m}^{2}\right)$;

$\mathrm{kf}_{\mathrm{i}}=$ coeficiente global de transferência de massa, $(\mathrm{m} / \mathrm{s})$;

$Y_{i}=$ concentração do adsorvato na fase fluida no interior do poro da partícula sólida $\left(\mathrm{kg} / \mathrm{m}^{3}\right)$.

Aglutinando as equações, resulta a equação diferencial da fase fluida para a espécie química i:

$$
\frac{\partial C_{i}}{\partial t}+v \frac{\partial C_{i}}{\partial z}-D_{L i} \frac{\partial^{2} C_{i}}{\partial z^{2}}+\left(\frac{1-\varepsilon_{b}}{\varepsilon_{b}}\right) \frac{3 k_{f i}}{R_{p}}\left(C_{i}-Y_{i}\right)_{R=R_{p}}=0
$$

Para viabilizar a solução das equações diferenciais do modelo e, portanto, conhecer as distribuições, na posição e no tempo das concentrações da espécie adsorvida na coluna, torna-se necessário aplicar condições iniciais e de contorno. As condições de Danckwerts (1953), segundo Fogler (2009), aplicam-se nos casos em que não há dispersão fora do volume de controle, conforme ilustrado na Figura 5.2. Entretanto, em $0<z<L$, temos dispersão e adsorção.

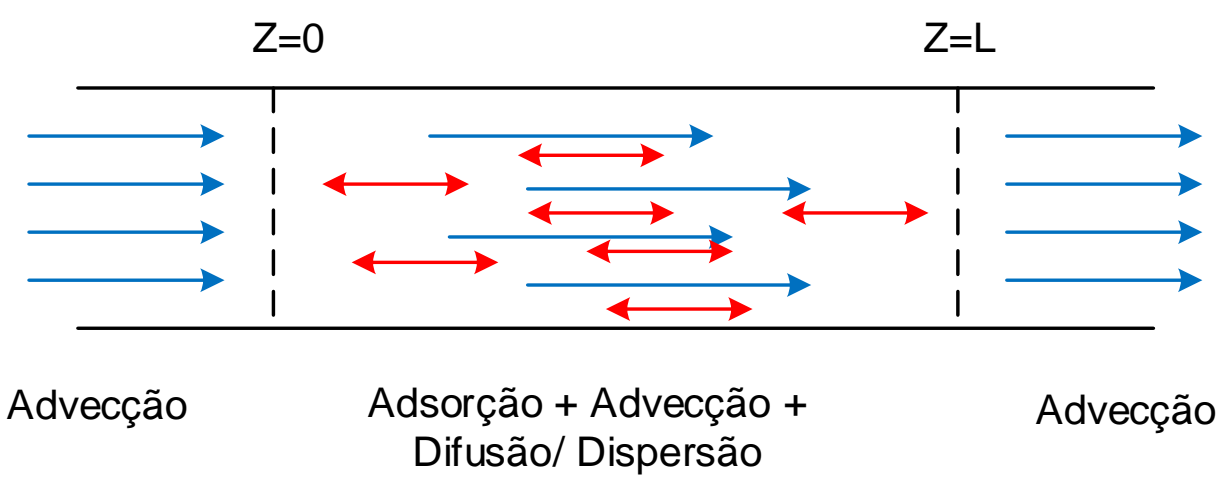

Figura 5.2. llustração das condições de contorno de Danckwerts.

A correspondente condição de contorno na entrada da coluna é (FOGLER, 2009):

$$
C_{i}=0(i=1,2) ; t \leq 0, \quad 0 \leq z \leq L
$$




$$
D_{L i} \frac{\partial C_{i}}{\partial z}=v\left(C_{i}-C_{i}^{0}\right)(i=1,2) ; t>0, z=0
$$

Em que $C_{i}^{0}$ indica a condição de alimentação da coluna para z $=0$.

$$
\frac{\partial C_{i}}{\partial z}=0(i=1,2) ; t>0, z=L
$$

A condição de derivada nula na saída equivale a gradiente de concentração nulo na saída do volume de controle, $z=L$. Sendo, L o comprimento total do leito.

\subsection{Balanço de massa na fase sólida}

O balanço de massa da fase fluida no interior do adsorvente, volume de controle ilustrado na Figura 5.3 é obtido através do conceito de conservação de massa, seguindo as hipóteses listadas na sequência.

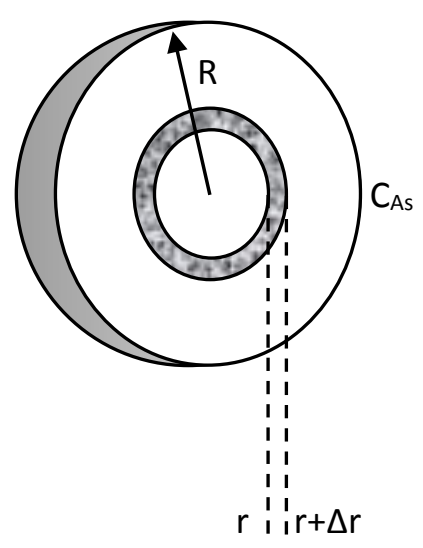

Figura 5.3. Volume de controle da partícula de adsorvente.

Hipóteses:

a) Condições isotérmicas;

b) Fluido incompressível, $\rho=$ constante;

c) Variação da velocidade do fluido no poro desprezível;

d) Sem reação química;

e) Tamanho uniforme e porosidade constante das partículas esféricas de adsorvente. 
Taxa de massa acumulada:

$$
\left(1-\varepsilon_{b}\right) A d z\left[\varepsilon_{p} \frac{\partial Y_{i}}{\partial t}+\left(1-\varepsilon_{p}\right) \rho_{p} \frac{\partial q_{i}^{*}}{\partial t}\right]
$$

Taxa de massa transferida:

$$
\operatorname{Adz}\left(1-\varepsilon_{b}\right) a_{p} k_{f i}\left(C_{i}-\mathrm{Y}_{i}\right)
$$

Igualando-se as equações, dividindo-se por $\operatorname{Adz}\left(1-\varepsilon_{b}\right)$ (volume da fase sólida no volume de controle) e tomando o limite para o volume tendendo a zero, tem-se a equação diferencial do balanço de massa para a fase fluida no interior da partícula adsorvente:

$$
\varepsilon_{p} \frac{\partial Y_{i}}{\partial t}+\left(1-\varepsilon_{p}\right) \rho_{p} \frac{\partial q_{i}^{*}}{\partial t}=a_{p} k_{f i}\left(C_{i}-Y_{i}\right)
$$

Sendo:

$\varepsilon_{p}=$ porosidade da partícula, Volume $_{\text {vazios }} /$ Volume $_{\text {total }}$

$Y_{i}=$ concentração do soluto na fase fluida no interior da partícula adsorvente $\left(\mathrm{kg} / \mathrm{m}^{3}\right)$

$q_{i}^{*}=$ quantidade de soluto adsorvido pela fase sólida ( $\mathrm{kg}$ do soluto/ $\mathrm{kg}$ adsorvente) de acordo com a isoterma de equilíbrio de adsorção

$\rho_{p}=$ massa específica do adsorvente ( $\mathrm{kg}$ do adsorvente $/ \mathrm{m}^{3}$ do adsorvente)

Podendo ser representado pelo modelo de isoterma selecionado, de acordo com a Equação:

$$
\frac{\partial q_{i}^{*}}{\partial t}=\frac{\partial f_{\text {isoterma }}\left(Y_{i}\right)}{\partial Y_{i}} \frac{\partial Y_{i}}{\partial t}
$$

A relação de equilíbrio, $f_{\text {isoterma }}\left(Y_{i}\right)$, poderá assumir qualquer forma de correlação experimental ou uma abordagem teórica mais preditiva. Nesse trabalho, utilizou-se o modelo proposto por Langmuir.

Condição inicial: 


$$
Y_{i}=0 ; t \leq 0, \quad 0 \leq z \leq L
$$

Para chegar a estas equações, que são chamadas de modelo generalizado para a partícula adsorvente, a dependência da concentração interna, $Y_{i}$, com o raio da partícula pode ser desprezada e a função $Y_{i}(r, t)$ é substituída pela concentração média $Y_{i}(t)$. (SANTACESARIA et al., 1982)

\subsection{Adimensionalização}

Para a adimensionalização das equações é necessária a definição dos parâmetros adimensionais (SCHEER, 2002), como segue:

- Concentração da fase fluida externa: $\bar{C}_{i}=C_{i} / C_{i}^{0}$

- Concentração da fase fluida interna na partícula: $\bar{Y}_{l}=Y_{i} / C_{i}^{0}$

- Para variável espacial: $\bar{z}=z / L$

- Variável temporal: $\tau=v t / L$

- Taxa de adsorção: $\bar{q}_{i}=q_{i}^{*} / q_{m i}$

- Número de Peclet: $P e_{L i}=v L / D_{L i}$

- $\lambda_{i}=3 k_{f i} L /\left(v_{0} R_{p}\right)$

- $\varphi_{i}=\rho_{p} q_{m i}\left(1-\varepsilon_{p}\right) / C_{i}^{0}$

Em que:

$\bar{C}_{i}=$ concentração adimensional do adsorvato i na fase fluida externa

$\bar{Y}_{l}=$ concentração adimensional do adsorvato i na fase fluida interna

$C_{i}^{0}=$ concentração de alimentação do adsorvato na coluna, $\left(\mathrm{kg} / \mathrm{m}^{3}\right)$

$\tau=$ tempo adimensional

$\bar{Z}=$ posição axial adimensional

$\bar{q}_{i}=$ quantidade adimensional adsorvida

$q_{m i}=$ quantidade máxima adsorvida do soluto no sólido 
Aplicando as variáveis adimensionais, as equações do modelo podem ser transformadas nas seguintes equações:

Balanço na fase fluida externa:

$$
\varepsilon_{b} \frac{\partial \bar{C}_{i}}{\partial \tau}+\frac{\partial \bar{C}_{i}}{\partial \bar{z}}-\frac{1}{\operatorname{Pe}} \frac{\partial^{2} \bar{C}_{i}}{\partial \bar{z}^{2}}+\lambda_{i}\left(1-\varepsilon_{b}\right)\left(\overline{C_{i}}-\overline{\mathrm{Y}}\right)=0
$$

Balanço na fase fluida interna:

$$
\varepsilon_{p} \frac{\partial \bar{Y}_{l}}{\partial \tau}-\varphi_{i} \frac{\partial \bar{q}_{i}}{\partial \tau}=\lambda_{i}\left(\bar{C}_{l}-\bar{Y}_{i}\right)
$$

As condições de contorno na forma adimensional são expressas por:

$$
\begin{gathered}
\frac{\partial \bar{C}_{l}}{\partial \bar{z}}=\operatorname{Pe}\left[\bar{C}_{l}-1\right] \rightarrow \bar{z}=0, \tau>0 \\
\frac{\partial \bar{C}_{l}}{\partial \bar{z}}=0 \rightarrow \bar{z}=1, \tau>0
\end{gathered}
$$

E as condições iniciais são expressas por:

$$
\begin{gathered}
\bar{C}_{l}(0, \bar{z})=C_{i}^{0}(\bar{z}) \rightarrow \tau=0, \quad \bar{z}>0 \\
\bar{Y}_{l}(0, \bar{z})=0 \rightarrow \tau=0, \quad \bar{z}>0
\end{gathered}
$$

\subsection{Solução numérica}

Um sistema tanto monocomponente quanto multicomponente é certamente enquadrado como um modelo não linear. Para este caso não há solução analítica. Assim, o modelo de equações deve ser solucionado numericamente.

A técnica numérica utilizada para solucionar o sistema de derivadas parciais do modelo foi diferenças finitas. 


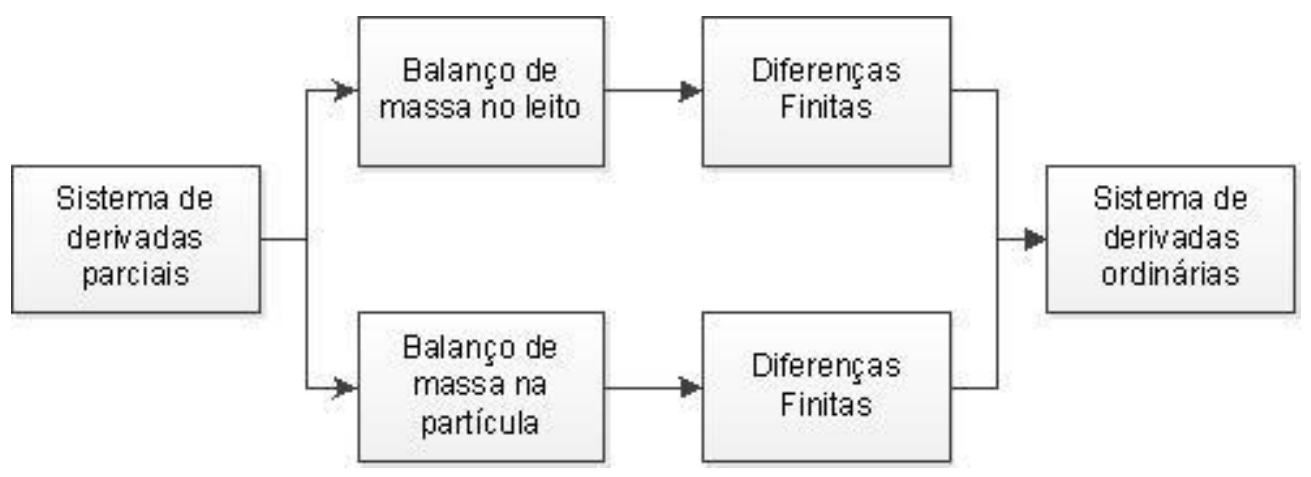

\subsubsection{Diferenças finitas}

O método das diferenças finitas (DF) é uma clássica aproximação para encontrar a solução numérica das equações que governam o modelo matemático de um sistema contínuo. Baseia-se na aproximação de derivadas por diferenças finitas, possibilitando transformar equações diferencias parciais em um sistema de equações diferenciais ordinárias, através de expansões de Taylor.

N o método de diferenças finitas, o domínio é dividido em Nz partes.

Logo, trabalhando as expansões de Taylor para a primeira derivada, temos:

Derivada downstream: $\left.\frac{d y}{d x}\right|_{x_{i}}=\frac{y_{i+1}-y_{i}}{\Delta x}$

Derivada upstream: $\left.\frac{d y}{d x}\right|_{x_{i}}=\frac{y_{i}-y_{i-1}}{\Delta x}$

Segunda derivada: $\left.\frac{d^{2} y}{d x^{2}}\right|_{x_{i}}=\frac{y_{i+1}-2 y_{i}+y_{i-1}}{\Delta x^{2}}$

Aplicando-se este conceito para os balanços de massa da fase fluida e da fase sólida, tem-se $\mathrm{Nz}$ pares de equações para Nc componentes diferentes representando cada ponto do domínio. Assim, o sistema torna-se o conjunto de EDOs a seguir:

Balanço de massa na fase fluida externa: 


$$
\begin{gathered}
\varepsilon_{b} \frac{\partial \bar{C}_{i, j}}{\partial \tau}+\frac{\bar{C}_{i+1, j}-\bar{C}_{i, j}}{\Delta \bar{z}}-\frac{1}{\mathrm{Pe}_{j}} \frac{\bar{C}_{i+1, j}-2 \bar{C}_{i, j}+\bar{C}_{i-1, j}}{\partial \bar{z}^{2}} \\
+\lambda_{i}\left(1-\varepsilon_{b}\right)\left(\bar{C}_{i, j}-\bar{Y}_{i, j}\right)=0
\end{gathered}
$$

Balanço de massa na fase fluida interna:

$$
\frac{\partial\left[\varepsilon_{p} \bar{Y}_{i, j}+\varphi_{j} \bar{q}_{i, j}\right]}{\partial \tau}=\lambda_{i}\left(\bar{C}_{i, j}-\bar{Y}_{i, j}\right)
$$

\subsection{Simulação computacional}

A partir do sistema de equações diferenciais ordinárias definido para os métodos numéricos, faz-se a conversão para a forma matricial, podendo assim ser processado pelo MATLAB®, mais especificamente o ODE15S, para solução de equações diferenciais do tipo stiff, numericamente instáveis, a menos que o tamanho do passo seja suficientemente pequeno (MATHEWS, 2004). A equação inclui alguns termos que podem levar a rápidas variações na solução, como o formato em "S" das curvas de ruptura.

O método ODE15S resolve um sistema de equações na forma ou problemas que envolvem matrix $M(t, y) y^{\prime}=f(t, y)$. (SHAMPINE; REICHELT; 1997). Como para um dado ponto do domínio $\bar{q}_{1}\left(I_{i}\right)$ é um vetor de Nc valores que representam cada componente e o cálculo de cada valor depende do vetor I, podemos usar $\frac{\partial\left[\varepsilon_{p} \bar{Y}_{j, k}+\varphi_{k} \bar{q}_{j, k}\right]}{\partial \tau}$ no formato: $\sum_{j=1}^{N_{c}} \frac{\partial\left[\varepsilon_{p} \bar{Y}_{j, k}+\varphi_{k} \bar{q}_{j, k}\right]}{\partial \bar{Y}_{j, k}} \frac{\partial \bar{Y}_{j, k}}{\partial \tau}$. Assim, seguem as matrizes:

$$
\left[\begin{array}{ccc}
\frac{\partial\left[\varepsilon_{p} \bar{Y}_{1}+\varphi_{1} \bar{q}_{1}\right]}{\partial \bar{Y}_{1}} & \cdots & \frac{\partial\left[\varepsilon_{p} \bar{Y}_{N c}+\varphi_{1} \bar{q}_{N c}\right]}{\partial \bar{Y}_{1}} \\
\vdots & \ddots & \vdots \\
\frac{\partial\left[\varepsilon_{p} \bar{Y}_{1}+\varphi_{1} \bar{q}_{1}\right]}{\partial \bar{Y}_{N c}} & \cdots & \frac{\partial\left[\varepsilon_{p} \bar{Y}_{N c}+\varphi_{1} \bar{q}_{N c}\right]}{\partial \bar{Y}_{1}}
\end{array}\right]\left[\begin{array}{c}
\frac{\partial \bar{Y}_{1}}{\partial \tau} \\
\vdots \\
\frac{\partial \bar{Y}_{N c}}{\partial \tau}
\end{array}\right]=J_{i}\left[\begin{array}{c}
\frac{\partial \bar{Y}_{1}}{\partial \tau} \\
\vdots \\
\frac{\partial \bar{Y}_{N c}}{\partial \tau}
\end{array}\right]
$$

Unindo então essa série de matrizes para cada ponto do domínio, com a matriz de massa da fase fluida externa temos, no caso do método das Diferenças Finitas, o seguinte sistema representando o sistema de EDOs no formato $M(t, y) y^{\prime}=f(t, y)$ : 


$$
\left[\begin{array}{ccccc}
\varepsilon_{b} & 0 & \ldots & 0 & 0 \\
0 & \ddots & 0 & 0 & 0 \\
\vdots & 0 & J_{1} & 0 & \vdots \\
0 & 0 & 0 & \ddots & 0 \\
0 & 0 & \ldots & 0 & J_{N Z}
\end{array}\right]\left[\begin{array}{c}
\frac{\partial \bar{C}_{1,1}}{\partial \tau} \\
\vdots \\
\frac{\partial \bar{C}_{N Z, 1}}{\partial \tau} \\
\frac{\partial \bar{C}_{1,2}}{\partial \tau} \\
\vdots \\
\frac{\partial \bar{C}_{N Z, N c}}{\partial \tau} \\
\frac{\partial \bar{Y}_{1,1}}{\partial \tau} \\
\vdots \\
\frac{\partial \bar{Y}_{1, N c}}{\partial \tau} \\
\frac{\partial \bar{Y}_{2,1}}{\partial \tau} \\
\vdots \\
\bar{y}_{2, N c} \\
\frac{\partial \tau}{\vdots} \\
\frac{\partial \bar{Y}_{N c, N z}}{\partial \tau}
\end{array}\right]=\left[\begin{array}{c}
F_{1,1}(\bar{C}, \bar{Y}) \\
\vdots \\
F_{N Z, N c}(\bar{C}, \bar{Y}) \\
\vdots \\
G_{1,1}(\bar{C}, \bar{Y}) \\
\vdots \\
G_{N Z, N c}(\bar{C}, \bar{Y})
\end{array}\right]
$$

Em que:

$$
\begin{gathered}
F_{i, j}(\bar{C}, \bar{Y})=\frac{1}{\mathrm{Pe}} \frac{\bar{C}_{i+1, j}-2 \bar{C}_{i, j}+\bar{C}_{i-1, j}}{\partial \bar{z}^{2}}-\frac{\bar{C}_{i+1, j}-\bar{C}_{i, j}}{\Delta \bar{Z}}-\lambda_{i}\left(1-\varepsilon_{b}\right)\left(\bar{C}_{i, j}-\bar{Y}_{i, j}\right. \\
G_{i, j}(\bar{C}, \bar{Y})=\left(\bar{C}_{i, j}-\bar{Y}_{i, j}\right)
\end{gathered}
$$

Retornando agora para a estrutura do programa em si, uma vez que o sistema foi completamente descrito, a implementação seguiu o padrão descrito abaixo:

- Definir as variáveis globais;

- Receber dados do sistema a ser simulado;

- Definir Nz e a extensão da simulação

- Calcular as variáveis dependentes e de adimensionalização;

- Preparar e executar a ODE15s 
- Processar e plotar os resultados

Segue descrição das principais funções utilizadas na simulação:

Entrada de dados: função genérica que fornece dados do sistema em estudo e parâmetros de processo.

Funções secundárias $M(\tau,[E ; I]), F(\tau,[E ; I]), G(\tau,[E ; I])$ e Isoterma(I): tratam-se das funções, cujos cálculos estão descritos nos itens e organizam os resultados no formato matricial.

Função jacobiano $J(I)$, calcula o jacobiano usando o método de derivação numérica chamado extrapolação de Richardson (LAZO, 1999).

\subsection{Coeficientes de transporte}

Analisando-se os termos das equações do modelo matemático, foram considerados o coeficiente global de transferência de massa interfase e a dispersão axial. Apresentam-se, a seguir, as principais correlações para o cálculo destes parâmetros.

\section{Coeficiente de dispersão axial}

Quando um líquido flui através do leito há uma tendência de haver dispersão axial, o que reduz a eficiência de separação. Assim, minimizar a dispersão axial é o objetivo nos casos de projeto do processo de adsorção.

O coeficiente de dispersão axial concentra os mecanismos de mistura axial, de modo que considera não somente a difusão molecular, como os efeitos de convecção e também de uniformidades na velocidade do fluido através da coluna. (RUTHVEN,1984).

O limite mínimo do coeficiente de dispersão axial pode ser estimado pelas correlações encontradas em Ruthven (1984) e Perry (1999), conforme equações (57) e (60):

$$
\frac{D_{L i}}{D_{p i}}=\gamma_{1}+\gamma_{2} \frac{\operatorname{Re} S c}{\varepsilon_{b}}
$$




$$
\begin{gathered}
\gamma_{1}=0,45+0,55 \varepsilon_{b} \\
\gamma_{2}=0,5\left(1+\frac{13 \gamma_{1} \varepsilon_{b}}{\operatorname{Re} S c}\right)^{-1}
\end{gathered}
$$

Sendo:

$D_{L i}=$ Coeficiente de dispersão axial do componente $\mathrm{i},\left(\mathrm{m}^{2} / \mathrm{s}\right)$

$D_{p i}=$ Difusão molecular do componente $\mathrm{i},\left(\mathrm{m}^{2} / \mathrm{s}\right)$

$\varepsilon_{b}=$ Porosidade do leito

$R e=$ Número de Reynolds

$S c=$ Número de Schmidt

$\gamma_{1}=$ constante do modelo calculada na equação 58

$\gamma_{2}=$ constante do modelo calculada na equação 59

Cerutti (2007) utiliza a correlação de Butt (1980), válida para líquidos em leito empacotado, e obtém bons resultados na simulação de seu modelo matemático proposto. Seguem equações (60) e (61) a partir do número adimensional de Peclet da partícula e do número de Reynolds.

$$
\begin{aligned}
& \qquad D_{L i}=\frac{v_{o} d_{p}}{P e_{p}} \\
& \qquad P e_{p} \varepsilon_{b}=0,2+0,11 R e^{0,48} \\
& v_{o}=\text { velocidade superficial do fluido, }(\mathrm{m} / \mathrm{s}) \\
& d_{p}=\text { diâmetro equivalente da partícula de adsorvente, (m) } \\
& P e_{p}=\text { Número de Peclet da partícula }
\end{aligned}
$$$$
d_{p}=\text { diâmetro equivalente da partícula de adsorvente, }(\mathrm{m})
$$ 


\section{Coeficiente de transferência de massa externa}

As curvas de ruptura são dominadas, nas baixas concentrações do soluto, pela difusão do filme externo e nas altas concentrações, pela difusão na partícula, e com um coeficiente global de transferência de massa, $k_{f}(\mathrm{~m} / \mathrm{s})$, esses efeitos estão interligados. (SHEER, 2002).

A resistência à transferência de massa externa, $k_{e}(\mathrm{~m} / \mathrm{s})$, é um parâmetro afetado pelas condições hidrodinâmicas do fluxo podendo ser descritas pelo número adimensional de Sherwood (Sh). Das diversas correlações existentes na literatura para se obter o número de Sherwood em função dos números de Reynolds $(R e)$ e Schmidt (Sc), é apresentada a correlação de Perry (1999) considerada para a fase líquida, com $\rho$ sendo a massa específica do fluido $\left(\mathrm{kg} / \mathrm{m}^{3}\right)$

$$
\begin{gathered}
S c=\frac{\mu}{\rho D_{p}} \\
R e_{p}=\frac{\rho v_{o} d_{p}}{\mu} \\
S h=\frac{1,09}{\varepsilon_{b}} R e_{p}{ }^{0,33} S c^{0,33}
\end{gathered}
$$

Sendo $0,0015<\operatorname{Re}<55$ e $165<$ Sc $<70600$

$$
k_{e}=\frac{S h D_{p}}{2 R_{p}}
$$

Outra correlação, pesquisada em Geankopolis (1966), para o cálculo do coeficiente de transferência de massa externo é apresentada na equação (66) para o número de Sherwood.

$$
S h=\frac{1}{\varepsilon_{b}}\left(\frac{0,765}{R e_{p}^{0,82}}+\frac{0,365}{R e_{p}^{0,386}}\right) R e_{p} S c^{0,33}
$$

Sendo $0,01<\operatorname{Re}<15000$. 
Para determinação do coeficiente de transferência de massa interno, $k_{i}(\mathrm{~m} / \mathrm{s})$, utilizouse o modelo proposto por Glueckauf (1955), conforme equação (67).

$$
k_{i}=\frac{10 D_{p}}{\tau_{p} d_{p}}
$$

O coeficiente global de transferência de massa, $k_{f}(\mathrm{~m} / \mathrm{s})$, é obtido da expressão (68) que considera as resistências à transferência de massa externa $k_{e}(\mathrm{~m} / \mathrm{s})$ e interna à partícula $k_{i}(\mathrm{~m} / \mathrm{s})$ dispostas em série. (PERRY, 1999).

$$
\frac{1}{k_{f}}=\frac{1}{k_{e}}+\frac{1}{k_{i} \varepsilon_{b}}
$$

\section{Difusividade no líquido}

Para soluções diluídas em solventes orgânicos, Lusis e Ratcliff (1968) apresentam a seguinte correlação:

$$
\frac{D_{P i} \mu}{T}=\frac{8,52 \times 10^{-8}}{V_{b_{m}}^{1 / 3}}\left[1,40\left(\frac{V_{b_{m}}}{V_{b_{A}}}\right)^{1 / 3}+\left(\frac{V_{b_{m}}}{V_{b_{A}}}\right)\right]
$$

Sendo:

$D_{P i}=$ Difusividade molecular, $\left(\mathrm{m}^{2} / \mathrm{s}\right)$

$\mu=$ viscosidade do fluido, $(\mathrm{kg} / \mathrm{ms})$

$\mathrm{T}=$ Temperatura, $\left({ }^{\circ} \mathrm{C}\right)$

$V_{b_{A}}=$ volume molecular do soluto, $\left(\mathrm{m}^{3} / \mathrm{kmol}\right)$

$V_{b_{m}}=$ volume molecular do solvente, $\left(\mathrm{m}^{3} / \mathrm{kmol}\right)$

Outra correlação é descrita por Wilke e Chang em Suzuki (1990) para difusão em líquidos, sendo a representação para solução diluída mostrada na equação (68):

$$
\frac{D_{P i} \mu}{T}=7,4 \times 10^{-8}\left(\lambda M_{B}\right)^{1 / 2} V_{b A}^{0,6}
$$


Considerando:

$\lambda=$ razão entre os raios do soluto $\left(r_{m}\right)$ e do poro $\left(r_{p}\right), \lambda=r_{m} / r_{p}$

$M_{B}=$ massa molecular do solvente, $(\mathrm{kg} / \mathrm{kmol})$

Segundo Perry (1999), $r_{m}$ é o raio de Stokes-Einstein do soluto que pode ser determinado pela equação

$$
r_{m}=\frac{k_{b} T}{6 \pi \mu D_{p i}}
$$

Sendo, $k_{b}\left(\mathrm{~m}^{2} \mathrm{~kg} / \mathrm{s}^{2} \mathrm{~K}\right)$ a constante de Boltzman com valor de 1,38E-23.

Quando o transporte do fluido através de uma rede de poros dentro da partícula fornece acesso para os sítios ativos, o fluxo difusivo pode ser expresso em termos do coeficiente de difusão efetivo no poro $\left(D_{e}\right)$. Esse coeficiente é menor que a difusividade molecular do soluto na mistura $D_{p}$ na medida em que os poros são distribuídos de maneira randômica e possuem variações em seu diâmetro. Esses efeitos são retratados pela tortuosidade $\tau_{p}$.

A princípio, a tortuosidade pode ser estimada se a estrutura, tamanho e distribuição do poro são conhecidas. Entretanto, segundo Perry (1999), a previsão dos valores obtidos pelas equações (72), (73) e (74) é incerta e apresenta diferentes resultados, embora todas mantenham a relação de aumento da tortuosidade com a diminuição da porosidade. É recomendado, portanto, que este dado seja obtido experimentalmente para o adsorvente em estudo.

As seguintes equações são recomendadas para o cálculo da tortuosidade:

Mackie e Meares, 1955

$$
\tau_{p}=\frac{\left(2-\varepsilon_{p}\right)^{2}}{\varepsilon_{p}}
$$

Wakao e Smith, 1962. 


$$
\tau_{p}=\frac{1}{\varepsilon_{p}}
$$

Suzuki e Smith, 1972

$$
\tau_{p}=\varepsilon_{p}+1,5\left(1-\varepsilon_{p}\right)
$$

Assim, para o coeficiente de difusão efetivo, tem-se a equação (PERRY, 1999):

$$
D_{e i}=\left(\varepsilon_{p} / \tau_{p}^{2}\right) D_{p i}
$$

Para difusão em fase líquida para grandes moléculas de adsorvato, quando a razão é maior que zero. Quando $\lambda<0,2$, a expressão derivada por Brenner e Gaydos (1977) pode ser encontrada em Perry (1999), para uma partícula esférica difundindo em um poro cilíndrico pode ser usada:

$$
D_{e i}=\frac{D_{p i}}{\tau_{p}}(1-\lambda)^{-2}\left[1+\frac{9}{8} \lambda \ln \lambda-1.539 \lambda\right]
$$

Os valores dos parâmetros de transporte de massa, juntamente com a indicação das equações utilizadas, estão sumarizados na Tabela 5-1.

A tarefa de encontrar os parâmetros de transporte que mais se ajustassem às equações do modelo matemático considerado, de maneira a obter sua simulação mais próxima dos dados experimentais, foi um tanto complexa. Isso, porque como pode ser notado pela descrição desta seção, existem diversas correlações na literatura para o cálculo dos coeficientes de transporte. Só para tortuosidade são três, com a diferença entre os resultados obtidos usando cada uma destas 3 equações chegando até $100 \%$. Assim, são diversas combinações que podem levar a divergência de até 30 vezes entre os valores obtidos para a dispersão axial, por exemplo, como apresentado na Tabela 5-1. Ainda assim, os números encontrados não se encaixaram muito bem na simulação do modelo matemático. Então, optou-se por encontrar uma correlação empírica através da simulação dos dados experimentais, cujos valores encontrados também estão na Tabela 5-1. 
Tabela 5-1. Parâmetros de transporte teóricos para os experimentos em escala laboratorial e piloto.

\begin{tabular}{|c|c|c|}
\hline \multicolumn{3}{|c|}{ ESCALA LABORATORIAL } \\
\hline Parâmetros de transporte & $\begin{array}{c}\text { Teórico } \\
\left.\text { (Equação }{ }^{1}\right)\end{array}$ & $\begin{array}{c}\text { Teórico } \\
\text { (Equação') }\end{array}$ \\
\hline Difusividade da partícula, $D_{p},\left(m^{2} / s\right)$ & 7,07E-09 (69) & $8,75 \mathrm{E}-09(70)$ \\
\hline Difusividade efetiva, $D_{e},\left(m^{2} / s\right)$ & $\begin{array}{c}2,46 \mathrm{E}-09(72), \\
(75)\end{array}$ & $\begin{array}{c}6,90 \mathrm{E}-09(74), \\
(76)\end{array}$ \\
\hline Dispersão axial, $D_{\llcorner}\left(\mathrm{m}^{2} / \mathrm{s}\right)$ & 1,37E-05 (57) & $4,22 \mathrm{E}-06(60)$ \\
\hline Coeficiente de transf. de massa externo, $\mathrm{k}_{\mathrm{e}}(\mathrm{m} / \mathrm{s})$ & $\begin{array}{l}9,81 \mathrm{E}-05(64), \\
(65)\end{array}$ & $\begin{array}{c}1,28 \mathrm{E}-04(66), \\
(65)\end{array}$ \\
\hline Coeficiente de transf. de massa interno, $\mathrm{k}_{\mathrm{i}}(\mathrm{m} / \mathrm{s})$ & $2,16 \mathrm{E}-05$ (67) & $9,90 \mathrm{E}-06(67)$ \\
\hline Coeficiente de transf. de massa global, $\mathrm{k}_{\mathrm{f}}(\mathrm{m} / \mathrm{s})$ & $1,26 \mathrm{E}-05(68)$ & $6,30 \mathrm{E}-06(68)$ \\
\hline \multicolumn{3}{|c|}{ ESCALA PILOTO } \\
\hline de transporte & $\begin{array}{c}\text { Teórico } \\
\text { (Equações }^{1} \text { ) }\end{array}$ & $\begin{array}{c}\text { Teórico } \\
\left.\text { (Equações }^{1}\right) \\
\end{array}$ \\
\hline Difusividade da partícula, $\mathrm{D}_{\mathrm{p}},\left(\mathrm{m}^{2} / \mathrm{s}\right)$ & 7,07E-09 (69) & $8,75 \mathrm{E}-09(70)$ \\
\hline Difusividade efetiva, $D_{e},\left(m^{2} / s\right)$ & $\begin{array}{c}2,46 \mathrm{E}-09(72), \\
(75)\end{array}$ & $\begin{array}{c}\text { 6,90E-09 (74), } \\
(76)\end{array}$ \\
\hline Dispersão axial, $D_{L}$ (m²/s) & 2,04E-05 (57) & $5,43 E-06(60)$ \\
\hline Coeficiente de transf. de massa externo, $\mathrm{k}_{\mathrm{e}}(\mathrm{m} / \mathrm{s})$ & $\begin{array}{l}1,85 \mathrm{E}-04(64) \\
(65)\end{array}$ & $\begin{array}{c}2,38 \mathrm{E}-04(66), \\
(65)\end{array}$ \\
\hline Coeficiente de transf. de massa interno, $\mathrm{k}_{\mathrm{i}}(\mathrm{m} / \mathrm{s})$ & $2,16 \mathrm{E}-05(67)$ & $9,90 \mathrm{e}-06(67)$ \\
\hline Coeficiente de transf. de massa global, $\mathrm{k}_{\mathrm{f}}(\mathrm{m} / \mathrm{s})$ & 1,69E-05 (68) & $1,72 \mathrm{E}-05(68)$ \\
\hline
\end{tabular}

1. Os números entre parênteses () referenciam as equações utilizadas para a obtenção dos valores apresentados. 


\section{RESULTADOS E DISCUSSÃO}

Neste capítulo são apresentados os resultados dos experimentos exploratórios e simulação, a saber: isotermas de adsorção (escala laboratório), curvas de ruptura obtidas através da operação da coluna de leito fixo em escala laboratorial e piloto, curvas de ruptura das colunas industriais e simulação do modelo matemático proposto para as colunas em escala laboratorial e piloto.

\subsection{Isotermas de equilíbrio de adsorção}

As isotermas de equilíbrio foram obtidas a partir dos experimentos realizados para a terc-butil-mercaptana, etil-mercaptana e n-propil-mercaptana em butano líquido, utilizando peneira molecular 13X, conforme procedimento descrito no item 4.4.3.

Dentre as dificuldades encontradas nos experimentos, destaca-se a variação do tempo para atingir o equilíbrio, que levou até 72 horas, dependendo da massa de peneira utilizada e da concentração de enxofre inicial utilizada. A baixa concentração de enxofre e a baixa difusividade para sistemas em fase líquida foram algumas das razões que contribuíram para isto.

A princípio, como não havia uma referência da capacidade de adsorção especificamente para o sistema estudado (compostos de enxofre em butano líquido pressurizado), esperava-se capacidades de adsorção próximas a 15\% em massa, considerando a folha de dados do fabricante da zeólita 13X (AXENS IFP GROUP TECHNOLOGIES) para remoção de umidade e de $\mathrm{H}_{2} \mathrm{~S}$ em sistemas gasosos, conforme Figura 6.1. 


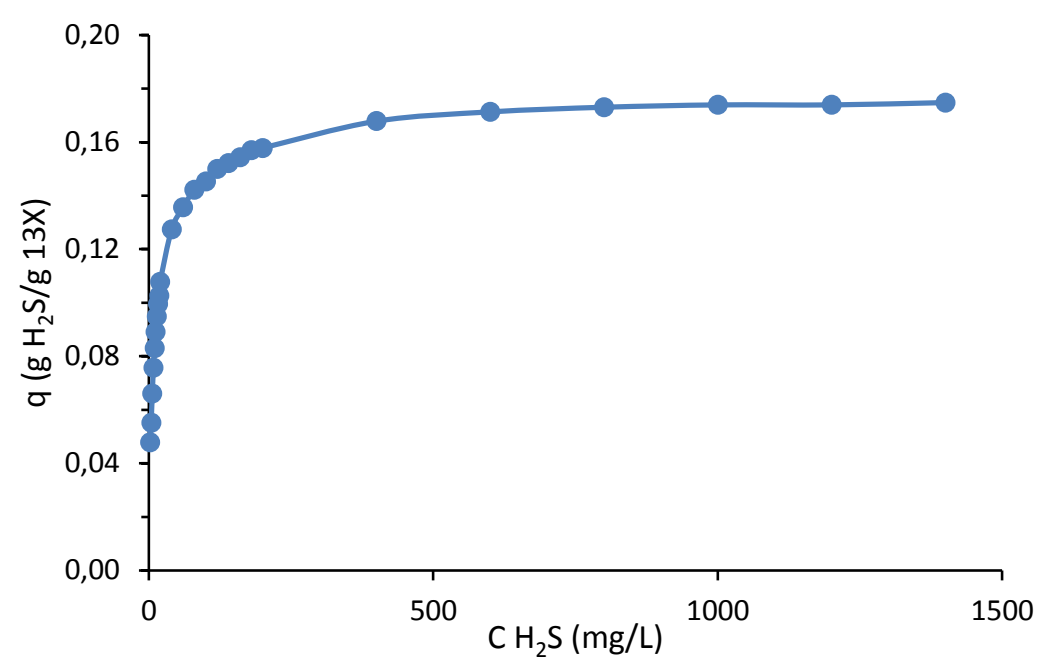

Figura 6.1. Gráfico da isoterma de equilíbrio de $\mathrm{H}_{2} \mathrm{~S}$ em usando peneira molecular 13X. (AXENS, 1990)

De acordo com Monfort et al (2005), a capacidade de adsorção de um sistema de leito fixo para remoção de enxofre e umidade de butano líquido giraria em torno de $10 \%$ a $15 \%$ em massa.

Outro estudo de sistema semelhante (dessulfurização de gás natural) consultado foi o de Souza (2002) em que foram testados vários materiais adsorventes e o que apresentou melhor desempenho para remoção de $\mathrm{H}_{2} \mathrm{~S}$ foi a peneira molecular $13 \mathrm{X}$ com capacidade máxima de adsorção de $0,053 \mathrm{~kg} \mathrm{H} 2 \mathrm{~S} / \mathrm{kg}$ peneira a $25 \stackrel{\circ}{ } \mathrm{C}$.

Contudo, a capacidade máxima de adsorção encontrada para as diferentes moléculas de enxofre ensaiadas é inferior aos valores mencionados, como pode ser visto na Tabela 6-1.

Para a faixa de medição considerada, o perfil da isoterma obtida experimentalmente apresenta-se como favorável e encaixou-se com boa aproximação no modelo proposto por Langmuir, conforme pode ser observado na Figura 6.2, Figura 6.3 e Figura 6.4 .

Para obter a curva ajustada ao modelo de Langmuir a partir dos pontos experimentais, utilizou-se o método dos mínimos quadrados, equação (77), admitindo-se o menor erro residual possível entre o ponto experimental e o ponto teórico ao variar $\mathrm{K}$ e qm usando a função "solver" do Excel ${ }^{\circledR}$. 


$$
r=\frac{1}{u} \sum_{i=1}^{n} \sqrt{\left(\mathrm{q}(\mathrm{C})-q_{\text {expe }}\right)^{2}}
$$

Sendo:

$r=$ residual

$q_{\text {exp }}=$ capacidade de adsorção experimental ( $\mathrm{kg}$ adsorvato $/ \mathrm{kg}$ peneira $)$

$q(C)$ = capacidade de adsorção teórica ( $\mathrm{kg}$ adsorvato/kg peneira)

$\mathrm{u}=$ número de pontos experimentais

Tabela 6-1. Parâmetros para as isotermas de equilíbrio a $25^{\circ} \mathrm{C}$ do tipo I, Langmuir a partir de dados experimentais.

\begin{tabular}{lccc}
\hline Composto de enxofre & $\mathbf{K}\left(\mathbf{m}^{\mathbf{3}} / \mathbf{k g}\right)$ & $\mathbf{q}(\mathbf{k g S} / \mathbf{k g}$ pen) & Residual $(\%)$ \\
\hline Tercbutil mercaptana & 39,01 & 0,008 & 0,01 \\
N-propil-mercaptana & 57,65 & 0,0247 & 0,06 \\
Etil-mercaptana & 110,66 & 0,0264 & 0,04 \\
\hline
\end{tabular}

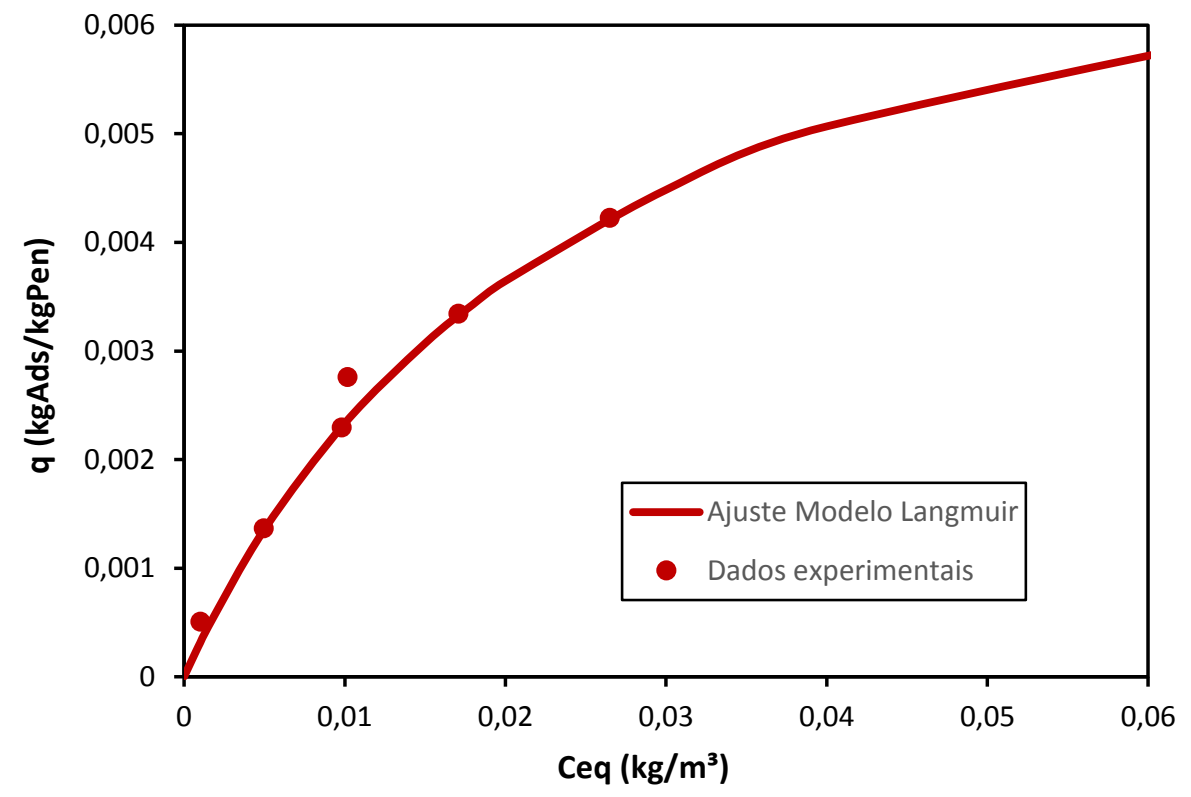

Figura 6.2. Isoterma de equilíbrio a $25^{\circ} \mathrm{C}$ obtida experimentalmente para tercbutil-mercaptana em butano em zeólita 13X como adsorvente. 


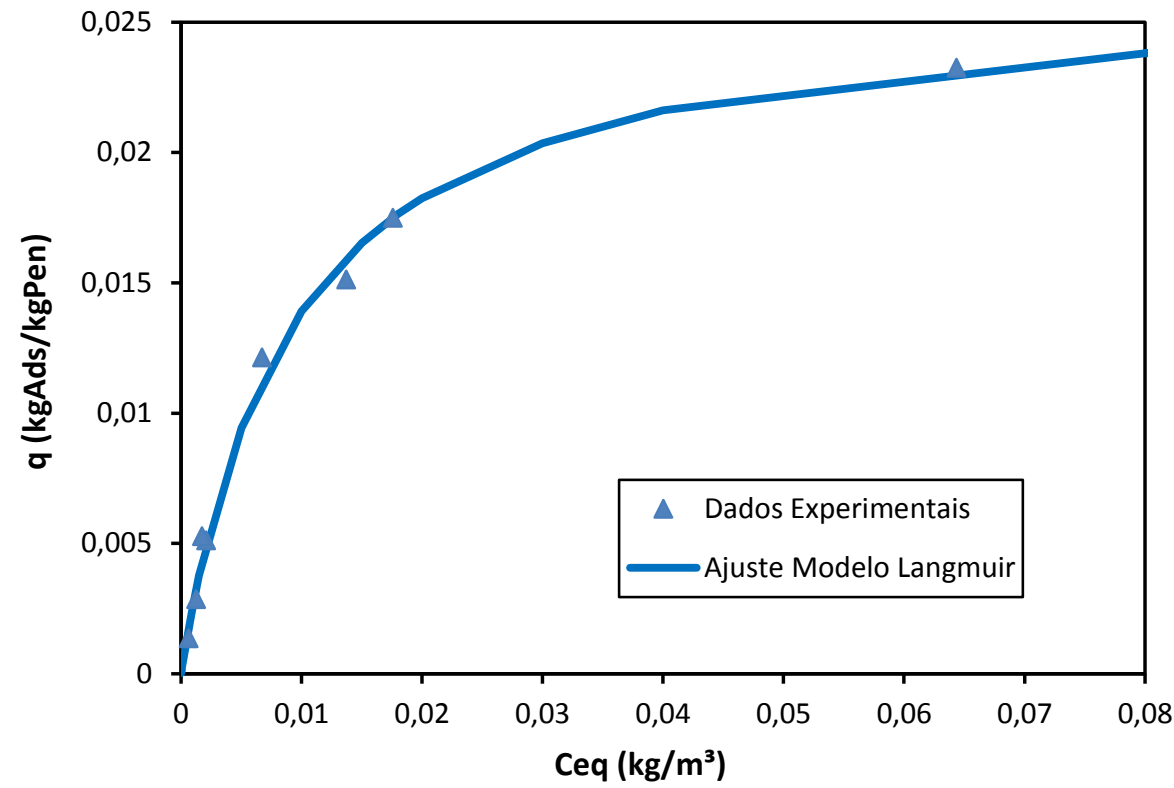

Figura 6.3. Isoterma de equilíbrio a $25^{\circ} \mathrm{C}$ obtida experimentalmente para etil-mercaptana em butano em zeólita 13X como adsorvente.

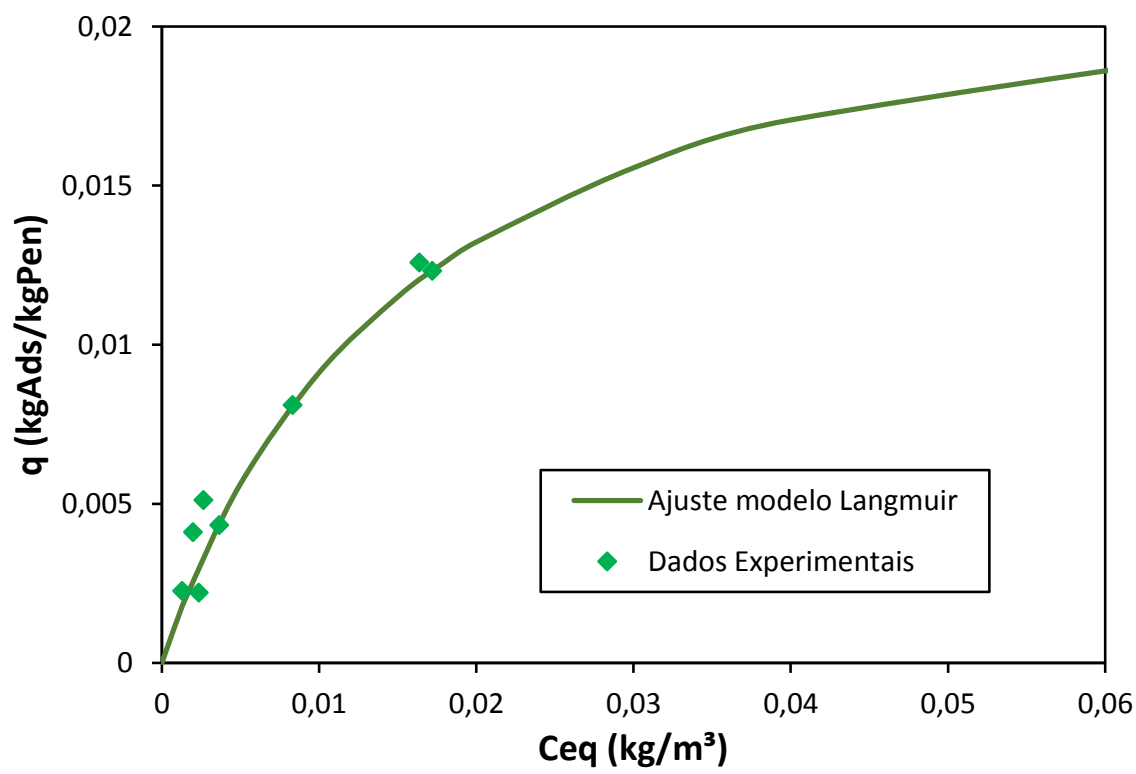

Figura 6.4. Isoterma de equilíbrio a $25 \stackrel{\circ}{ } \mathrm{C}$ obtida experimentalmente para $n$-propil-mercaptana em butano em zeólita $13 \mathrm{X}$ como adsorvente.

Considerando que o processo industrial é multicomponente, é de interesse comparar as isotermas obtidas individualmente para os diferentes tipos de molécula da família das mercaptanas, conforme demonstrado na Figura 6.5. Entretanto, a análise do sistema multicomponente torna-se complexa, na medida em que se considera que há possibilidade de haver competição entre os diferentes compostos de enxofre. 


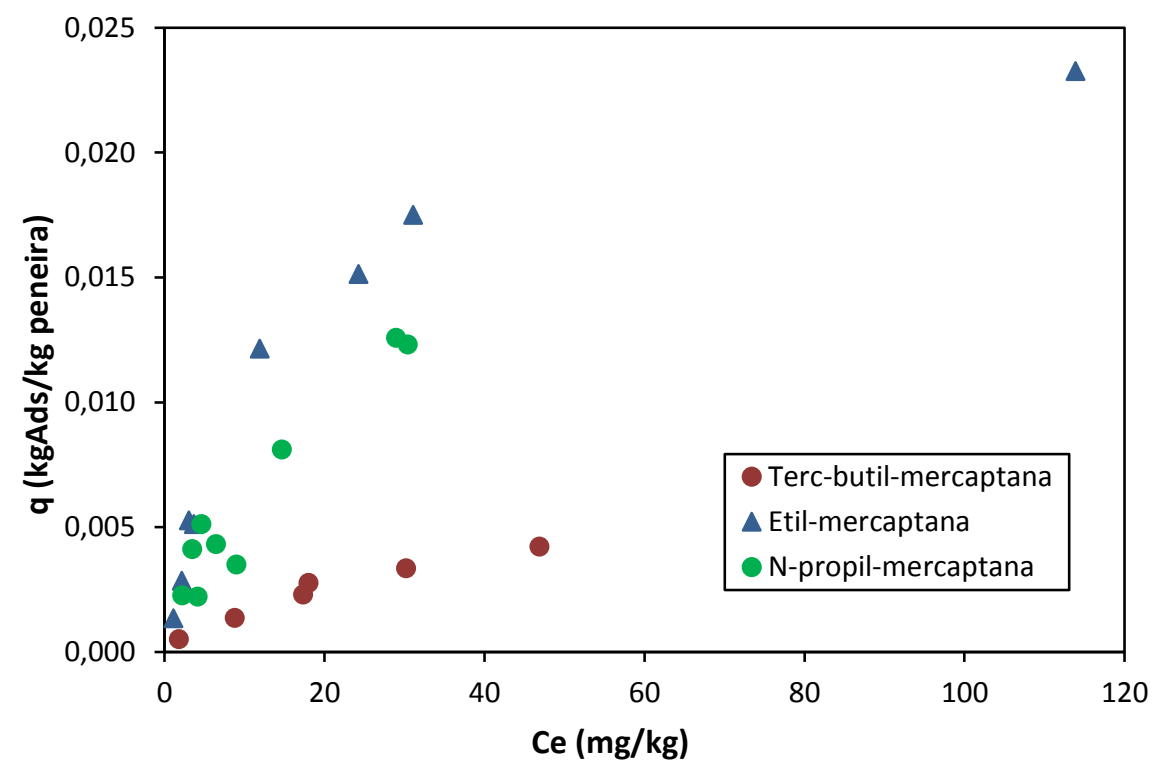

Figura 6.5. Comparação entre as isotermas de equilíbrio a $25 \stackrel{\circ}{\circ} \mathrm{C}$ dos solutos (terc-butil-mercaptana, n-propil-mercaptana e etil-mercaptana)

De acordo com os resultados, a etil-mercaptana apresentou maior interação com a peneira molecular 13X. Isto provavelmente se deve tanto ao menor tamanho da molécula, que facilita seu transporte entre os poros do adsorvente, quanto à sua maior polaridade, possuindo maior atração pelos sítios das cavidades da zeólita.

Para baixas concentrações de soluto (abaixo de10 ppm ou 0,056 kg/m³), os pontos de equilíbrio obtidos para a etil-mercaptana e para n-propil-mercaptana estão muito próximos, entretanto quando a concentração é aumentada a etil-mercaptana tende a atingir a capacidade máxima de adsorção mais rapidamente, como pode ser observado pela acentuação da curva representada pela maior constante de equilíbrio encontrada $\left(110 \mathrm{~m}^{3} / \mathrm{kg}\right)$.

\subsubsection{Isoterma de equilíbrio estendida}

As curvas de ruptura geradas pelas colunas de adsorção em escala laboratorial também se apresentam como fonte de pontos de equilíbrio de adsorção. A capacidade de adsorção do leito em $\mathrm{kg}$ de adsorvente por kg peneira é calculada conforme descrito no item 3.4.2, usando a equação:

$$
q_{m}=\frac{Q C_{0} t_{t}}{m_{p e n}}
$$

Considerando: 
$\mathrm{qm}_{\mathrm{m}}=$ capacidade de adsorção do leito, ( $\mathrm{kg}$ ads/ kg pen)

$\mathrm{Q}=$ vazão de alimentação, $(\mathrm{m} / \mathrm{s})$

$\mathrm{C}_{0}=$ concentração inicial de soluto, $\left(\mathrm{kg} / \mathrm{m}^{3}\right)$

$\mathrm{t}_{\mathrm{t}}=$ tempo equivalente à quantidade total processada, $(\mathrm{h})$

$\mathrm{m}_{\text {pen }}=$ massa de peneira no leito, $(\mathrm{kg})$

Para obter $t_{t}(h)$ através da integral das curvas de ruptura da n-propil-mercaptana foi utilizada a soma de Reimann simples. Nos casos em que a coluna não foi saturada completamente, foi realizada extrapolação dos resultados por simetria de modo que o valor pudesse ser obtido. Assim, segue a isoterma de adsorção modificada, incluindo os pontos de equilíbrio obtidos através das curvas de ruptura. A inclusão destes pontos alterou as constantes de equilíbrio calculadas usando o modelo de Langmuir e como poderá ser verificado no item 6.4, proporcionou melhores resultados nas simulações computacionais em escala laboratorial e piloto. De acordo com a equação (77), as novas constantes obtidas através do ajuste dos dados experimentais ao modelo de Langmuir são: $\mathrm{K}=34,84 \mathrm{~m}^{3} / \mathrm{kg}$ e $\mathrm{q}=0,0346 \mathrm{~kg}$ adsorvato/ $\mathrm{kg}$ peneira.

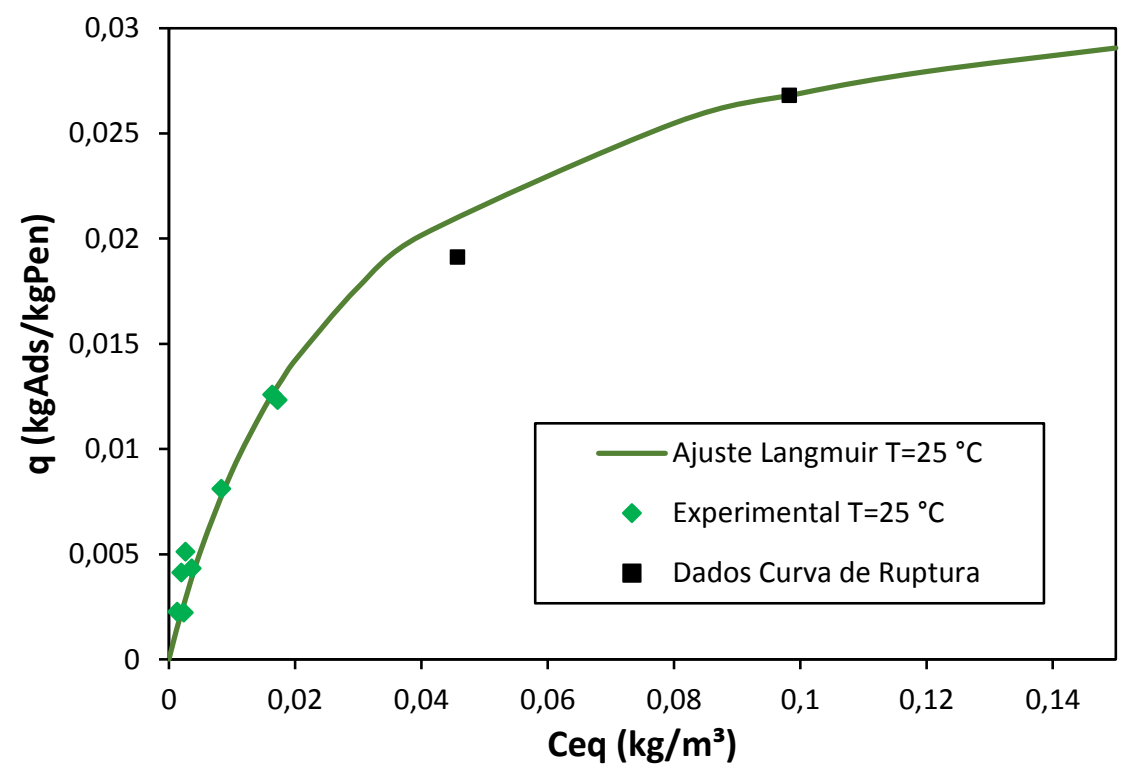

Figura 6.6. Isoterma de equilíbrio modificada a $25{ }^{\circ} \mathrm{C}$ obtida experimentalmente para $\mathrm{n}$-propilmercaptana em butano em zeólita $13 \mathrm{X}$ como adsorvente, incluindo pontos obtidos das curvas de ruptura.

Para avaliar os efeitos da temperatura na isoterma de equilíbrio da $n$-propilmercaptana em butano com a peneira molecular $13 \mathrm{X}$, realizaram-se experimentos a $10^{\circ} \mathrm{C}$ e $25^{\circ} \mathrm{C}$, conforme ilustrado na Figura 6.8. A partir da constante de adsorção 
obtida para cada uma das temperaturas e das equações (14) e (15), obtiveram-se as propriedades termodinâmicas como a entalpia de adsorção, a energia livre de Gibbs e a entropia, apresentadas na Tabela 6-2.

O efeito térmico é um fenômeno complexo, que pode afetar tanto as propriedades físico-químicas do adsorvente quanto as propriedades do soluto. Este comportamento pode ser observado a partir do resultado obtido para entalpia de adsorção negativa, que possibilitou o aumento da capacidade de adsorção de 0,0346 para 0,0392 com a redução da temperatura de $25 \stackrel{\circ}{\circ}$ para $10 \stackrel{\circ}{\circ}$, conforme Figura 6.7 .

Tabela 6-2. Propriedades termodinâmicas e parâmetros de equilíbrio para as isotermas de n-propilmercaptana obtidos pelo ajuste ao modelo de Langmuir a partir de dados experimentais.

\begin{tabular}{ccccccc}
\hline $\mathbf{T}(\mathbf{K})$ & $\mathbf{K}\left(\mathbf{m}^{3} / \mathbf{k g}\right)$ & $\begin{array}{c}\mathbf{q} \\
(\mathbf{k g S} / \mathbf{k g p e n})\end{array}$ & Erro $(\%)$ & $\begin{array}{c}\mathbf{\Delta}_{\text {ads }} \mathbf{H} \\
(\mathbf{k J / m o l})\end{array}$ & $\begin{array}{c}\mathbf{\Delta}_{\text {ads }} \mathbf{S} \\
(\mathbf{k J} / \mathbf{m o l K})\end{array}$ & $\begin{array}{c}\boldsymbol{\Delta}_{\text {ads }} \mathbf{G} \\
(\mathbf{k J} / \mathbf{m o l})\end{array}$ \\
\hline $\mathbf{2 8 3 , 1 5}$ & 58,13 & 0,0392 & 0,05 & $-23,95$ & 0,0019 & $-24,46$ \\
$\mathbf{2 9 8 , 1 5}$ & 34,84 & 0,0346 & 0,04 & $-23,95$ & 0,0019 & $-24,52$ \\
\hline
\end{tabular}

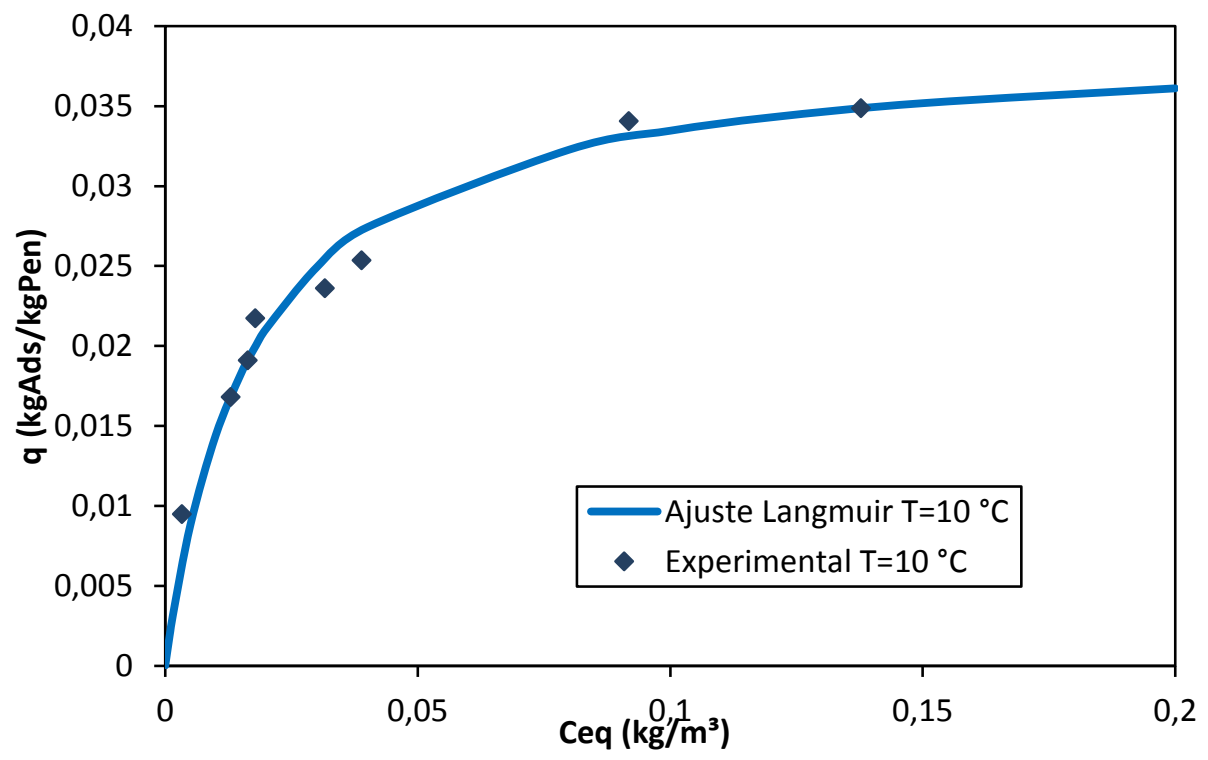

Figura 6.7. Isoterma de equilíbrio a $10 \stackrel{\circ}{ } \mathrm{C}$ obtida experimentalmente para n-propil-mercaptana em butano em zeólita 13X como adsorvente. 


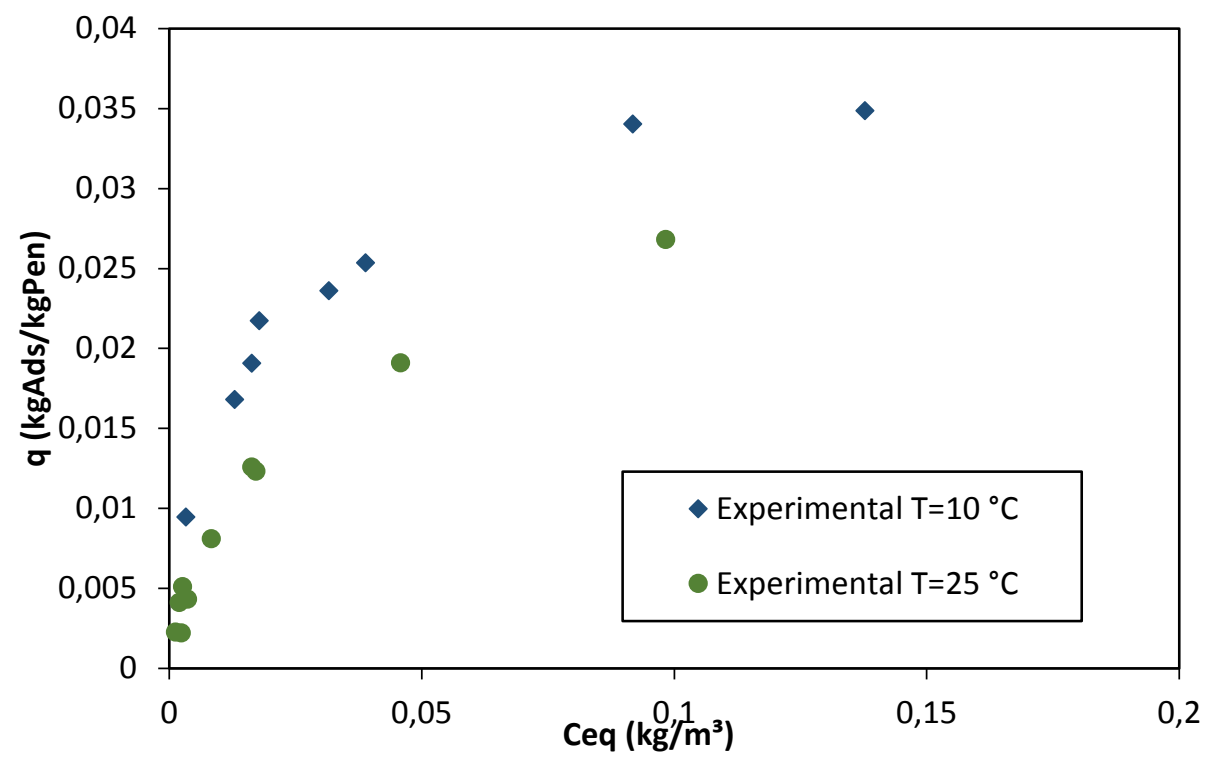

Figura 6.8. Comparação das isotermas de equilíbrio de n-propil-mercaptana em butano líquido na zeólita $13 \mathrm{X}$ nas temperaturas de $10^{\circ} \mathrm{C}$ e $25^{\circ} \mathrm{C}$.

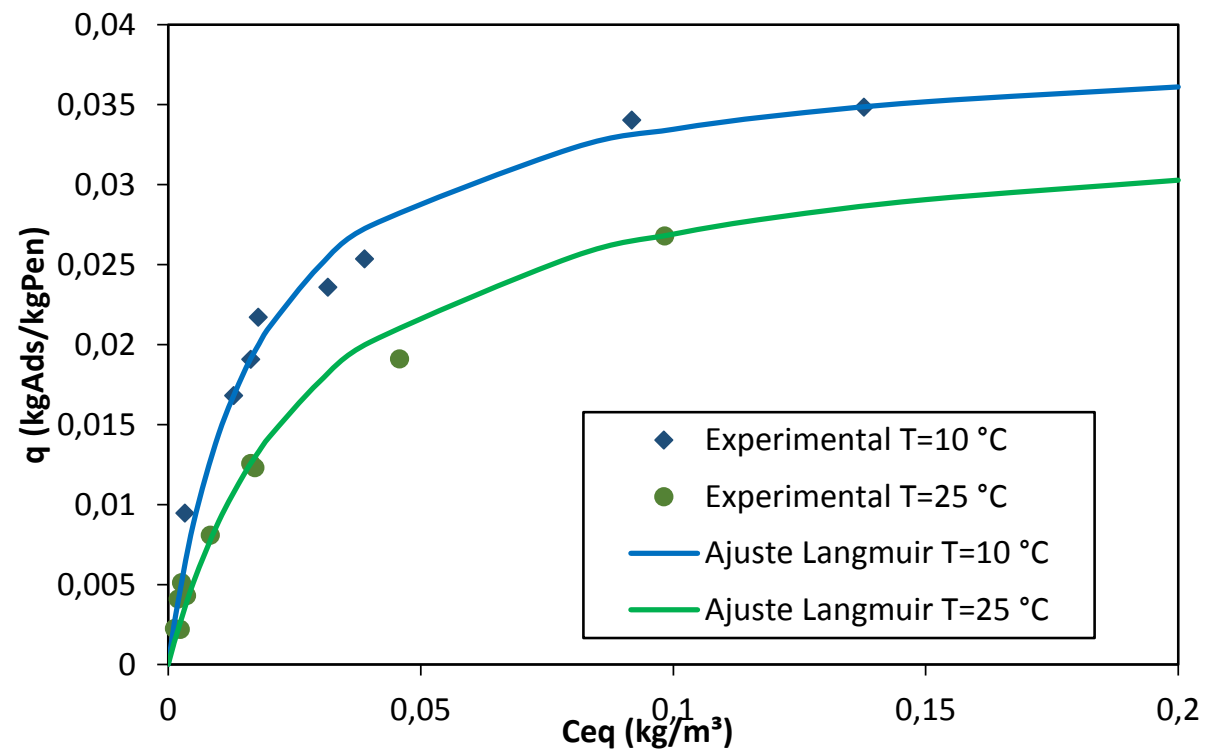

Figura 6.9. Comparação das isotermas de equilíbrio de n-propil-mercaptana em butano líquido usando zeólita $13 \mathrm{X}$ nas temperaturas de $10^{\circ} \mathrm{C}$ e $25^{\circ} \mathrm{C}$, incluindo as curvas de ajuste ao modelo de Langmuir.

\subsection{Curva de ruptura em escala laboratorial}

Realizaram-se experimentos em escala laboratorial, no leito fixo recheado com peneiras moleculares $13 \mathrm{X}$, para remoção de n-propil-mercaptana em butano líquido. 
Conforme condições descritas no item 4.5.1, para estudo da influência dos parâmetros: concentração inicial e velocidade no leito.

A Figura 6.10 ilustra a comparação das curvas de ruptura obtidas experimentalmente variando-se a concentração inicial de n-propil-mercaptana e mantendo a velocidade constante e similar à velocidade do processo industrial.

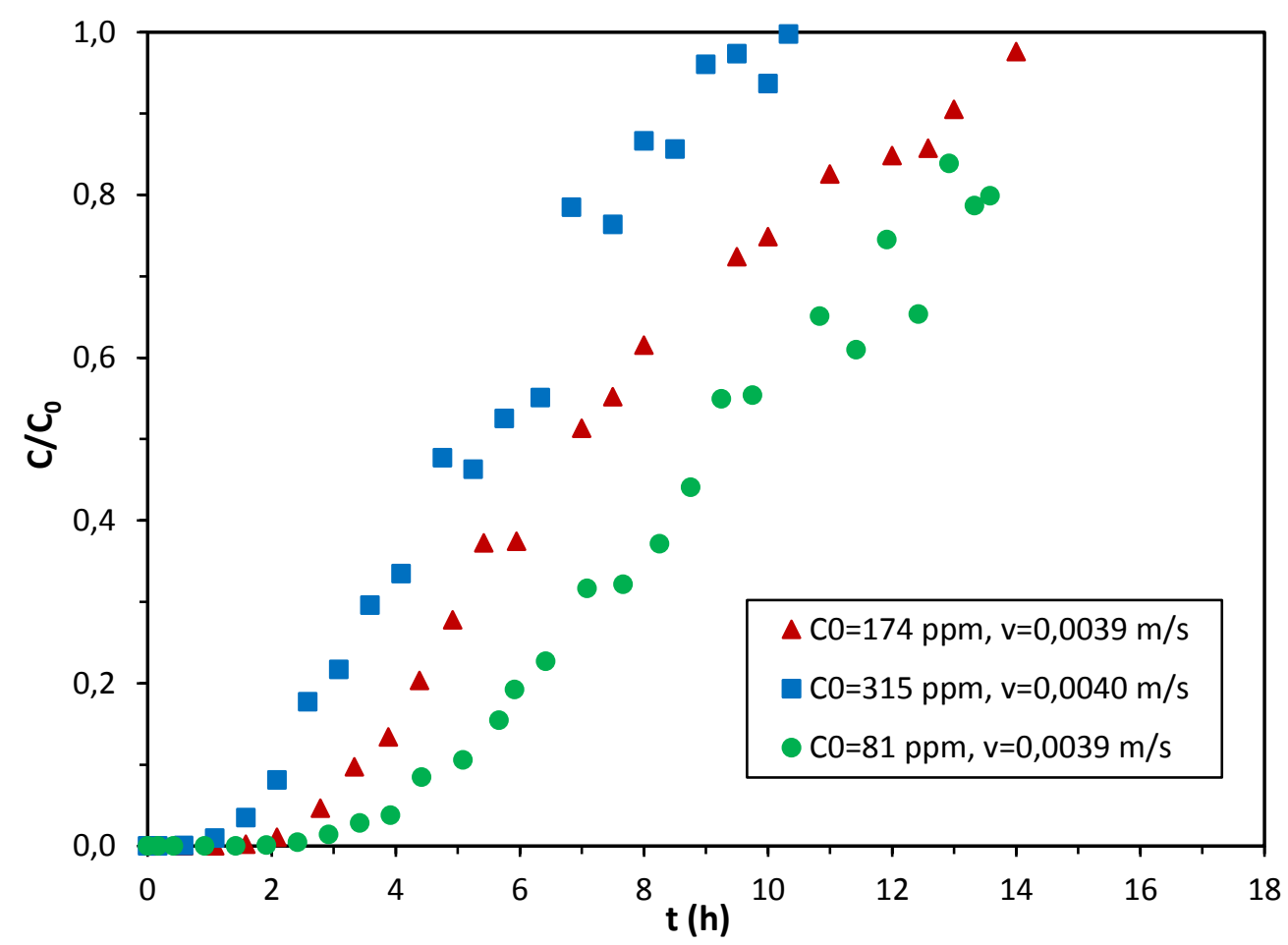

Figura 6.10. Curvas de ruptura obtidas experimentalmente (coluna laboratório) para as concentrações de alimentação: 81 ppm, 174 ppm e 315 ppm de n-propil-mercaptana, mantendo constante a velocidade média de $0,0040 \mathrm{~m} / \mathrm{s}$ que equivale a $4,5 \mathrm{~kg} / \mathrm{h}$ de vazão mássica.

Nos casos em que o experimento não atingiu o ponto máximo de saturação da curva de ruptura, quando $\mathrm{C} / \mathrm{C}_{0}=1$, foi realizada extrapolação dos resultados por simetria, de modo que o valor pudesse ser obtido. Para o cálculo dos parâmetros: $t_{t}(h)$ e $t_{u}(h)$, utilizaram-se as equações apresentadas no item 3.4.3. A integral das curvas foi obtida através da soma de Reimann simples.

$\mathrm{Na}$ Tabela 6-3, são apresentadas as condições experimentais dos ensaios e os valores calculados para: (i) o tempo equivalente à capacidade útil do leito (tu) até o tempo de ruptura (tb); (ii) o tempo equivalente à quantidade de soluto trocada se todo o leito estivesse em equilíbrio com a alimentação $\left(\mathrm{t}_{\mathrm{t}}\right.$ ); (iii) ZTM, correspondente à 
diferença entre a altura total e útil do leito; (iv) a quantidade de soluto removido pela zeólita $13 \mathrm{X}$ até a saturação e; (v) quantidade mássica total de solução processada; (vi) quantidade mássica de solução processada até o tempo de ruptura ( $\mathrm{t}_{\mathrm{b}}$ ).

Tabela 6-3. Resultados zona de transferência de massa (ZTM) nas curvas de ruptura com aumento da concentração inicial de n-propil-mercaptana e vazão constante de $4 \mathrm{~kg} / \mathrm{h}$.

\begin{tabular}{|c|c|c|c|}
\hline Parâmetros do experimento & $\begin{array}{c}\text { Teste Lab } \\
1\end{array}$ & $\begin{array}{c}\text { Teste Lab } \\
2\end{array}$ & $\begin{array}{c}\text { Teste Lab } \\
3\end{array}$ \\
\hline Comprimento da coluna, L (m) & 0,58 & 0,58 & 0,58 \\
\hline Diâmetro da coluna, $d_{B}(m)$ & 0,027 & 0,027 & 0,027 \\
\hline $\mathrm{C}_{0}(\mathrm{mg} / \mathrm{kg}) /\left(\mathrm{kg} / \mathrm{m}^{3}\right)$ & $81 / 0,045$ & $174 / 0,098$ & $315 / 0,177$ \\
\hline Vazão (kg/h) & 4,70 & 4,61 & 4,73 \\
\hline Velocidade superficial $(\mathrm{m} / \mathrm{s})$ & 0,0039 & 0,0039 & 0,0040 \\
\hline Reynolds & 35,4 & 34,6 & 36,6 \\
\hline Temperatura $\left({ }^{\circ} \mathrm{C}\right)$ & 25 & 25 & 25 \\
\hline \multicolumn{4}{|l|}{ Parâmetros calculados } \\
\hline Tempo útil, $t_{u}(\mathrm{~h})$ & 4,2 & 2,8 & 1,7 \\
\hline Tempo estequiométrico, $\mathrm{t}_{\mathrm{t}}(\mathrm{h})$ & 10,8 & 7,77 & 5,44 \\
\hline Zona de transferência de massa, ZTM (m) & 0,354 & 0,367 & 0,392 \\
\hline Fração comprimento útil da coluna, $\theta(\%)$ & 39 & 36 & 33 \\
\hline Massa total processada, $\mathrm{M}_{\mathrm{T}}(\mathrm{kg})$ & 80 & 69 & 49 \\
\hline Massa processada até $t_{\mathrm{u}}, \mathrm{M}_{\mathrm{u}}(\mathrm{kg})$ & 19,2 & 12,8 & 8,27 \\
\hline Massa de soluto adsorvida, q (kgad/kgpen) & 0,0191 & 0,0268 & 0,0377 \\
\hline
\end{tabular}

É previsto que o aumento da concentração antecipe o tempo de ruptura, conforme pode ser notado na Tabela 6-3, em que ao dobrar o teor do composto de enxofre inicial de $81 \mathrm{ppm}$, o tempo de ruptura diminui 34\% e, quadruplicando o valor inicial do composto de enxofre na entrada, o tempo de ruptura cai cerca de $60 \%$.

A diferença entre o valor máximo e mínimo obtida para a ZTM é de $10 \%$, o que é esperado considerando que a velocidade dos 3 experimentos foi constante. $O$ experimento que apresenta o maior valor para $\theta(0,39 \mathrm{~m})$ é na condição de maior concentração inicial (315 ppm massa). Assim, a condição que apresenta o maior aproveitamento do leito adsortível, ou seja, o que possui a menor ZTM, zona na qual ainda ocorre o processo de transferência de massa, é o teste lab 1 (81 ppm massa), em que $22 \mathrm{~cm}$ do leito está em equilíbrio com a solução alimentada. Mas, pondera-se considerando que as diferenças nos valores de ZTM estão dentro do erro 
experimental. De acordo com Veit et al (2009) quanto menor o comprimento da ZTM, mais próximo da idealidade o sistema se encontra, o que, por conseguinte, indica uma menor resistência difusional no interior da partícula, que é a etapa controladora do processo.

O teste lab 1 (81 ppm) apresenta a menor quantidade de soluto removido, quando comparado aos testes lab 2 e 3, por conta de o equilíbrio de adsorção ser mais favorável com o aumento da concentração do adsorvato.

Os demais experimentos dinâmicos propuseram-se a examinar os efeitos da velocidade do sistema monocomponente. Espera-se que o aumento deste parâmetro provoque uma diminuição da resistência à transferência de massa no filme e, por conseguinte, uma redução da zona de transferência de massa (ZTM) e um aumento da inclinação das curvas de ruptura. Entretanto, a elevação da velocidade reduz também o tempo médio de residência do fluido do leito. Assim, dependendo do tempo necessário para difusão no interior do poro, uma alta vazão pode não proporcionar o período de contato suficiente para ocorrer a adsorção e, neste caso, resultar numa maior extensão da ZTM. (GEANKOPLIS, 1993).

A Figura 6.11 ilustra a comparação das curvas de ruptura obtidas experimentalmente para o sistema monocomponente (n-propil-mercaptana), conforme procedimento descrito no item 4.5.1. Realizaram-se e experimentos em diferentes velocidades, mantendo-se a concentração de entrada de n-propil-mercaptana. 


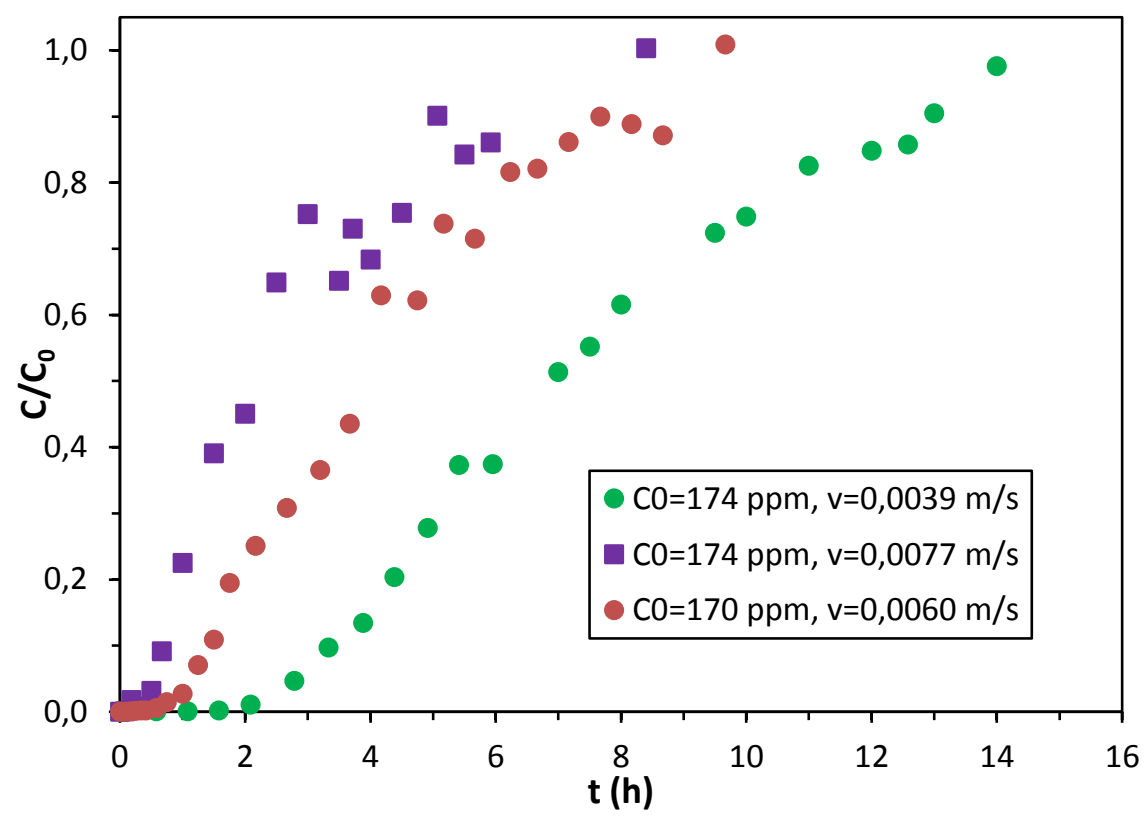

Figura 6.11. Curvas de ruptura obtidas experimentalmente para as vazões de $4,61 \mathrm{~kg} / \mathrm{h}, 7,01 \mathrm{~kg} / \mathrm{h}$ e $9,15 \mathrm{~kg} / \mathrm{h}$, mantendo a concentração inicial de n-propil-mercaptana em torno de $174 \mathrm{mg} / \mathrm{kg}$.

Os resultados dos cálculos para (i) o tempo equivalente à capacidade útil do leito (tu) até o tempo de ruptura (tb); (ii) o tempo equivalente à quantidade de soluto trocada se todo o leito estivesse em equilíbrio com a alimentação (tt); (iii) ZTM, correspondente à diferença entre a altura total e útil do leito; (iv) a quantidade de soluto removido pela zeólita 13X até a saturação e; (v) quantidade mássica total de solução processada; (vi) quantidade mássica de solução de entrada até o tempo de ruptura (tb), estão na

Tabela 6-4 para a concentração inicial Co constante em torno de 174 mg/kg.

Tabela 6-4. Resultados dos experimentos para obtenção de curvas de ruptura com aumento da velocidade, considerando constante a concentração inicial de n-propil-mercaptana em média a $\mathrm{C}_{0}=$ $174 \mathrm{mg} / \mathrm{kg}$.

\begin{tabular}{lccc}
\hline Parâmetros do experimento & Teste Lab & Teste Lab & Teste Lab \\
& $\mathbf{2}$ & $\mathbf{4}$ & $\mathbf{5}$ \\
\hline Comprimento da coluna, L $(\mathrm{m})$ & 0,58 & 0,58 & 0,58 \\
Diâmetro da coluna, $\mathrm{d}_{\mathrm{B}}(\mathrm{m})$ & 0,027 & 0,027 & 0,027 \\
$\mathrm{C}_{0}(\mathrm{mg} / \mathrm{kg}) /\left(\mathrm{kg} / \mathrm{m}^{3}\right)$ & $174 / 0,098$ & $170 / 0,096$ & $174 / 0,098$ \\
Vazão $(\mathrm{kg} / \mathrm{h})$ & 4,61 & 7,01 & 9,15 \\
Velocidade superficial $(\mathrm{m} / \mathrm{s})$ & 0,0039 & 0,0060 & 0,0077 \\
Reynolds, adim. & 34,6 & 52,8 & 68,9 \\
Temperatura $\left({ }^{\circ} \mathrm{C}\right)$ & 25 & 25 & 25
\end{tabular}

Continua. 


\begin{tabular}{lccc}
\hline Parâmetros do experimento & Teste Lab & Teste Lab & Teste Lab \\
\hline Tempo útil, $\mathrm{t}_{\mathrm{u}}(\mathrm{h})$ & $\mathbf{2}$ & $\mathbf{4}$ & $\mathbf{5}$ \\
\hline Tempo estequiométrico, $\mathrm{t}_{\mathrm{t}}(\mathrm{h})$ & 7,77 & 1,20 & 0,56 \\
Zona de transferência de massa, ZTM $(\mathrm{m})$ & 0,37 & 4,79 & 2,68 \\
Fração comprimento útil da coluna, $\theta(\%)$ & 36 & 25 & 0,43 \\
Massa total processada, $\mathrm{M}_{\mathrm{T}}(\mathrm{kg})$ & 69,2 & 67,7 & 21 \\
Massa processada até $\mathrm{t}_{\mathrm{u}}, \mathrm{M}_{\mathrm{u}}(\mathrm{kg})$ & 12,8 & 8,4 & 64,5 \\
Massa de soluto adsorvida, $\mathrm{q}(\mathrm{kgad} / \mathrm{kgpen})$ & 0,0268 & 0,0269 & 0,0201 \\
\hline
\end{tabular}

Conclusão.

Analisando os resultados, nota-se que a elevação progressiva da velocidade gera maiores valores calculados para a zona de transferência de massa (ZTM) e, por conseguinte, menores frações de comprimento úteis do leito empacotado $\theta\left(t_{u} / t_{t}\right)$. Infere-se, portanto, que para velocidades acima de 0,0039 m/s, a etapa limitante do processo dinâmico de adsorção é a resistência à transferência de massa intrapartícula. Este comportamento foi observado também por Valdman et al. (2001) no estudo da biossorção dos íons metálicos zinco e cobre pela biomassa algácea Sargassum sp com aumento da velocidade do processo.

Quanto à capacidade de adsorção, espera-se que o aumento da velocidade até um certo limite não prejudique a capacidade dinâmica do processo e sim o contrário, haja vista que as resistências à transferência de massa entre as fases líquida e sólida tendem a diminuir. Nota-se, através dos resultados apresentados, que esta tendência não foi observada no aumento de velocidade realizado para os testes lab 2 e 4, em que as capacidades de adsorção permaneceram constantes, mas foi reduzida em cerca de $25 \%$ no teste lab 5 ( $v=0,0077 \mathrm{~m} / \mathrm{s}$ e $\mathrm{C}_{0}=174$ ppm). Acredita-se neste caso, que o sistema possa não ter atingido o equilíbrio e que o tempo do experimento deveria ser prolongado.

Em relação à quantidade total processada até a saturação do leito, houve pequenas diferenças entre os 3 experimentos, aproximadamente $69 \mathrm{~kg}$, variando até $6 \%$. Entretanto, avaliando-se o experimento sob o aspecto da produtividade, obtêm-se maior massa total de solvente purificado até o tempo de ruptura $\left(\mathrm{t}_{\mathrm{r}}\right)$ na condição de menor velocidade $(0,0039 \mathrm{~m} / \mathrm{s})$ para a mesma concentração de entrada, em torno de 
$12,8 \mathrm{~kg}$, sendo $35 \%$ menor para a velocidade de $0,0060 \mathrm{~m} / \mathrm{s}$ e $60 \%$ mais baixa para $0,0077 \mathrm{~m} / \mathrm{s}$.

Assim sendo, a melhor condição de equilíbrio entre as resistências difusionais e que proporciona a maior produtividade, é curva de ruptura obtida a 0,0039 m/s $(4,61 \mathrm{~kg} / \mathrm{h})$ a $\mathrm{C}_{0}=174$ ppm.

Conforme Veit et al. (2009), nos casos em que o processo de adsorção é controlado pela resistência à transferência de massa no interior da partícula: baixas vazões volumétricas resultam em elevados tempos de residência e maior aproveitamento do leito adsortível.

\subsection{Curva de ruptura em escala piloto}

As curvas de ruptura em escala piloto foram realizadas com o intuito de complementar os dados experimentais que possibilitam a validação do modelo matemático, conforme descrito no item 6.4. Adicionalmente, em razão das condições fluidodinâmicas serem mais próximas do processo industrial, há a tentativa de correlacionar seus resultados com o comportamento das colunas em grande escala.

Os ensaios atenderam sistemas monocomponentes com os compostos sulfurados: tercbutil-mercaptana, isopropil-mercaptana e n-propil-mercaptana em butano líquido. Os parâmetros do experimento estão descritos no item 4.5.2.

A vazão volumétrica foi registrada durante todo o teste e apresentou variação média em torno de $15 \%$. A temperatura também foi medida durante o experimento. Houve elevação inicial de cerca de $8{ }^{\circ} \mathrm{C}$ medida ao longo da coluna, resultado da reação exotérmica de adsorção, mas após alguns minutos a temperatura retornou à temperatura inicial. A média esteve em torno de $26^{\circ} \mathrm{C}$ com desvio de $3^{\circ} \mathrm{C}$.

Dentre as dificuldades para a realização do experimento, vale pontuar a necessidade de grande volume de butano líquido (mínimo 9 t), sendo que os caminhões utilizados possuíam no máximo 9 t; e a extensa duração do experimento. Por esses motivos, não foram obtidos os tempos de exaustão do leito dos experimentos. A extrapolação até o ponto de saturação foi obtida através do mesmo método usado para as curvas 
de ruptura dos ensaios laboratoriais, que não atingiram o equilíbrio. Outro ponto problemático foi obter diferentes vazões, já que o sistema de bombeamento estava acoplado a cada caminhão e não permitia alterações de maneira a manter a velocidade constante.

Seguem os resultados calculados na Tabela 6-5 a partir das curvas de ruptura da $1^{\underline{a}}$ coluna do protótipo em escala piloto apresentadas na Figura 6.12, mostrando a grande dispersão da ZTM para todos os sistemas.

Tabela 6-5. Resultados calculados da ZTM nos experimentos em escala piloto para saturação da $1^{\text {a }}$ coluna do protótipo.

\begin{tabular}{lccc}
\hline Parâmetros do experimento & Teste Piloto & Teste Piloto & Teste Piloto \\
\hline Comprimento da coluna, $\mathrm{L}(\mathrm{m})$ & $\mathbf{6}$ & $\mathbf{7}$ & $\mathbf{8}$ \\
Diâmetro da coluna, $\mathrm{d}_{\mathrm{B}}(\mathrm{m})$ & 1,02 & 1,02 & 1,02 \\
Composto de enxofre & 0,14 & 0,14 & 0,14 \\
$\mathrm{C}_{0}(\mathrm{mg} / \mathrm{kg}) /\left(\mathrm{kg} / \mathrm{m}^{3}\right)$ & Tercbutil- & Iso-propil- & N-propil- \\
Vazão $(\mathrm{kg} / \mathrm{h})$ & mercaptana & mercaptana & mercaptana \\
Velocidade superficial $(\mathrm{m} / \mathrm{s})$ & $12,1 / 0,0068$ & $13,0 / 0,0073$ & $91,8 / 0,051$ \\
Reynolds & 414 & 418 & 530 \\
Temperatura (으) & 0,0132 & 0,0134 & 0,0169 \\
\hline Parâmetros calculados & 116,0 & 117,2 & 148,6 \\
\hline Tempo útil, tu $(\mathrm{h})$ & 25 & 25 & 25 \\
Tempo estequiométrico, $\mathrm{t}_{\mathrm{t}}(\mathrm{h})$ & & & \\
Zona de transferência de massa, ZTM (m) & 0,13 & 3,00 & 0,93 \\
Fração comprimento útil da coluna, $\theta(\%)$ & 2,95 & 15,59 & 4,38 \\
Massa de soluto adsorvida, q (kgad/kgpen) & 0,0026 & 0,0073 & 0,0189 \\
\hline
\end{tabular}




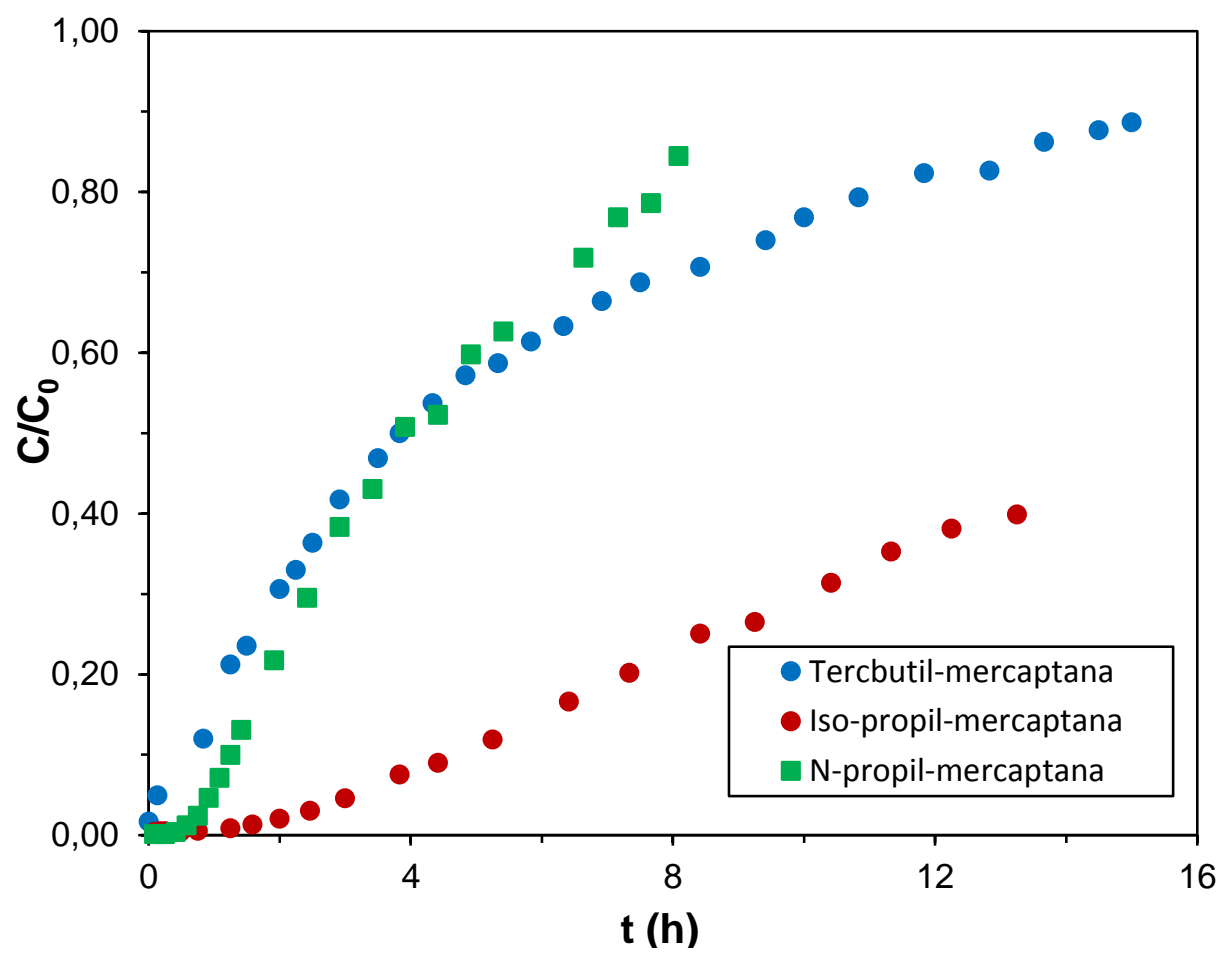

Figura 6.12. Curvas de ruptura em escala piloto para diferentes compostos sulfurados em butano através de um leito recheado com peneira molecular 13X.

Dois dos experimentos realizados (teste piloto 7 - terc-butil-mercaptana) e (teste piloto 8 - isopropil-mercaptana) são passíveis de comparação, na medida em que as condições do experimento, como velocidade, concentração de entrada e temperatura são semelhantes, tendo como única variável o tipo de composto de enxofre empregado.

Houve diferenças na ZTM e na massa de soluto adsorvida, considerando a mesma concentração de entrada, de modo que se observa grande influência dos parâmetros de equilíbrio de adsorção no processo dinâmico. O que reforça o carácter experimental para bom ajuste do modelo matemático do processo de adsorção.

\subsection{Estudo do modelo e simulação}

Com o intuito de validar o modelo matemático proposto para o sistema de leito fixo para dessulfurização de butano com peneira molecular 13X, simulou-se, através do software Matlab $\AA$, as condições de diversos experimentos realizados em escala laboratorial e piloto. 
As Tabela 6-6 e Tabela 6-7 apresentam os parâmetros usados para simulação dos experimentos em escala laboratorial.

Tabela 6-6. Parâmetros utilizados para simulação dos experimentos em escala laboratorial com variação da concentração de entrada.

\begin{tabular}{lccc}
\hline Parâmetros do experimento & Teste Lab 1 & Teste Lab 2 & Teste Lab 3 \\
\hline Comprimento da coluna, $\mathrm{L}(\mathrm{m})$ & 0,58 & 0,58 & 0,58 \\
Diâmetro da coluna, $\mathrm{d}_{\mathrm{B}}(\mathrm{m})$ & 0,027 & 0,027 & 0,027 \\
$\mathrm{C}_{0}(\mathrm{mg} / \mathrm{kg})$ & 81 & 174 & 325 \\
Vazão $(\mathrm{kg} / \mathrm{h})$ & 4,70 & 4,61 & 4,73 \\
Velocidade superficial $(\mathrm{m} / \mathrm{s})$ & 0,0039 & 0,0039 & 0,0040 \\
Massa específica do fluido $\left(\mathrm{kg} / \mathrm{m}^{3}\right)$ & 565 & 565 & 565 \\
Viscosidade do fluido $(\mathrm{kg} / \mathrm{ms})$ & $1,47 \mathrm{E}-04$ & $1,47 \mathrm{E}-04$ & $1,47 \mathrm{E}-04$ \\
Porosidade do leito & 0,35 & 0,35 & 0,35 \\
Porosidade da partícula & 0,67 & 0,67 & 0,67 \\
Reynolds $($ adim.) & 35,4 & 34,6 & 36,6 \\
Temperatura $(-\mathrm{C})$ & 25 & 25 & 25 \\
\hline Parâmetros de Transporte & & & \\
\hline Coeficiente de dispersão axial, $\mathrm{D}_{\mathrm{L}}$ & $3,0 \mathrm{E}-03$ & $3,0 \mathrm{E}-03$ & $3,0 \mathrm{E}-03$ \\
(m²/s) & $3,9 \mathrm{E}-03$ & $3,9 \mathrm{E}-03$ & $3,9 \mathrm{E}-03$ \\
Coeficiente global de transf. massa & & & \\
externa, $\mathrm{k}_{\mathrm{f}}(\mathrm{m} / \mathrm{s})$ & &
\end{tabular}

Tabela 6-7. Parâmetros utilizados para simulação dos experimentos em escala laboratorial com variação da velocidade do fluido.

\begin{tabular}{lccc}
\hline Parâmetros do experimento & Teste Lab 2 & Teste Lab 4 & Teste Lab 5 \\
\hline Comprimento da coluna, $\mathrm{L}(\mathrm{m})$ & 0,58 & 0,58 & 0,58 \\
Diâmetro da coluna, $\mathrm{d}_{\mathrm{B}}(\mathrm{m})$ & 0,027 & 0,027 & 0,027 \\
$\mathrm{C}_{0}(\mathrm{mg} / \mathrm{kg}) /\left(\mathrm{kg} / \mathrm{m}^{3}\right)$ & 174 & 170 & 174 \\
Vazão $(\mathrm{kg} / \mathrm{h})$ & 4,61 & 7,01 & 9,15 \\
Velocidade superficial $(\mathrm{m} / \mathrm{s})$ & 0,0039 & 0,0060 & 0,0077 \\
Massa específica do fluido $\left(\mathrm{kg} / \mathrm{m}^{3}\right)$ & 565 & 565 & 565 \\
Viscosidade do fluido $(\mathrm{kg} / \mathrm{ms})$ & $1,47 \mathrm{E}-04$ & $1,47 \mathrm{E}-04$ & $1,47 \mathrm{E}-04$ \\
Porosidade do leito & 0,35 & 0,35 & 0,35 \\
Porosidade da partícula & 0,67 & 0,67 & 0,67 \\
Reynolds (adim.) & 34,6 & 52,8 & 68,9 \\
Temperatura (으) & 25 & 25 & 25 \\
\hline Parâmetros de Transporte & & & \\
Coeficiente de dispersão axial, $\mathrm{D}_{\mathrm{L}}$ & $3,0 \mathrm{E}-03$ & $9,5 \mathrm{E}-03$ & $2,2 \mathrm{E}-02$ \\
(m²/s) & & & \\
Coeficiente global de transf. massa & $3,90 \mathrm{E}-03$ & $3,99 \mathrm{E}-03$ & $4,04 \mathrm{E}-03$ \\
externa, $\mathrm{k}_{\mathrm{f}}(\mathrm{m} / \mathrm{s})$ & & & \\
\hline
\end{tabular}


Os experimentos foram testados utilizando o método de diferenças finitas, usando um nível elevado de refinamento, sendo o domínio subdivido em $\mathrm{Nz}=128$ partes. O tempo para cada simulação foi de aproximadamente 20 segundos em computador.

Dentro das variáveis necessárias para simulação do modelo matemático, houve dificuldade em se obter a porosidade da partícula junto aos fabricantes, por se tratar de segredo industrial relacionado a expertise de fabricação. Além disso, na literatura foram encontrados valores muito distintos para o mesmo tipo de zeólita $13 \mathrm{X}$, como o valor obtido em Lessa (2001): 0,23 em Shams et al (2007): 0,9 e Perry (1999): 0,38. Então, usando um balanço de massa estimou-se a porosidade baseado em dados experimentais.

Outro problema encontrado está relacionado à adequação dos modelos teóricos de equações para obter os parâmetros de transporte ao sistema em estudo. Os resultados da simulação obtidos utilizando os coeficientes baseados em modelos da literatura, de acordo com as equações apresentadas no item 5.6, divergiram dos dados experimentais. Por esse motivo, optou-se pelo ajuste de dois parâmetros do modelo (dispersão axial e coeficiente de transferência de massa global) através da simulação, que reproduzissem adequadamente a correlação entre o modelo matemático e as curvas de ruptura experimentais.

As Figuras 6.13 a 6.17 apresentam os resultados obtidos pela simulação, com os parâmetros ajustados, e os dados experimentais para os ensaios em coluna de laboratório. 


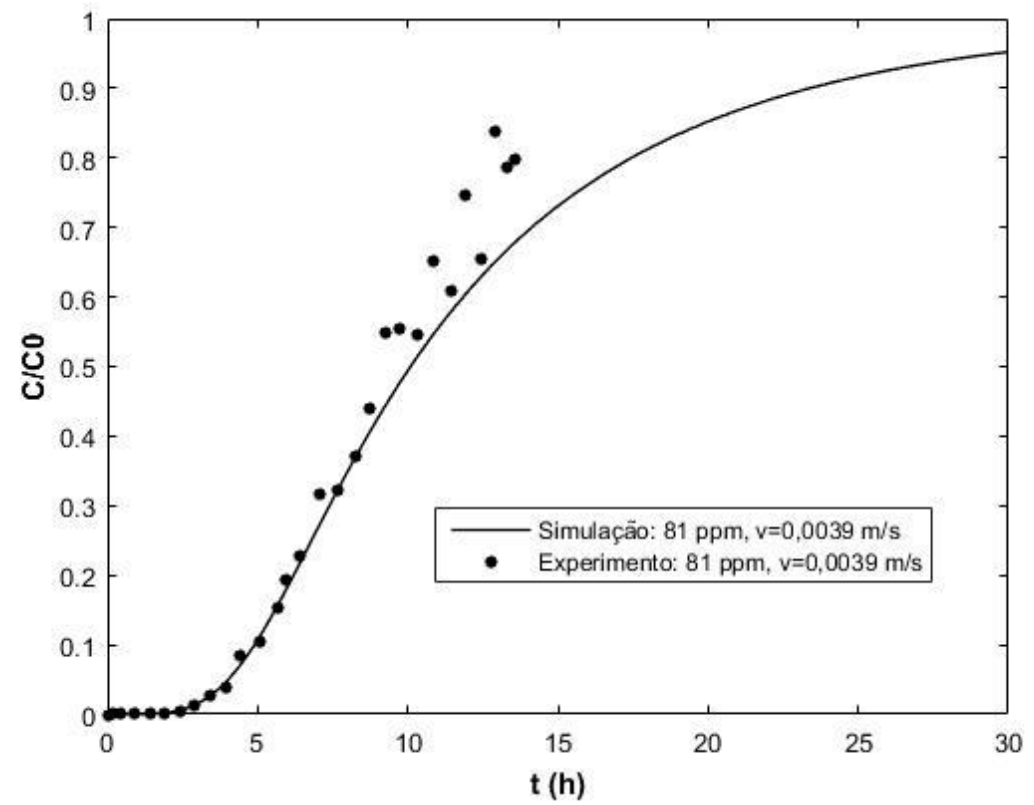

Figura 6.13. Resultado simulação computacional diferenças finitas. Teste Lab 1: N-propil-mercaptana $\mathrm{C}_{0}=81 \mathrm{ppm}, \mathrm{v}=0,0039 \mathrm{~m} / \mathrm{s}$.

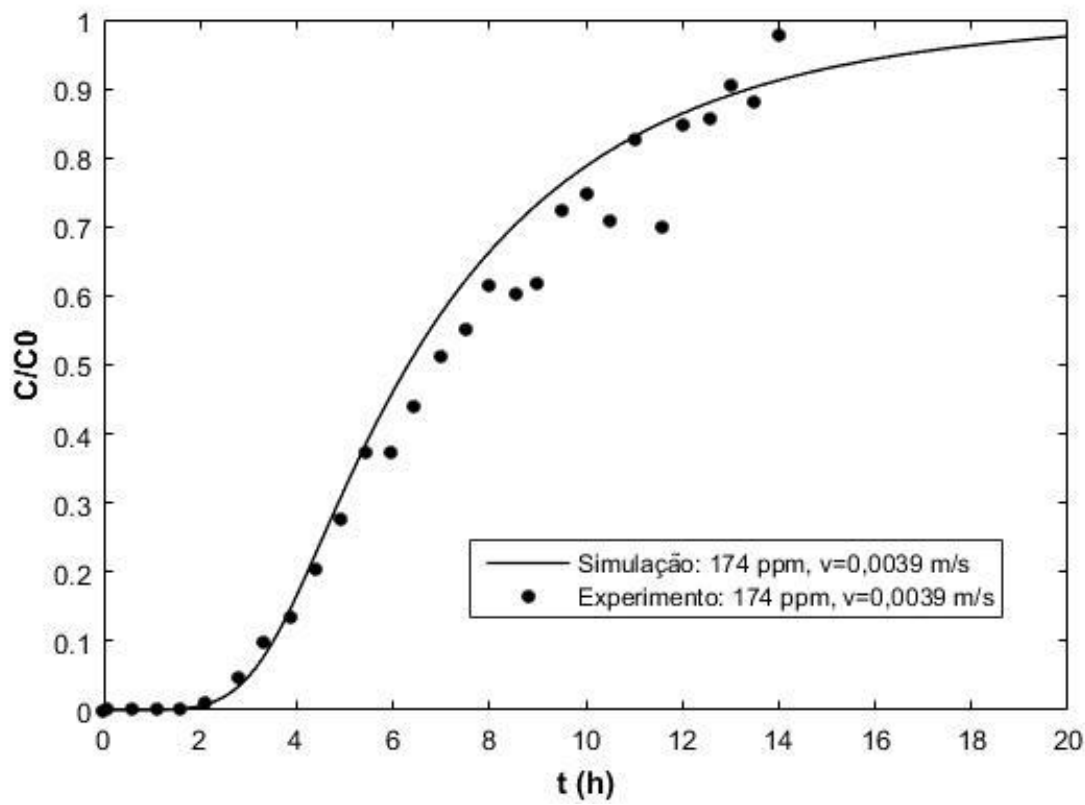

Figura 6.14. Resultado simulação computacional diferenças finitas. Teste Lab 2: N-propil-mercaptana $\mathrm{C}_{0}=174 \mathrm{ppm}, \mathrm{v}=0,0039 \mathrm{~m} / \mathrm{s}$. 


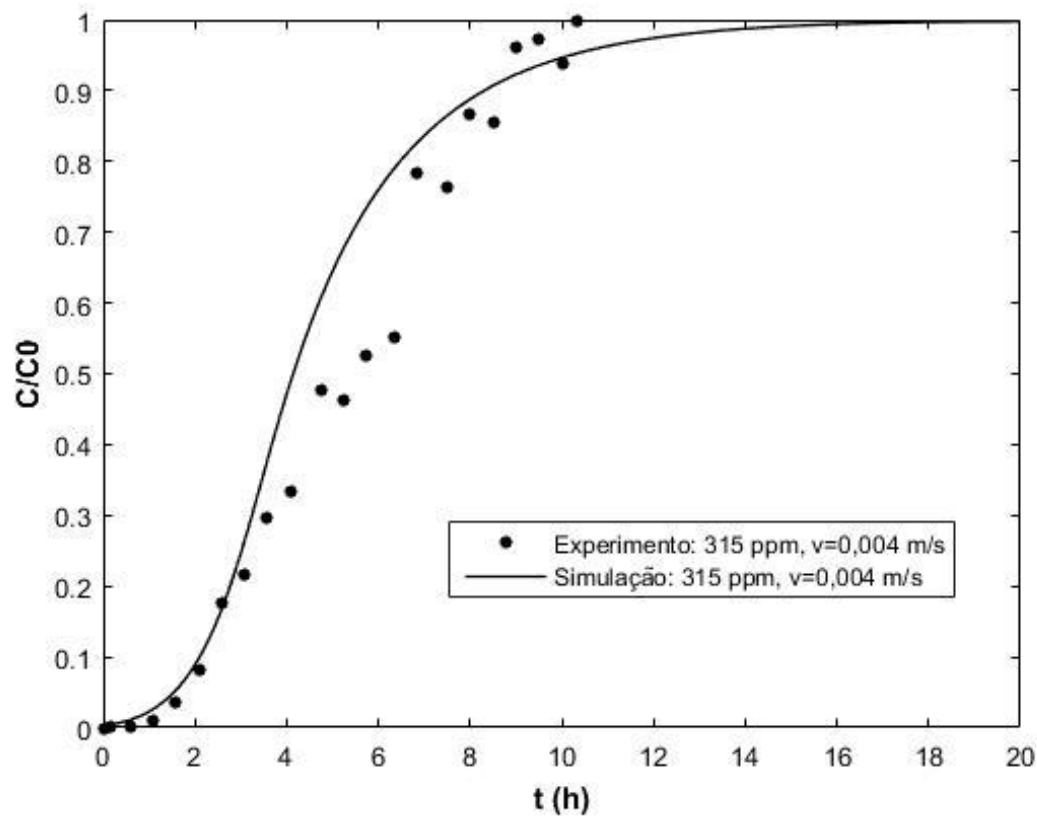

Figura 6.15. Resultado simulação computacional diferenças finitas. Teste Lab 3: N-propil-mercaptana $\mathrm{C}_{0}=315 \mathrm{ppm}, \mathrm{v}=0,0040 \mathrm{~m} / \mathrm{s}$.

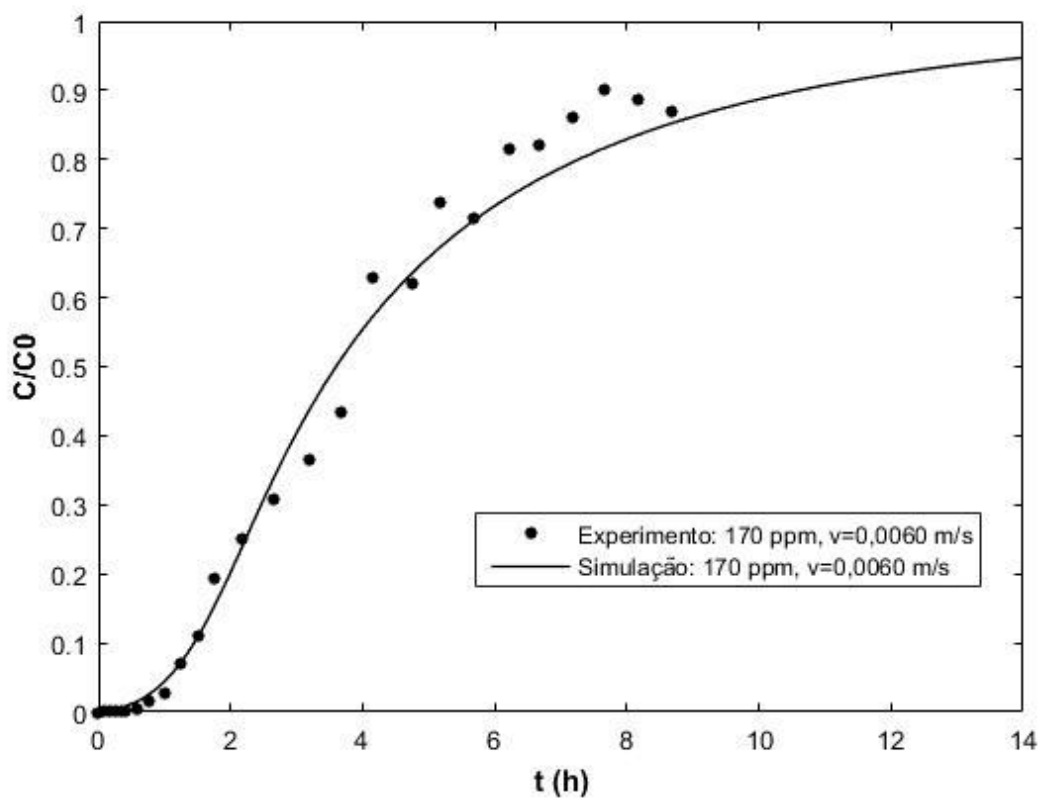

Figura 6.16. Resultado simulação computacional diferenças finitas. Teste Lab 4: N-propil-mercaptana $\mathrm{C}_{0}=170 \mathrm{ppm}, \mathrm{v}=0,0060 \mathrm{~m} / \mathrm{s}$. 


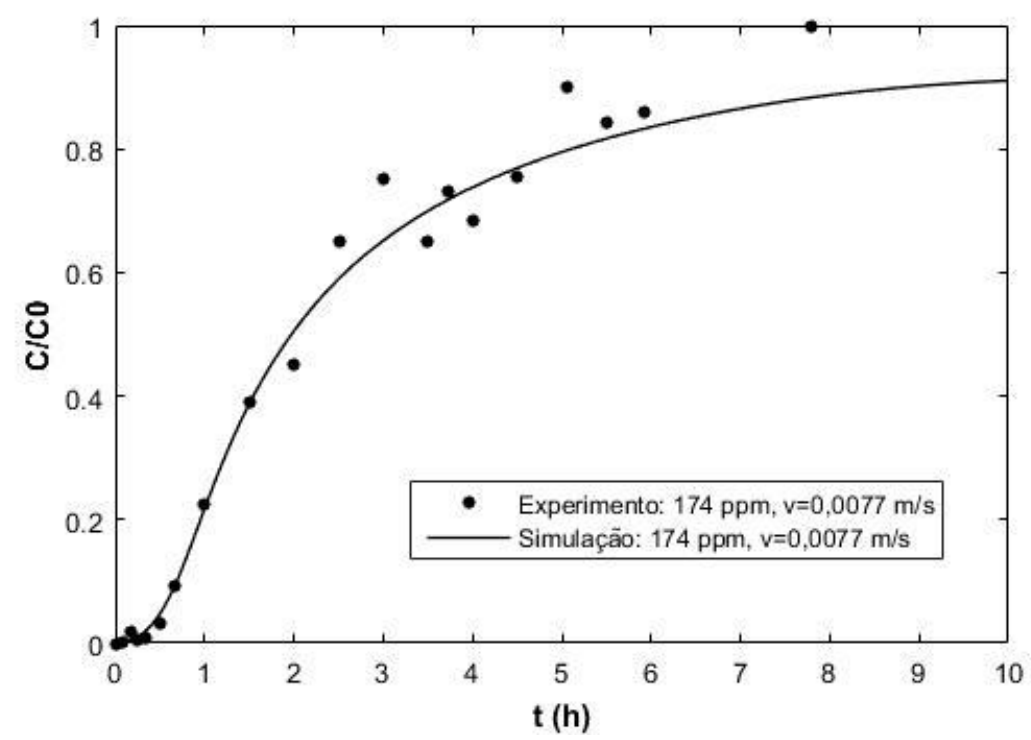

Figura 6.17. Resultado simulação computacional diferenças finitas. Teste Lab 5: N-propil-mercaptana $\mathrm{C}_{0}=174 \mathrm{ppm}, \mathrm{v}=0,0077 \mathrm{~m} / \mathrm{s}$.

Avaliando-se especificamente os perfis das curvas laboratoriais obtidas pela simulação em relação aos dados experimentais com variação da concentração de entrada, observa-se uma boa precisão dos resultados tanto na previsão do tempo de ruptura quanto no perfil da zona de transferência de massa.

A partir da definição do primeiro valor para o coeficiente de dispersão axial pela simulação do experimento "Teste Lab 1", o coeficiente global de transferência de massa foi alterado com o aumento da velocidade utilizando-se da correlação proposta por Perry (1999) para o kf usando a equação (68), considerando o cálculo do ke pela equação (65) e do ki pela equação (67). Os valores obtidos para a dispersão axial foram ajustados para adequação aos dados experimentais de cada experimento, respeitando o aumento progressivo da velocidade.

Com isso, observou-se novamente boa estimativa dos resultados relativos ao tempo de ruptura e no perfil da zona de transferência de massa para os ensaios de n-propilmercaptana em escala laboratorial com variação da velocidade. Nota-se uma correlação entre o coeficiente de dispersão axial e a velocidade. 
A Tabela 6-8 apresenta as condições de operação e parâmetros ajustados para simulação em escala piloto.

Tabela 6-8. Parâmetros utilizados para simulação dos experimentos em escala piloto.

\begin{tabular}{lccc}
\hline Parâmetros do experimento & Teste Piloto & Teste Piloto & Teste Piloto \\
\hline Comprimento da coluna, $\mathrm{L}(\mathrm{m})$ & $\mathbf{6}$ & $\mathbf{7}$ & $\mathbf{8}$ \\
Diâmetro da coluna, $\mathrm{d}_{\mathrm{B}}(\mathrm{m})$ & 1,02 & 1,02 & 1,02 \\
Composto de enxofre & 0,14 & 0,14 & 0,14 \\
$\mathrm{C}_{0}(\mathrm{mg} / \mathrm{kg}) /\left(\mathrm{kg} / \mathrm{m}^{3}\right)$ & $\mathrm{C}_{4} \mathrm{H}_{9}-\mathrm{SH}$ & $\mathrm{C}_{2} \mathrm{H}_{5}-\mathrm{SH}-\mathrm{CH}$ & $\left(\mathrm{CH}_{3}\right)_{3} \mathrm{C}-\mathrm{SH}$ \\
Vazão $(\mathrm{kg} / \mathrm{h})$ & $12,1 / 0,0068$ & $13,6 / 0,0073$ & $91,8 / 0,051$ \\
Velocidade superficial $(\mathrm{m} / \mathrm{s})$ & 414 & 418 & 530 \\
Porosidade do leito & 0,0132 & 0,0134 & 0,0169 \\
Porosidade da partícula & 0,35 & 0,35 & 0,35 \\
Massa específica do fluido $\left(\mathrm{kg} / \mathrm{m}^{3}\right)$ & 0,67 & 0,67 & 0,67 \\
Viscosidade do fluido $(\mathrm{kg} / \mathrm{ms})$ & 565 & 565 & 565 \\
Raio equivalente da partícula $(\mathrm{m})$ & $1,47 \mathrm{E}-04$ & $1,47 \mathrm{E}-04$ & $1,47 \mathrm{E}-04$ \\
Reynolds $($ adim.) & $12 \mathrm{E}-04$ & $12 \mathrm{E}-04$ & $12 \mathrm{E}-04$ \\
Temperatura $\left({ }^{\circ} \mathrm{C}\right)$ & 116,0 & 117,2 & 148,6 \\
\hline Parâmetros de Transporte & 25 & 25 & 25 \\
\hline Coeficiente de dispersão axial, $\mathrm{D}_{\mathrm{L}}\left(\mathrm{m}^{2} / \mathrm{s}\right)$ & $3,7 \mathrm{E}-02$ & $3,7 \mathrm{E}-02$ & $4,0 \mathrm{E}-02$ \\
Coeficiente global de transf. massa & $4,13 \mathrm{E}-03$ & $4,13 \mathrm{E}-03$ & $4,2 \mathrm{E}-03$ \\
externa, $\mathrm{k}_{\mathrm{f}}(\mathrm{m} / \mathrm{s})$ & & &
\end{tabular}

As Figura 6.18 a Figura 6.20 apresentam os resultados obtidos pela simulação, com os parâmetros de transporte ajustados, em comparação os dados experimentais para os ensaios em coluna em escala piloto. 


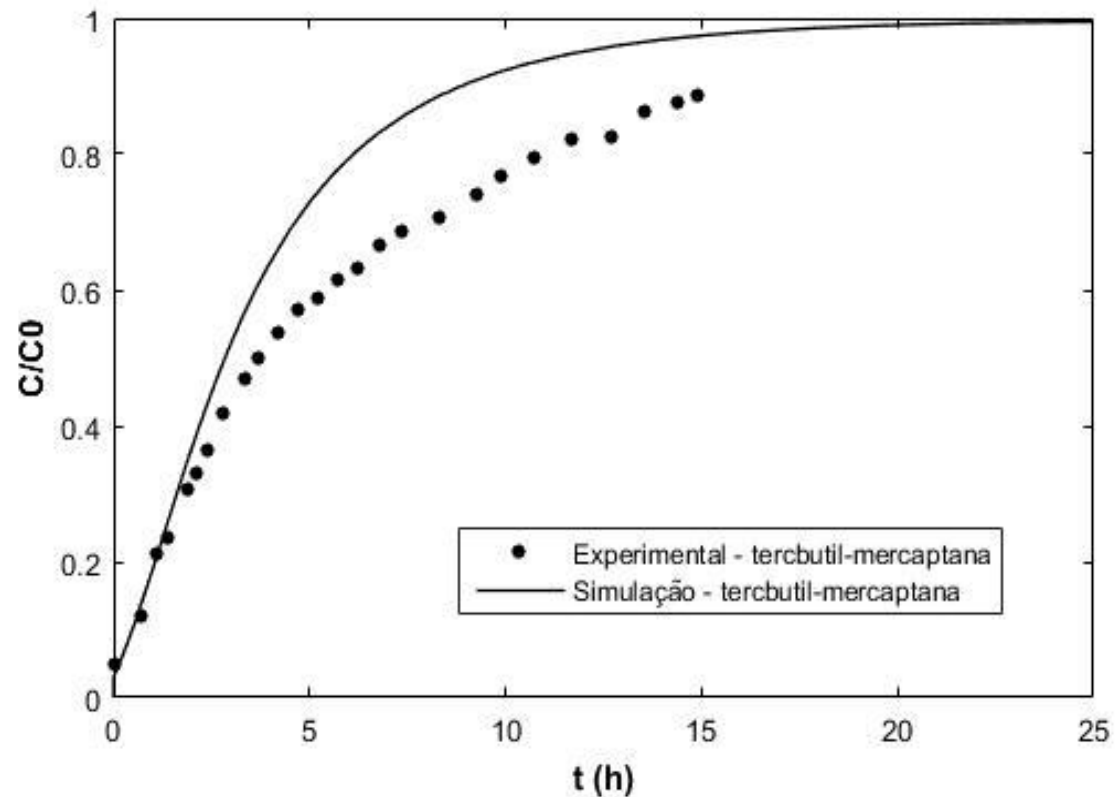

Figura 6.18. Resultado simulação computacional diferenças finitas. Teste Piloto 6: Tercbutilmercaptana $\mathrm{C}_{0}=12,1 \mathrm{ppm}, \mathrm{v}=0,0132 \mathrm{~m} / \mathrm{s}$.

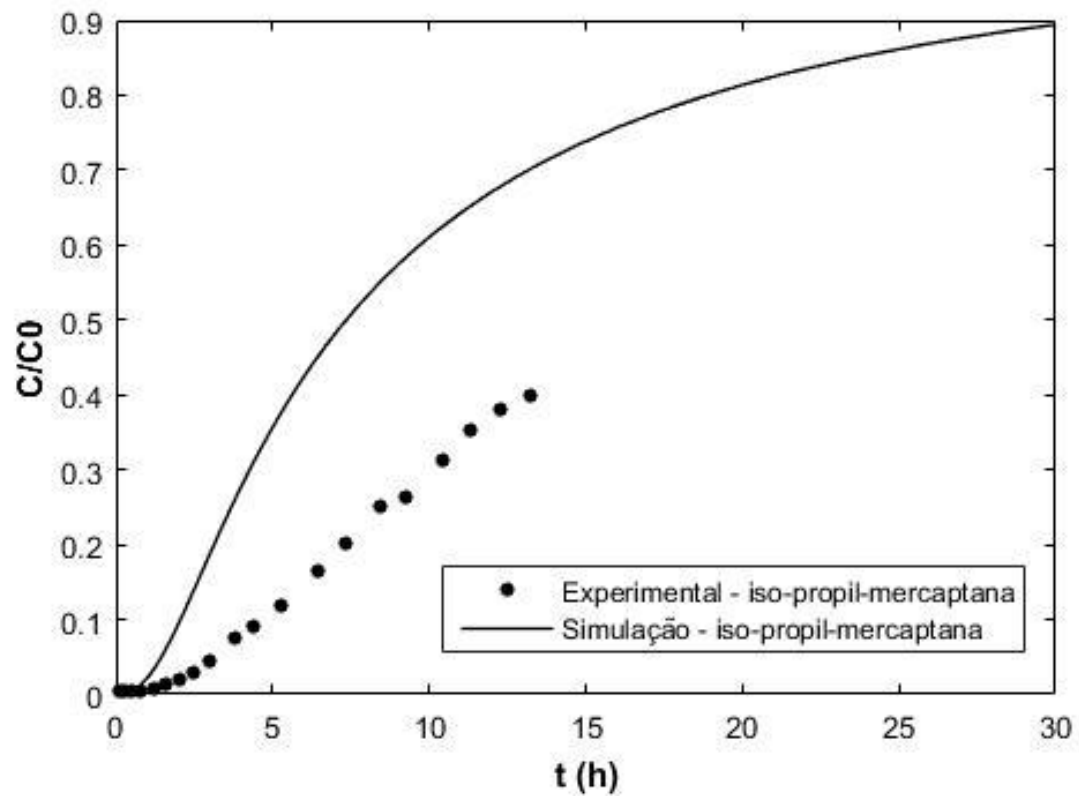

Figura 6.19. Resultado simulação computacional diferenças finitas. Teste Piloto 7: Iso-propilmercaptana $\mathrm{C}_{0}=13,6 \mathrm{ppm}, \mathrm{v}=0,0134 \mathrm{~m} / \mathrm{s}$. 


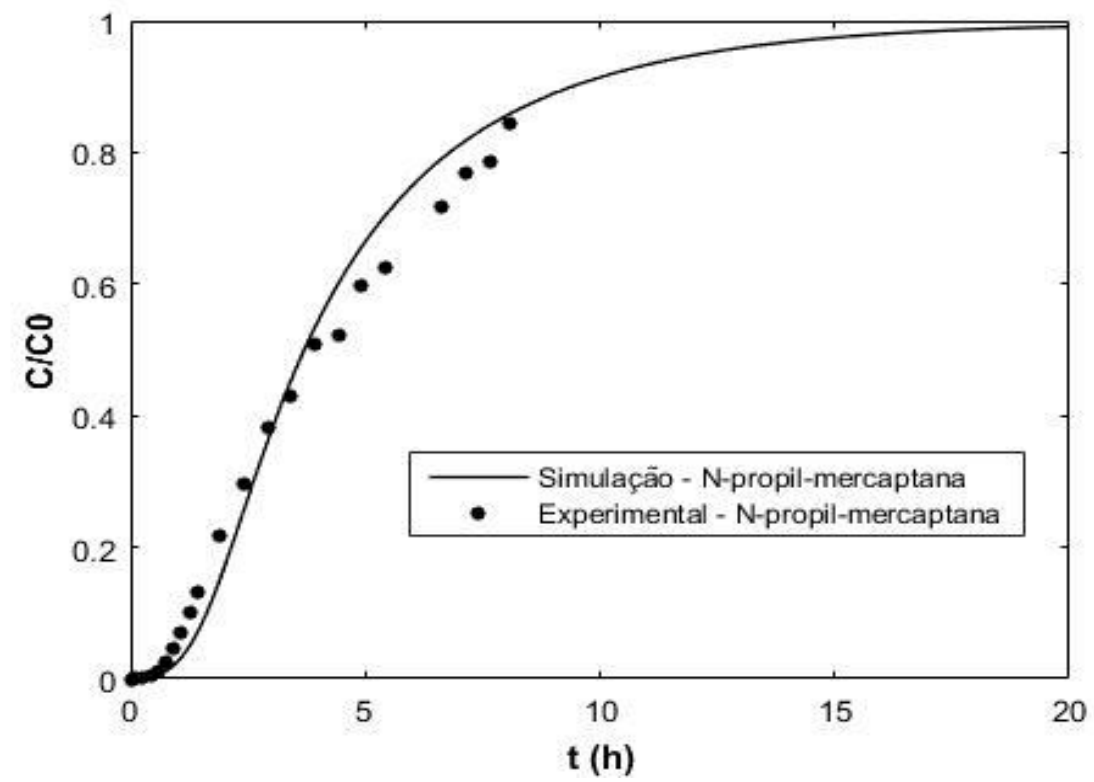

Figura 6.20. Resultado simulação computacional diferenças finitas. Teste Piloto 8: N-propilmercaptana $\mathrm{C}_{0}=91,8 \mathrm{ppm}, \mathrm{v}=0,0169 \mathrm{~m} / \mathrm{s}$.

Os resultados da simulação do modelo matemático em relação aos dados obtidos experimentalmente em escala piloto para os testes pilotos 6 e 8 também apresentaram boa similaridade, estimando de maneira apropriada o tempo de ruptura e o comportamento da curva em relação à zona de transferência de massa. Vale destacar que os experimentos foram realizados alterando-se variáveis de forte interferência no processo de adsorção como, dados de equilíbrio de adsorção, velocidade e até mesmo a concentração de entrada. Portanto, as hipóteses consideradas no modelo matemático e o método numérico selecionado apresentam-se razoáveis para prever o comportamento do processo monocomponente.

Entretanto, o resultado para a simulação do "Teste piloto 8" para a iso-propilmercaptana divergiu dos dados experimentais. Acredita-se que isso possa ter ocorrido pelo fato de terem sido utilizadas as constantes de equilíbrio obtidas para o componente n-propil-mercaptana, pelo fato de serem isômeros. Reitera-se, portanto, a forte influência dos dados experimentais no estudo do processo de adsorção. Devese ponderar também, que houve certa variação da temperatura durante os experimentos em escala piloto, considerando que o protótipo estava exposto ao ambiente sem qualquer isolamento térmico.

Dado que os coeficientes de transporte $k_{f}$ e $D\llcorner$ obtidos para os experimentos "Teste Lab 1 ao 3" através de ajuste do modelo aos dados experimentais apresentam a 
mesma velocidade que o processo industrial, utilizaram-se os mesmos parâmetros para simulação em escala industrial. Os dados de equilíbrio de adsorção da etilmercaptana foram considerados, em razão deste composto de enxofre aparecer com maior frequência e teor nas matérias-primas processadas. As concentrações de alimentação simuladas são os limites mínimo e máximo encontrados, geralmente, pela análise de enxofre total na matéria-prima processada industrialmente. Para simulação industrial, considerou-se a soma da altura das 3 primeiras colunas do processo. Isso porque a troca dos materiais adsorventes é realizada a partir do ponto de ruptura da $3^{\text {a }}$ coluna industrial.

A descrição completa das condições operacionais utilizadas para simulação está na Tabela 6-9.

Tabela 6-9. Parâmetros utilizados para simulação em escala industrial.

\begin{tabular}{lcc}
\hline Parâmetros do experimento & Industral 1 & Industrial 2 \\
\hline Comprimento das 3 colunas em série, $\mathrm{L}(\mathrm{m})$ & 11,4 & 11,4 \\
Diâmetro da coluna, $\mathrm{d}_{\mathrm{B}}(\mathrm{m})$ & 0,60 & 0,60 \\
$\mathrm{C}_{0}(\mathrm{mg} / \mathrm{kg}) /\left(\mathrm{kg} / \mathrm{m}^{3}\right)$ & 5 & 15 \\
Vazão $(\mathrm{kg} / \mathrm{h})$ & 2.000 & 2.000 \\
Velocidade superficial $(\mathrm{m} / \mathrm{s})$ & 0,0039 & 0,0039 \\
Massa específica do fluido $\left(\mathrm{kg} / \mathrm{m}^{3}\right)$ & 565 & 565 \\
Viscosidade do fluido $(\mathrm{kg} / \mathrm{ms})$ & $1,47 \mathrm{E}-04$ & $1,47 \mathrm{E}-04$ \\
Porosidade do leito & 0,35 & 0,35 \\
Porosidade da partícula & 0,67 & 0,67 \\
Reynolds (adim.) & 35,4 & 34,6 \\
Temperatura ( $\left.{ }^{\circ} \mathrm{C}\right)$ & 25 & 25 \\
\hline Parâmetros & & \\
\hline Coeficiente de dispersão axial, $\mathrm{D}_{\mathrm{L}}\left(\mathrm{m}^{2} / \mathrm{s}\right)$ & $3,0 \mathrm{E}-03$ & $3,0 \mathrm{E}-03$ \\
Coeficiente global de transf. massa externa, $\mathrm{k}_{\mathrm{f}}$ & $3,9 \mathrm{E}-03$ & $3,9 \mathrm{E}-03$ \\
(m/s) & & \\
Capacidade de adsorção máxima etil-mercaptana, & 0,0264 & 0,0264 \\
qm $(\mathrm{kgad} / \mathrm{kgpen})$ & 110,6 & 110,6 \\
Constante de Langmuir etil-mercaptana, K (m³/kg) & &
\end{tabular}


A Figura 6.21 mostra os resultados da simulação em escala industrial e o efeito da variação dos limites de concentração de enxofre total encontrados mais frequentemente nas matérias-primas processadas.

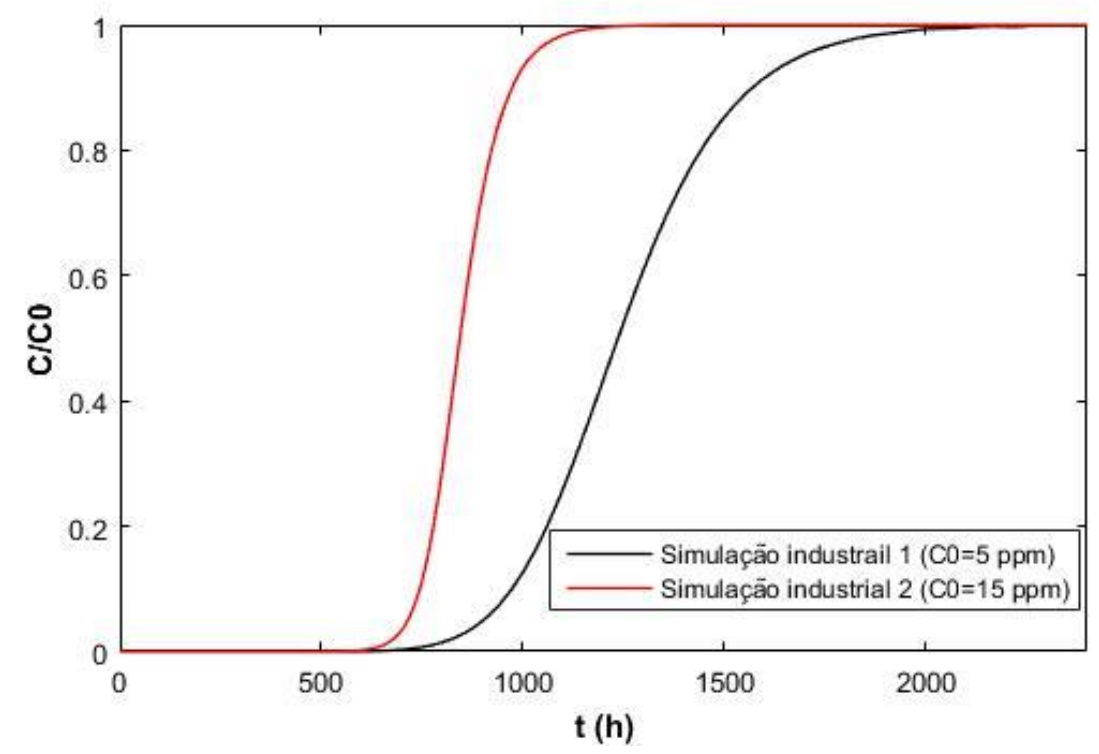

Figura 6.21 - Resultado simulação computacional de escala industrial para etil-mercaptana com variação da concentração de alimentação.

Interessante notar que apesar de haver diversas variáveis com forte influência no processo de adsorção que não foram consideradas para simulação, como, por exemplo, sistema multicomponente, variação de temperatura e nível de saturação da zeólita, o tempo de ruptura encontrado é similar à média de vida útil anual dos materiais adsorventes utilizados, que está em torno de $900 \mathrm{~h}$ para concentração inicial de $5 \mathrm{ppm}$ de enxofre total (soma de todos os componentes de enxofre). 


\section{CONCLUSÕES}

A interação entre diferentes moléculas de compostos de enxofre (tercbutilmercaptana, n-propil-mercaptana e etil-mercaptana) em butano líquido com a peneira molecular $13 \mathrm{X}$ foi estudada através das isotermas de equilíbrio de adsorção.

Os dados experimentais de equilíbrio de adsorção foram aproximados de maneira satisfatória pelo modelo teórico de Langmuir. Os resultados indicaram diferenças significativas no equilíbrio de adsorção, sendo que a etil-mercaptana apresentou maior afinidade, seguida de maneira decrescente da n-propil-mercaptana e da terc-butilmercaptana, sendo as capacidades máximas de adsorção de $0,0264 \mathrm{kgS} / \mathrm{kg}$ para a etil-mercaptana, $0,0247 \mathrm{kgS} / \mathrm{kgpen}$ para a n-propil-mercaptana e 0,008 $\mathrm{kgS} / \mathrm{kgpen}$ para a terc-butil-mercaptana. Este fato representa a complexidade em se tratar de um sistema multicomponente, pois a maior atração de um componente pelos sítios ativos da zeólita em relação ao outro pode provocar a dessorção do mais fraco.

No estudo do efeito da temperatura nas isotermas de equilíbrio de adsorção a $10{ }^{\circ} \mathrm{C}$ e $25 \stackrel{\circ}{ } \mathrm{C}$ para n-propil-mercaptana em butano líquido, usando a zeólita 13X, identificouse uma maior capacidade de adsorção e menor tempo para atingir o equilíbrio na condição de baixa temperatura.

Obtiveram-se as curvas de ruptura em escala laboratorial para n-propil-mercaptana em butano líquido com leito recheado de peneira molecular $13 \mathrm{X}$ com o objetivo de avaliar o comportamento do sistema a partir da variação de dois importantes parâmetros testados isoladamente: a velocidade no leito e a concentração de alimentação.

Conforme esperado, o aumento da concentração de entrada de 81 ppm (massa) para 174 ppm (massa) e para 315 ppm (massa) provocou redução do tempo de ruptura e a elevação das capacidades de adsorção do leito. Isso porque as isotermas de equilíbrio preveem maior ocupação dos sítios ativos do adsorvente, de acordo com o aumento da concentração do soluto. Analisando-se a zona de transferência de massa para as 3 concentrações, houve pequena variação entre os resultados, haja vista a velocidade ter sido constante. 
$\mathrm{Na}$ investigação sobre a influência do aumento da velocidade, avaliaram-se 3 diferentes valores desta para obtenção das curvas de ruptura. De acordo com Geankoplis (1993), o aumento da velocidade implicaria na redução da resistência à transferência de massa do filme líquido externo à partícula e, por conseguinte na redução da ZTM da curva de ruptura. Contudo, a partir de uma determinada velocidade este efeito não foi significativo, de acordo com o observado por Veit (2009), pois com a diminuição do tempo de residência, estabelece-se como etapa controladora do processo dinâmico de adsorção a resistência intra-partícula.

Quanto à concordância entre a simulação computacional do modelo matemático em relação aos dados experimentais escala laboratorial e piloto, observa-se que houve, de maneira geral, bastante similaridade tanto na previsão do tempo de ruptura quanto no perfil da zona de transferência de massa, considerando-se que foi feito o ajuste dos parâmetros de dispersão axial e coeficiente de transferência de massa. A partir destes parâmetros, pode-se avaliar as condições operacionais para as colunas industriais com velocidades no leito equivalentes.

Deste modo, observa-se a grande influência dos parâmetros de equilíbrio de adsorção no processo dinâmico e como o processo de adsorção é fortemente dependente de parâmetros obtidos através ensaios experimentais específicos para o sistema em estudo.

Visando complementar e continuar esta investigação, sugere-se para futuros trabalhos:

- Investigar a porosidade específica dos pellets de peneira molecular $13 \mathrm{X}$, visto que é uma característica de extrema relevância na modelagem matemática e que os valores encontrados na literatura divergem de maneira significativa e não são divulgados pelos fabricantes do material.

- Ampliar os estudos já realizados na obtenção das constantes de equilíbrio de adsorção para outros compostos de enxofre, em especial, a etil-mercaptana, que apresenta maior recorrência nas matérias-primas processadas em escala industrial a fim de obter isotermas de equilíbrio multicomponente para melhor aproximação da modelagem matemática do processo industrial. 
- Expandir os estudos já realizados na obtenção das constantes de equilíbrio de adsorção para outras temperaturas, principalmente maiores que $25 \stackrel{\circ}{\circ}$, a fim de estudar sua influência, em razão de se tratar de um parâmetro importante na avaliação do processo de adsorção em escala industrial.

- Estudar a influência da variação de temperatura na obtenção das curvas de ruptura, de modo a promover maior conhecimento do comportamento dos parâmetros envolvidos no processo produtivo industrial.

- Testar o comportamento e a capacidade de adsorção da zeólita 13X dos compostos de enxofre em outro solvente, o propano, também utilizado como propelente para aerossol. 


\section{REFERÊNCIAS BIBLIOGRÁFICAS}

ABAS 50 ANOS, Associação Brasileira de Aerossóis e Saneantes Domissanitários. São Paulo: Public Projetos Editoriais. 2014. Disponível em: $<$ http://publicbrasil.com.br/abas 2014.pdf>. Acesso em: 04 jul. 2015.

ALMEIDA, A. M. Estudo numérico de colunas de adsorção de leito fixo. Dissertação (Mestrado) - Universidade Federal do Paraná, Curitiba, 2012.

AUERBACH, S. M.; Handbook of zeolite Science and technology. New York. Marcel Dekker Inc. 2003.

AXENS IFP GROUP TECHNOLOGIES. MSE 13X Technical data sheet. Salindres, França, 2000.

AXENS IFP GROUP TECHNOLOGIES. Activated alumina \& molecular sieves Quality and advanced technology. Ruel-Malmaison Cedex, França.

BAGREEV, A., S. et al. Dual Role of Water in the Process of Methylmercaptan Adsorption on Activated Car- bons. Langmuir, 2002.

BASHKOVA, S., et al. Adsorption of Methyl Mercaptan on Activated Carbons. Environ. Sci. Technol., 2002.

BUTT, J. B. Reaction Kinetics and Reactor Design. Prentice Hall: Enclewood Cliffs. NJ, 1980.

CARBERRY, J. Chemical and Catalytic Reaction Engineering. McGraw Hill, New York, 1996.

CAVALCANTE Jr., C. L. Separação de Misturas por Adsorção: dos Fundamentos ao Processamento em Escala Comercial. Tese submetida ao concurso público para Professor Titular do Departamento de Engenharia Química da UFC - Universidade Federal do Ceará, Fortaleza, 1998.

CEJKA, J. et al. Introduction to zeolite Science and practice. 3를 Edição. Elsevier. Amsterdam. 2007

CERUTTI, M. L. M. N. Dessulfurização da gasolina por adsorção em zeólitas Y trocadas com cobre. Tese (Doutorado) - Universidade Federal de Santa Catarina, Florianópolis, 2007.

CHEREMISINOFF, N. P. Handbook of Heat and Mass Transfer: Volume 2 Mass Transfer and Reactor Design. $1^{\text {rst }}$ Ed. Houston: Gulf Publishing Company, 1986.

CHIANG, H. L., et al. Diffusion of hydrogen sulfide and methyl mercaptan onto microporous alkaline activated carbon. Chemosphere, 2000. 
COELHO, J. A. Estudo da adsorção de compostos sulfurados em carbon ativado. Monografia - Universidade Federal do Ceará, Fortaleza, 2009.

CRITTENDEN, B; THOMAS, W. J. Adsorption technology \& design. Oxford: Butterworth Heinemann, $1^{\text {st }}$ Ed., 1998.

CUSSLER, E. L. Diffusion: Mass Transfer in Fluid Systems. New York: Cambridge University Press, $3^{\text {rd }}$ Ed., 2009.

DANTAS, T. L. P.; et al. Adsorção de $\mathrm{CO}_{2}$ e $\mathrm{N}_{2}$ sobre carvão ativado e zeólita 13X: isotermas de equilíbrio através de medidas gravimétricas. $7^{\circ}$ Encontro Brasileiro de Adsorção, Campina Grande, 2008.

DENNY, L. C.; LUXON, L. L., Handbook Butane-Propane Gases. Fourth Edition. Chilton Company. 1962.

DO, D. D. Adsortion Analysis: Equilibria and Kinetcs. Imperial College Press, Queensland, Australia, 1998.

FOGLER, H. SCOTT. Elementos de Engenharia das Reações Químicas. LTC, $4^{\text {th }}$ Ed., 2009.

GEANKOPLIS, C. J. Transport processes and unit operations. PTR Prentice Hall, New York, $4^{\text {th }}$ Ed., 1993.

GLUECKAUF, E. Formula for diffusion into sphere and their application to chromatography. Trns. Faraday Soc., 1955.

GOLLAKOTA, S. V.; CHRISWELL, D. Study of an adsorption process using silicate for sulfur dioxide removal from combustion gases. Industrial \& Engineering Chemistry Research, 1988.

GOMES L. L. V. Adsorção como alternative para dessulfurização profunda da gasolina brasileira: estudo para remoção do benzotiofeno. Monografia Universidade Federal do Ceará, Fortaleza, 2010.

GUPTA A. et al. Breakthrough analysis for adsorption of sulfur-dioxide over zeolites. Chemical Engineering and Processing, Kanpur, Índia, 2002.

GUTIÉRREZ, M. T. O. Caracterización de minerales zeolíticos mexicanos. Universidad Autónoma del Estado de México, México, 2004.

HANSEN, E. Application of the linear driving force approximation to the study of mass transfer in ion-exchange chromatography. 2000. Department of Chemical Engineering. University of Denmark - DTU, Lyngby, Denmark. Disponível em: $<$ http://orbit.dtu.dk/fedora/objects/orbit:76392/datastreams/file 2497419/content.> Acesso em 20 jan. 2015. 
JUNIOR, J. B. S. Avaliação de técnicas de planejamento de experimentos no reconhecimento do equilíbrio de adsorção em sistemas cromatográficos. $305 \mathrm{p}$. Tese (doutorado) - Universidade Federal do Rio de Janeiro, Rio de Janeiro, 2011.

KARGE, H. G.; WEITKAMP, J. Molecular sieves. Vol. 7. Springer. Berlim. 2008

KACZMARSKI, K. \& ANTOS, O. Fast finite difference method for solving multicomponent adsorption-chromatography models. Computers Chem. E.ngng., v.20, n. 11, 1996.

KOPAC, T. Non-isobaric adsorption analysis of $\mathrm{SO}_{2}$ on molecular sieve $13 \mathrm{X}$ and activated carbon by dynamic technique. Chemical Engineering Processing, 1999.

LAZO, C. Simulation of liquid chromatography and simulated moving bed systems. Technische Universitat Hamburg, Harburg, 1999.

LESSA, M. O. Avaliação da capacidade de adsorção do $\mathrm{CO}_{2}$ em zeólita $13 \mathrm{X}$ com gases sintéticos e originados da pirólise do lodo de esgoto. 102 p. Dissertação de Mestrado - Universidade Federal do Rio Grande do Norte, Natal, 2012.

LEVAN, M. D.; VERMEULEN, T. AIChE Symp. Series, 1984.

LIMA, A. R. Simulação computacional da adsorção de tiofeno e propanotiol em zeólita NaY. Dissertação de Mestrado. Universidade Federal de Pernambuco, Recife, 2011.

LIRA, R. A. Equilíbrio de adsorção de glicomacropeptídeo em resina aniônica e análise termodinâmica. Dissertação (Mestrado) - Universidade Estadual do Sudoeste da Bahia, Itapetinga, 2008.

LU, G.; DO, D. D. Preparation of economical sorbents for $\mathrm{SO}_{2}$ and $\mathrm{NO}_{x}$ removal using coal washery reject. Carbon, 1991.

LUSIS, M. A.; RATCLIFF, G. A. Diffusion in Binary Liquid Mixtures at Infinite Dilution. Can J. Chem. Eng., v46, 1968.

LUTZ, W.; SUCKOW, M.; BILLOW, M. Adsorption of hydrogen sulphide on molecular sieves. Central Institute of Physical Chemistry, Berlin, 1990.

LUZ, D. A. Estudo de Equilíbrio e Dinâmica de Adsorção em Leito Fixo para o Sistema Glicose/Frutose em Resinas Catiônicas: Aplicação ao Suco de Caju Clarificado. Dissertação de Mestrado - Universidade Federal do Ceará-UFC, Fortaleza, 2006.

MARSH, H.; Reinoso, F. R. Activated Carbon. Elsevier Science \&Technology Books. 2006. 
MARTINS, V. A; et al. Isotermas de equilíbrio e termodinâmica da adsorção do corante tartrazina utilizando esferas recobertas com quitosana. Anais $\mathrm{XI}$ Congresso Brasileiro de Engenharia Química, São Paulo, Blucher, 2015.

MASCARENHAS, A. J. S.; OLIVEIRA, E. C.; PASTORE, H. O. Peneiras Moleculares - Selecionando as moléculas por seu tamanho. Cadernos Temáticos de Química Nova na Escola, 2001. Disponível em: $<$ http://qnesc.sbq.org.br/online/cadernos/02/peneiras.pdf>. Acesso em: 12/12/2012.

MATHEWS, J. H.; FINK, K. D. Numerical Methods Using MATLAB. New Jersey, Pearson Prentice Hall, 2004.

MCCABE, W.; SMITH, J. C.; HARRIOTT, P. Unit Operations of Chemical Engineering. $6^{\text {th }}$ Ed, Mc Graw Hill, New York, 2001.

MONFORT, A. J; NARDINI, G. Manual de Seguridad: Aspectos técnicos de la inflamabilidad de lós gases hidrocarburos. PUMA - Programa de Las Naciones Unidas para El Medio Ambiente, 2005. Disponível em: $<$ http://www.unep.fr/ozonaction/information/mmcfiles/4487-s-safetyfirst.pdf $>$. Acesso em: 06 set. 2013.

OLAFADEHAN, A. O.; SUSU, A. S. Modeling and Simulation of Liquid-Phase Ternary Adsorption in Activated Carbon Column. Department of Chemical Engineering, University of Lagos, Nigéria, 2004

PAYRA, P.; DUTTA, P. K. Handbook of zeolite science and technology. Marcel Dekker, Inc. New York, 2003.

PERRY, R. H.; GREEN, D. W. Perry's Chemical Engineers Handbook. $7^{\text {th }}$ Ed., Mac Graw Hill Companies, 1999.

RUSSEL, J. B. Química geral $-2^{\text {nd }}$ Ed., v.1., Pearson Makron Books, São Paulo, 1994.

RUTHVEN, D. M. Principles of Adsorption and Adsorption Processes. New York, John Wiley \& Sons Inc.,453p, 1984.

RUTHVEN, D. M. Encyclopedia of Separation Technology, A Kirk-Othmer Encyclopedia. 1st Ed.; John Wiley \& Sons; New York; 1997.

SAKANO, T., et al. Improvement of adsorption selectivity of methylmercaptan on microporous carbon by surface oxidation. J. Chem. Eng. Jpn., 1997.

SALEM, A. S. H.; HAMID, H. S. Removal of sulfur compound from naptha solutions using solid adsorbents. Chem. Eng. Technology, 342p, 1997. 
SANTACESARIA, E.; et al. Separation of Xylenes on Y Zeolites with X-Ray Photoelectron Spectroscopy and Transmission Electron Microscopy. J. Elect. Spect. Rl. Phen., 1985.

SANTACESARIA, E.; et al. Separation of Xylenes on Y Zeolites: Breakthrough curves and their Interpretation. Ind. Eng. Chem. Process Des. Dev, v.21, 1982.

SCHEER, A. P. Desenvolvimento de um Sistema para Simulação e Otimização do Processo de Adsorção para Avaliação da Separação de Misturas Líquidas. 2002, 223p. Tese de doutorado - Faculdade de Engenharia Química, Universidade Estadual de Campinas, São Paulo, 2002. Disponível em: $<$ http://www.bibliotecadigital.unicamp.br/document/?code=vtls000253769>. Acesso em: 02 mai. 2014.

SCHNEIDER, E. L. Adsorção de compostos fenólicos sobre carvão ativado. Dissertação de Mestrado - Universidade Estadual do Oeste do Paraná, Paraná, 2008.

SHAMPINE, L. F.; REICHELT, M. W. The Matlab ODE suite. SIAM Journal on Scientific Computing, v.18, 1997. Disponível em: $<$ https://www.mathworks.com/help/pdf doc/otherdocs/ode suite.pdf $>$. Acesso em 08 mai. 2016.

SHAMS, A.; DEHKORDI, A. M.; GOODARZNIA, I. Dessulfurization of liquid-phase butane by zeólita molecular sieve $13 \mathrm{X}$ in a fixed bed: Modeling, Simulation and Comparison with commercial-scale plant data. Energy \& Fuels, Tehram, Iran, 2008.

SIAHPOOSH, M.; FATEMI, S.; VATANI, A. Mathematical modeling of single and multi-component adsorption fixed beds to rigorously predict the mass transfer zone and breakthrough curves. J. Chem, Chem Eng Iran, v. 28, 2009.

SIRCAR, S.; HUFTON J. R. Why Does the linear driving force model for adsorption kinetics work? 2000, 137-147p, Kluwer Academic Publishers. Netherlands. Disponível em: $<$ http://link.springer.com/article/10.1023\%2FA\%3A1008965317983\#page-2>.Acesso em: 25 dez. 2014.

SMITH, J. M.; et al. Introdução à termodinâmica da engenharia química. Rio de Janeiro. LTC Editora. 7ª̣ edição. 2007.

SOUZA, J. R. Dessulfurização de gás natural usando peneiras moleculares. 86p. Dissertação (Mestrado) - Universidade Federal do Rio Grande do Norte, 2002.

SUZUKI, M. Adsorption Engineering. Tokyo, Kodansha Itd, 1990.

TANTET, J., et al. Breakthrough study of the adsorption and separation of sulfur dioxide from wet gas using hydrophobic zeolites, Gas Separation and Purification. 1995. 
THOMAS, W. J.; CRITTENDEN, B. Adsorption Technology \& Design. Oxford: Reed Educational and Professional Publishing Ltd, 1998.

UOP CORPORATION. An Introduction to zeolite molecular sieves. Technical Data Sheet. 2004.

VALDMAN, E.; et al. Continuous Biosorption of $\mathrm{Cu}$ and $\mathrm{Zn}$ by Immobilized Waste Biomass Sargassum sp. Process Biochemistry, 2001.

VEIT, M. T., et al. Efeito da vazão volumétrica nas curvas de ruptura para o Sistema de biossorção de $\mathrm{Cr}$ (III) e Ni(II). Estudos Tecnológicos. v. 5, n², 2009.

WATSON, J.S. Separation methods for waste and environmental applications. New York, Marcel Dekker Inc., 600 p, 1999.

WEBER, G.; et al. Adsorption equilibrium of light mercaptans on faujasites. Springer Science + Business Media, Netherland, 2005.

YANG, R. T. Gas separation by adsorption processes. Butterworths series in chemical engineering. 1987. 